Article

\title{
Detonation Nanodiamonds: A Comparison Study by Photoacoustic, Diffuse Reflectance, and Attenuated Total Reflection FTIR Spectroscopies
}

\author{
Dmitry S. Volkov *(1), Petr K. Krivoshein and Mikhail A. Proskurnin *(i) \\ Chemistry Department, Lomonosov Moscow State University, Moscow 119991, Russia; pkrivoshein@gmail.com \\ * Correspondence: dmsvolkov@gmail.com (D.S.V.); proskurnin@gmail.com (M.A.P.)
}

Received: 16 November 2020; Accepted: 11 December 2020; Published: 13 December 2020

check for updates

\begin{abstract}
The qualitative analysis of nanodiamonds by FTIR spectrometry as photoacoustic (FTIR-PAS), diffuse-reflectance (DRIFT), and attenuated total reflection (ATR) modalities was evaluated for rapid and nondestructive analysis and comparison of nanodiamonds. The reproducibility and signal-gathering depth of spectra was compared. The assignment of characteristic bands showed that only six groups of bands were present in spectra of all the modalities with appropriate sensitivity: 1760 ( $\mathrm{C}=\mathrm{O}$ stretch, isolated carboxyl groups); 1640-1632 ( $\mathrm{H}-\mathrm{O}-\mathrm{H}$ bend, liquid water); 1400-1370 (non-carboxyl C-O-H in-plane bend and $\mathrm{CH}_{2}$ deformation); 1103 (non-carboxyl C-O stretch); 1060 (in-plane $\mathrm{C}-\mathrm{H}$ bend, non-aromatic hydrocarbons and carbohydrates); $940 \mathrm{~cm}^{-1}$ (out-of-plane carboxyl $\mathrm{C}-\mathrm{O}-\mathrm{H}$ bend). DRIFT provides the maximum number of bands and is capable of measuring hydrogen-bonded bands and $\mathrm{CH}_{\mathrm{x}}$ groups. ATR provides the good sensitivity for water and $\mathrm{C}-\mathrm{H} / \mathrm{C}-\mathrm{C}$ bands in the range $2000-400 \mathrm{~cm}^{-1}$. FTIR-PAS reveals less bands than DRIFT but more intense bands than ATR-FTIR and shows the maximum sensitivity for absorption bands that do not appear in ATR-IR spectra and are expedient for supporting either DRIFT or FTIR-PAS along with depth-profiling. Thus, all three modalities are required for the full characterization of nanodiamonds surface functional groups.
\end{abstract}

Keywords: detonation nanodiamonds; photoacoustic IR spectroscopy; diffuse-reflectance IR spectroscopy; attenuated total internal reflection IR spectroscopy

\section{Introduction}

Nanodiamonds (ND), due to the nanometer size of their primary particles, have a surface with a significant area and many functional groups [1,2]. During the production cycle, the initial charge goes through several stages of chemical treatment, mainly of an oxidizing nature. This is necessary primarily for the removal of non-diamond forms of carbon. As a result, various functional groups form at the surface of nanodiamonds, which are responsible for the use of nanodiamonds as sorbents [1,3-5] and are crucial for technological and biomedical applications of nanodiamonds [6-11].

FTIR spectroscopy, usually in the mid-IR region, is widely used to characterize nanodiamonds and their surface groups [12]. Previous articles on the surface groups of nanodiamonds by FTIR are mostly based on sample-pellet transmission FTIR techniques [4]; less common are diffuse reflectance FTIR (DRIFT) [13] or attenuated total reflectance FTIR (ATR-FTIR) [14,15]. However, there are several contradictions in the selection and assignment of the main absorption bands of nanodiamonds, a unified scheme of sample preparation for the analysis of nanodiamonds has not been proposed, and rather wide comparative data on different samples or brands of nanodiamonds do not exist.

Transmission FTIR methods with pellets work with several milligrams of nanodiamond sample and ca. $150 \mathrm{mg}$ of $\mathrm{KBr}$ or $\mathrm{KCl}$, which are selected for the implementation of the Bouguer-Lambert-Beer 
law. The distribution of $\mathrm{KBr}$ particles and the test object should be uniform for better comparison between measurements [16]. Another disadvantage is the high hygroscopicity of $\mathrm{KBr}$ and $\mathrm{KCl}$ and the possible reactions of alkali metal halides with surface groups of nanodiamonds, the probability of which increases with grinding-assisted mechanochemistry of nanodiamonds with alkali metal halides [14]. $\mathrm{KBr}$ also absorbs radiation in the far infrared region, which does not allow for measurements below $400 \mathrm{~cm}^{-1}$ [17]; $\mathrm{KBr}$ or $\mathrm{KCl}$ should also be of an acceptable purity.

DRIFT is not the most common method for studying the surface of nanodiamonds due to the sensitivity to the particle distribution in the sample holder, the width of the nanodiamonds fraction; these features lead to low reproducibility of this method $[13,18]$. As transmission techniques, DRIFT requires the dilution of the test nanodiamond sample with $\mathrm{KBr}$ or $\mathrm{KCl}$ and subsequent grinding.

ATR-FTIR spectrometry is considered the most convenient selection for ND surfaces due to its simplicity and as it provides spectra comparable with the transmission spectra $[7,19,20]$. It does not require the sample dilution, which opens the far IR region. This method also allows for varying the depth of radiation penetration into the sample by changing the incidence angle of the radiation, but this feature is not implemented in most ATR units [21]. Additionally, it is considered that ND films and powders have the optimum particle size to achieve a good covering of the ATR crystal surface and sufficient adhesion. However, ATR-FTIR has several limitations. This method requires full contact of the test sample with the ATR crystal to improve the signal-to-noise ratio [16]. As diamond is one of the hardest known materials, the good contact between the NDs and the ATR crystal is a problem: materials such as ZnSe, Ge, or KRS- 5 are too soft and their surface at a considerable pressure of the ATR press can be damaged. In addition, a part of the ND sample may be retained in the crystal, leading to fast degradation of the crystal operability. Thus, for NDs, only a diamond ATR crystal is applicable, but it does not allow for measuring the diamond itself, thus, the absorption of surface ND groups may be acquired. The recording of the ATR-IR spectra of nanodiamonds without using a clamping screw are described [22]: a colloidal solution of nanodiamonds is prepared in a highly volatile solvent placed to the crystal after drying and ATR-FTIR spectra are recorded. In addition, raw ATR-FTIR spectra are usually strongly distorted: shifts to lower wavenumbers are observed. This requires extra (extended) ATR correction [16], but the parameters for this mathematical transform are selected manually, often empirically; therefore, some information may be degraded or warped.

Interferometer-based FTIR photoacoustic spectroscopy (FTIR-PAS) is a developed instrument for complex samples [23-27]. It can be used for mineral, polymer, and technological samples. Some capabilities of FTIR-PAS are analogous to ATR-FTIR, and some to DRIFT. As ATR-FTIR, it does not need sample dilution and is applicable in the far infrared (IR) region. FTIR-PAS has some advantages. It allows for varying the depth of radiation penetration by changing the modulation frequency, which provides a longer range of depths. FTIR-PAS was used to crush diamonds down to a micron size [28], FTIR-PAS and DRIFT methods showed comparable results [28]. However, as far as we know, the FTIR-PAS method has not been used to date for studying the surface of nanodiamonds. The whole comparison of various modalities for complex samples (biochars, soils) has recently become a topic of several review or feature papers [29,30]; however, usually the research is focused on specific characteristics, such as depth profiling in FTIR-PAS [27,31,32]. For nanodiamonds, as far as we are concerned, a full comparison of FTIR-PAS, DRIFT and ATR features in spectral information was not done.

The growing number of studies dealing with various modifications in the nanodiamond surface makes serious demands of the methods of surface characterization. Thus, the aim of this work was to compare the spectral information provided by these modalities for the same samples measured under the same conditions. To assess their capabilities from the point of view of maximum information content and reliability of the spectral information provided, we studied the surface of NDs using ATR-FTIR, DRIFT, and FTIR-PAS and compared the results for a rather wide selection of various ND brands. 


\section{Materials and Methods}

\subsection{Nanodiamonds}

We used commercially available NDs, summed up in Table 1 . Powders from aqueous suspension (SDND, PL-Nanopure-G01P) stock solutions were prepared by drying in a drying oven (SNOL 20/300, Snol-Therm, Russia) at $100{ }^{\circ} \mathrm{C}$. For analysis, nanodiamond powder was used as is or nanodiamonds were gently ground in a jasper mortar.

Table 1. Nanodiamonds used in the survey.

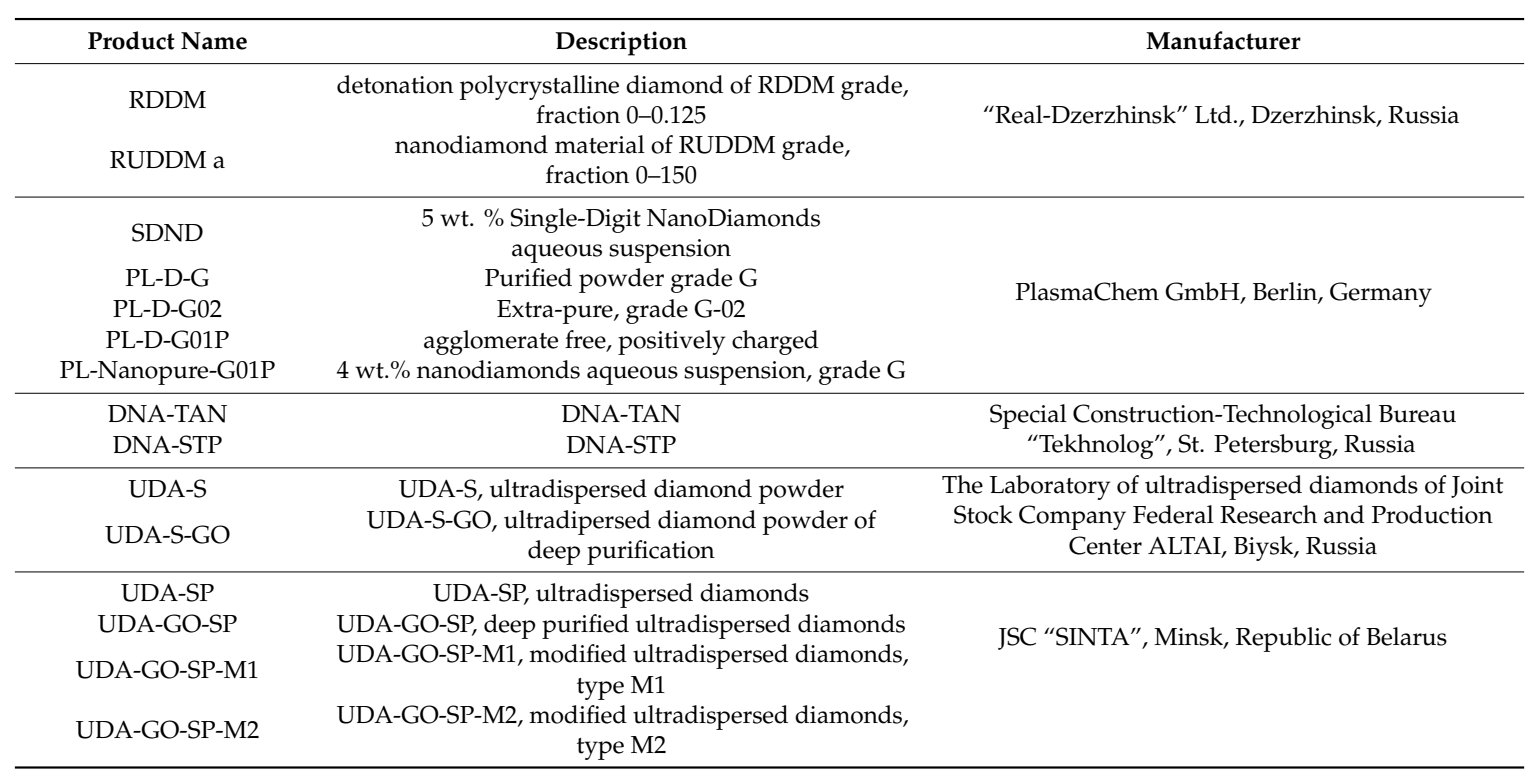

\subsection{Instrumentation}

IR spectra of nanodiamond powders were recorded on a Bruker Vertex 70 single-beam IR Fourier spectrometer (Bruker Optik GmbH, Ettlingen, Germany) equipped with a KBr beam splitter and a wide-range room temperature DLaTGS detector or liquid nitrogen cooled photovoltaic MCT detector. The spectrometer and accessories were continuously purged with $-70{ }^{\circ} \mathrm{C}$ dew point air (produced by a PG28L Purge Gas Generator, PEAK Scientific, Glasgow, UK) with a flow of 500 L/h. The overall laboratory temperature was maintained at $23{ }^{\circ} \mathrm{C}$ with an allowable variation in $\pm 1{ }^{\circ} \mathrm{C}$ using an air conditioner.

\subsubsection{FTIR-PAS}

An MTEC PAC300 photoacoustic accessory (MTEC Photoacoustic, Inc., Ames, IA, USA) and FTIR-PAS spectra were obtained by varying the scanning frequency; software correction of the peaks of $\mathrm{CO}_{2}$ and $\mathrm{H}_{2} \mathrm{O}$ was not used. The parameters for recording FTIR-PAS spectra are shown in Table 2. Samples of nanodiamonds were placed in a cell that was installed in the accessory, the cell compartment was purged with helium for 5-10 s. The number of scans for a sample and background: at an interferometer frequency of $1.6 \mathrm{kHz}$, this is 64 scans; at $2.5 \mathrm{kHz}$ this is 128 scans; at $5 \mathrm{kHz}$, this is 256 scans. In FTIR-PAS mode, before each image, the spectrum of the background signal was recorded using highly pure compressed graphite. Samples weighing 5-10 mg were examined. For interferometer frequencies of 1.6 and $2.5 \mathrm{kHz}$, sample signal amplification modes were 1000 and 2000 times, respectively. 
Table 2. Parameters of recording NDs spectra in the middle IR by FTIR-PAS.

\begin{tabular}{cc}
\hline Spectral range, $\mathrm{cm}^{-1}$ & $4000-500$ \\
Resolution, $\mathrm{cm}^{-1}$ & 4 \\
Background scan & $64 ; 256$ \\
Sample scan & $64 ; 256$ \\
Phase resolution & 10 \\
Phase correction mode & Mertz \\
Zero filling factor & 2 \\
Apodization function & Blackman-Harris 3-Term \\
Aperture setting & $8 \mathrm{~mm}$ \\
Interferometer frequency & $1.6 ; 2.5 ; 5 \mathrm{kHz}$ \\
Sample signal gain & B (middle amplification) \\
Detector & Auto \\
Source & microphone \\
Beam splitter & MIR \\
& KBr \\
\hline
\end{tabular}

The resulting spectra were subjected to automatic baseline correction and 25-point smoothing.

\subsubsection{ATR-FTIR}

The GladiATR ${ }^{\mathrm{TM}}$ single reflection attenuated total internal reflection accessory with a diamond crystal (Pike Technologies, Madison, WI, USA) was used for spectra registration in ATR mode. The accessory was configured for heating up to $215^{\circ} \mathrm{C}$. A background signal was recorded prior each new sample. The registration parameters of ATR spectra are shown in Table 3. Samples of nanodiamonds were transferred in a dry state to a crystal of an ATR attachment, and then clamped with a clamping screw.

Table 3. Parameters of recording NDs spectra in the middle IR by ATR-FTIR.

\begin{tabular}{cc}
\hline Spectral range, $\mathrm{cm}^{-1}$ & $4000-370$ (with DLaTGS detector) or 6000-700 (with MCT detector) \\
Resolution, $\mathrm{cm}^{-1}$ & 2 \\
Background scan & 128 \\
Sample scan & 128 \\
Aperture setting & $8 \mathrm{~mm}$ \\
Phase resolution & 4 \\
Phase correction mode & Mertz \\
Zero filling factor & 1 \\
Apodization function & Blackman-Harris 3-Term \\
Background signal gain & "Ref" (without amplification) \\
Sample signal gain & Auto \\
Scanner velocity & Auto \\
Detector & 10 kHz \\
Source & Mir \\
Beam splitter & KBr \\
Background & Doom temperature DLaTGS or liquid nitrogen cooled photovoltaic MCT \\
\end{tabular}

Room temperature DLaTGS did not have a software-variable gain level; therefore, in all measurements, the "Ref" level was used, which means no gain in OPUS software. The Photovoltaic MCT DETECTOR had three gain levels in order of increasing gain: no gain ("Ref"), a standard (low) gain (A), and a medium gain (B).

Before recording the spectra with heating, the spectrum of an empty ATR crystal was recorded at $25^{\circ} \mathrm{C}$ as a background, then a small amount of the sample was placed on its surface, pressed with a screw, and a program of controlled heating was started at a rate of $0.25{ }^{\circ} \mathrm{C} / \mathrm{min}$ from $25^{\circ} \mathrm{C}$ to $215^{\circ} \mathrm{C}$, and spectra registration step every $2.5^{\circ} \mathrm{C}$. After heating to $215^{\circ} \mathrm{C}$ and recording the spectrum, the sample was cooled to $25^{\circ} \mathrm{C}$. The resulting array of heating spectra $\left(25-215^{\circ} \mathrm{C}\right)$ was combined, and then a similar array of spectra of an empty ATR crystal was subtracted from it. 


\subsubsection{DRIFT}

The PrayingMantis ${ }^{\mathrm{TM}}$ diffuse reflection accessory (Harrick Scientific Products, INC, Pleasantville, NY, USA) was used for spectra registration in diffuse reflectance mode. The registration parameters of DRIFT spectra are shown in Table 4.

Table 4. Parameters of recording ND spectra in the near to middle IR by DRIFT.

\begin{tabular}{cc}
\hline Spectral range, $\mathrm{cm}^{-1}$ & $7000-400$ \\
Resolution, $\mathrm{cm}^{-1}$ & 2 \\
Background scan & 256 \\
Sample scan & 256 \\
Phase resolution & 16 \\
Phase correction mode & Mertz \\
Zero filling factor & 2 \\
Apodization function & Blackman-Harris 3-Term \\
Aperture setting & 3 mm \\
Sample and background pre-amplification gain & "Ref" (without amplification) for DLaTGS detector \\
Background signal gain & A (standard amplification) for MCT detector \\
Sample signal gain & Auto \\
Scanner velocity & Auto \\
Detector & $10 \mathrm{kHz}$ \\
Source & Moom temperature DLaTGS or liquid nitrogen cooled photovoltaic MCT \\
Beam splitter & KBr \\
Background & Mirror \\
\hline
\end{tabular}

Software automatically converted spectra measured in diffuse reflectance using the Kubelka-Munk (KM) conversion. The conversion is based on the following formula:

$$
K M=\frac{(1-R e f l)^{2}}{(2 \times R e f l)}
$$

where Refl is the relation between reflected and incident light. Absorbance spectra are first converted to transmittance spectra. The smallest value allowed for transmittance or reflectance is $0.001 \%$. This equals a Kubelka-Munk value of about 500 .

For background measurements the tilted alignment mirror for PrayingMantis ${ }^{\mathrm{TM}}$ accessory was used. For this, the alignment fixture was slid into the accessory, with the horizontal mirror going in first. In this orientation, the tilted mirror is in the sampling position. We compared this approach with $\mathrm{KBr}$ in the sample cup.

\subsection{Data Handling}

All spectra were processed in OPUS 7.5 software (Bruker Optik GmbH, Ettlingen, Germany). FTIR-PAS spectra were smoothed out by 25 points, and DRIFT and ATR-FTIR by 13 points (at some figures, spectra are presented without smoothing).

The penetration depth of damped IR radiation with the wavenumber $\widetilde{v}$ into the sample (approaching the ATR crystal/sample boundary at an angle $\theta$ to the normal) was estimated as:

$$
\mu_{A T R}(\widetilde{v})=\left(2 \pi \widetilde{v} n_{A T R} \sqrt{\left(\sin \theta^{2}-\left(n_{A T R} / n_{S}\right)^{2}\right)}\right)^{-1}
$$

where $n_{A T R}$ and $n_{S}$ are refractive indexes of the ATR crystal and sample, respectively.

In FTIR-PAS, the estimation of the radiation penetration depth is made using the dependence of the penetration depth of the heat wave

$$
\mu_{P A S}(\widetilde{v})=\sqrt{D_{T} / 2 \pi V \widetilde{v}}
$$


where $D_{T}$ is the thermal diffusivity of the sample and $V$ is the interferometer mirror velocity [32]. Thermal diffusivity $D_{T}$ was taken as $7.8 \mathrm{~cm}^{2} / \mathrm{s}$ [33], the velocities of the difference in optical paths of the IR spectrometer were obtained from the interferometer modulation frequencies and the $\mathrm{He}-\mathrm{Ne}$ laser reference lines were 0.1012 and $0.1582 \mathrm{~cm} / \mathrm{s}$, respectively.

\subsection{Procedures}

The FTIR-PAS spectra obtained by method 3 with an interferometer frequency of $1.6 \mathrm{kHz}$ and an amplification of the signal of sample 1000 were smoothed over 25 points and the intensity was multiplied by $\sqrt{\tilde{v}}$ [32]. The ATR spectra were additionally transformed as follows: $I_{0} a+b=I_{\text {corr }}$, where $I_{0}$ is the intensity of the ATR spectra after the operations described above, $I_{\text {corr }}$ is the intensity of the ATR spectra for comparison with the FTIR-PAS spectra, $a=150, b=1$.

Reproducibility

To compare reproducibility, ten ATR-IR spectra of nanodiamonds were recorded with reregistration of the background spectrum after each measurement due to the high abrasive ability of nanodiamonds. After registration, the spectra were not subjected to extended ATR correction. Baseline correction and anti-aliasing were not applied.

10 FTIR-PAS spectra were recorded according to method 3 with a complete overfilling of the sample cup and an interferometer frequency of $1.6 \mathrm{kHz}$. FTIR-PAS spectra were not subjected to automatic baseline correction and smoothing. RSD and signal-to-noise ratio ( $\mathrm{S} / \mathrm{N}=1 / \mathrm{RSD})$ were calculated as

$$
\mathrm{RSD}=\sqrt{\frac{\sum_{i}\left(x_{i}-\bar{x}\right)^{2}}{n-1}} \frac{1}{\bar{x}}
$$

\section{Results}

\subsection{Band Assignment}

The spectra of nanodiamonds for the studied brands are shown in Figures 1 and 2, and Figure A1 (Appendix A) for DRIFT, Figures 3 and 4, and Figure A2 for ATR, and Figure 5 for FTIR-PAS. All the assigned bands existing in the spectra of all the selected ND brands are summed up in Table 5. In this section, we describe the assignment of all major bands present in most brands in at least two modalities and all the measurement conditions; the comparison and differences in spectra for IR modalities and specific features of brands are given in the next section.

Table 5. The assignment of major bands common to most ND brands [16,34-40].

\begin{tabular}{|c|c|c|c|c|}
\hline Wavenumber & Assignment & ATR & DRIFT & PAS * \\
\hline $5900-5600$ & $2 v \mathrm{C}-\mathrm{H}$ aliphatic chain stretching & - & W & - \\
\hline 5300 & $\begin{array}{l}\text { Water combination band } \\
a v_{1}+v_{2}+b v_{3} ; a+b=1\end{array}$ & - & $\mathrm{Mb}$ & $\mathrm{Wb}$ \\
\hline 4800 & Aromatic $\mathrm{C}-\mathrm{H}$ combination bands (?) ** & - & $\mathrm{Wb}$ & - \\
\hline $4500-4100$ & Aliphatic $\mathrm{C}-\mathrm{H}$ combination bands & - & $\mathrm{Wb} \mathrm{To} \mathrm{Mb}$ & $\mathrm{W}$ \\
\hline 3715 & Hydrogen-bonded $-\mathrm{O}-\mathrm{H} \cdots \mathrm{H}-\mathrm{O}-$ stretch & - & Wp & Wp \\
\hline 3695 & Hydrogen-bonded $-\mathrm{O}-\mathrm{H} \cdots \mathrm{H}_{2} \mathrm{O}$ stretch & - & $\mathrm{Mp}$ & Wp (noisy) \\
\hline 3569 & $\begin{array}{c}\text { Hydrogen-bonded } \mathrm{RO}-\mathrm{H} \cdots \mathrm{H}_{2} \mathrm{O} \text { H-OR } \\
\text { stretch (?) }\end{array}$ & - & $\mathrm{W}$ & W (noisy) \\
\hline $3450-3420$ & Liquid: antisynchronous stretch $v_{3}$ & Mv & Sv & $\mathrm{Mv}$ \\
\hline 3407 & $\begin{array}{l}\mathrm{O}-\mathrm{H} \text { stretch and intermolecular hydrogen } \\
\text { bonds (unresolved) }\end{array}$ & $\mathrm{Mb}$ to $\mathrm{Wb}$ & - & $\mathrm{Mb}$ to $\mathrm{Wb}$ \\
\hline
\end{tabular}


Table 5. Cont.

\begin{tabular}{|c|c|c|c|c|}
\hline Wavenumber & Assignment & ATR & DRIFT & PAS * \\
\hline 3290 & $\mathrm{H}-\mathrm{O}-\mathrm{H}$ bend of liquid adsorbed water, $2 v_{2}$ & - & Wv & W \\
\hline $3230-3210$ & Liquid: synchronous stretch, $v_{1}$ & Sv & Sv & Sv \\
\hline 3050 & Aromatic $\mathrm{C}-\mathrm{H}$ stretching & $\mathrm{W}$ to none & S & M \\
\hline 2970 & Alkene $\mathrm{C}-\mathrm{H}$ stretch & W to none & M & W \\
\hline 2950-2940 & Aliphatic $\mathrm{C}-\mathrm{H}, \mathrm{CH}_{3}$ antisymmetric stretch & $\mathrm{W}$ to none & $S$ & M \\
\hline 2940-2930 & Aliphatic $\mathrm{C}-\mathrm{H}, \mathrm{CH}_{2}$ antisymmetric stretch & - & S & S \\
\hline $2880-2870$ & Aliphatic $\mathrm{C}-\mathrm{H}, \mathrm{CH}_{3}$ symmetric stretch & W to none & S & M \\
\hline $2850-2835$ & Aliphatic $\mathrm{C}-\mathrm{H}, \mathrm{CH}_{2}$ symmetric stretch & W to none & $\mathrm{Wb}$ & M \\
\hline $2750-2550$ & Carboxylic O-H stretch & $\mathrm{Wb}$ to none & $\mathrm{Mb}$ to $\mathrm{Wb}$ & $\mathrm{Wb}$ to none $\mathrm{e}^{*}$ \\
\hline 2150 & Water combination band $v_{2}+L_{2}$ & $\mathrm{~Wb}$ & $\mathrm{~Wb}$ & $\mathrm{~Wb}$ \\
\hline $1800-1780$ & $\mathrm{C}=\mathrm{O}$ stretch of conjugated carboxyl groups & M & S & $S$ to $M^{*}$ \\
\hline 1765-1730 & $\mathrm{C}=\mathrm{O}$ stretch of monomeric carboxyl groups & $\mathrm{Mb}$ & $\mathrm{Sb}$ & $\mathrm{Sb}$ to $\mathrm{Mb}$ * \\
\hline 1670 & $\begin{array}{l}\mathrm{C}=\mathrm{O} \text { stretch of non-carboxyl carbonyl (?) } \\
\qquad \mathrm{C}=\mathrm{C} \text { stretch }\end{array}$ & W & W & M \\
\hline 1644-1642 & $\mathrm{H}-\mathrm{O}-\mathrm{H}$ bend of liquid water, $v_{2}$ & Sv & Mv & Mv \\
\hline $1630-1625$ & $\mathrm{H}-\mathrm{O}-\mathrm{H}$ bend of adsorbed liquid water, $v_{2}$ & Sv & Mv & Mv \\
\hline 1610 & $\mathrm{H}-\mathrm{O}-\mathrm{H}$ bend of adsorbed liquid water, $v_{2}$ & Ssh & Msh & Msh \\
\hline $1580-1560$ & adsorbed water, C=C stretch, (?) & M & M & M \\
\hline $1470-1450$ & $\mathrm{sp}^{3} \mathrm{CH}_{2}$ wagging & S & M & \\
\hline 1440 & $\begin{array}{l}\text { Carboxyl } \mathrm{C}-\mathrm{O}-\mathrm{H} \text { in-plane bend } \\
\text { Aromatic, ring } \mathrm{C}=\mathrm{C} \text { stretch }\end{array}$ & - & $\mathrm{Wb}$ & W \\
\hline 1410 & Carboxyl C-O-H in-plane bend & Msh & Msh & Msh \\
\hline 1400-1395 & $\begin{array}{l}\text { Non-carboxyl } \mathrm{C}-\mathrm{O}-\mathrm{H} \text { in-plane bend } \\
\mathrm{CH}_{2} \text { deformation (scissors) }\end{array}$ & Msh & Ssh & Ssh \\
\hline 1373 & $\begin{array}{l}\text { Non-carboxyl } \mathrm{C}-\mathrm{O}-\mathrm{H} \text { in-plane bend } \\
\mathrm{CH}_{3} \text { deformation (umbrella) }\end{array}$ & M & Ssh & M \\
\hline 1330 & Non-carboxyl C-O-H in-plane bend (?) & S & M & $S$ to $M^{*}$ \\
\hline $1270-1267$ & Carboxyl C-O stretch & W & M & M \\
\hline 1245-1235 & $\mathrm{C}-\mathrm{N}$ stretch & W & W & W \\
\hline 1192 & $\mathrm{C}-\mathrm{C}-\mathrm{C}(?)$ & - & M & W \\
\hline $1145-1130$ & $\mathrm{C}-\mathrm{O}-\mathrm{C}(?)$ & - & M & W \\
\hline 1103 & Non-carboxyl C-O stretch & $\mathrm{Sb}$ & $\mathrm{Sb}$ & $\mathrm{Sb}$ \\
\hline 1060-1040 & $\begin{array}{c}\text { In plane }-\mathrm{C}-\mathrm{H} \text { bend (non-aromatic) and } \\
\text { carbohydrates (?) }\end{array}$ & W & Wsh & $\mathrm{Wb}$ \\
\hline $1000-500$ & Water librations, $L_{2}$ & $\mathrm{Sb}$ & $\mathrm{Sb}$ & $\mathrm{Mb}$ to $\mathrm{Wb}$ \\
\hline $960-940$ & $\begin{array}{l}\text { Carboxyl out-of-plane } \mathrm{C}-\mathrm{O}-\mathrm{H} \text { bend, } \\
=\mathrm{CH}_{2} \text { wagging (?) }\end{array}$ & M & $\mathrm{Wb}$ & $\mathrm{M}$ to $\mathrm{W}^{*}$ \\
\hline 830 & Aromatic $=\mathrm{C}-\mathrm{H}$ bend & $\mathrm{Mp}$ & Mp & $\mathrm{Mp}$ \\
\hline 760 & Polyaromatic $=\mathrm{C}-\mathrm{H}$ bend (?) & - & W & M to none * \\
\hline 610 & Non-carboxyl out-of-plane C-O-H bend & W & M & $\mathrm{Wb}$ to none * \\
\hline 410 & (?) $\mathrm{C}-\mathrm{C}$ in-phase vibrations & M & $\mathrm{Wb}$ & - \\
\hline
\end{tabular}

Notation: $\mathrm{S}$ = strong; $\mathrm{M}=$ medium; $\mathrm{W}$ = weak; $\mathrm{p}$ = peak (sharp); $\mathrm{b}=$ broad; $\mathrm{v}$ = variable; $\mathrm{sh}$ = shoulder; ${ }^{*}$ Intensity depends on the modulation frequency (PAS); ${ }^{* *}($ ?) not fully clear. 
The near IR region shows two wide bands at 5900-5600 and $4300 \mathrm{~cm}^{-1}$ that are $\mathrm{C}-\mathrm{H}$ first overtone and combination bands, respectively (Figure 1a). In some cases, a weak broad band at $4800 \mathrm{~cm}^{-1}$ that may be attributed to aromatic $\mathrm{C}-\mathrm{H}$ combination bands is present. They are revealed by DRIFT and FTIR-PAS and not ATR. Additionally, these modalities show a rather explicit combination band of water at $5300 \mathrm{~cm}^{-1}$ with intensities correlated with the intensities of water bands in the mid-IR range.

In the shortwave mid-IR region, a wide band of $3700-3000 \mathrm{~cm}^{-1}$ of $\mathrm{O}-\mathrm{H}$ stretch and intermolecular hydrogen bonds [35] and, at its shoulder, sharp bands at $3695 \mathrm{~cm}^{-1}$ of isolated water and $3569 \mathrm{~cm}^{-1}$ attributed to hydrogen-bon bonded water and non-water -OH groups are observed [34,35,41]. These bands are present in DRIFT and FTIR-PAS and are not reliably detected with ATR (Figures 3 and 4). Some brands show another sharp band at $3715 \mathrm{~cm}^{-1}$ that can be attributed to $\mathrm{ROH} \cdots \mathrm{HOR}$ hydrogen bonds.

Bands of $\mathrm{O}-\mathrm{H}$ stretching vibrations $\left(3500-3200 \mathrm{~cm}^{-1}\right)$ are present in all the spectra, and the shape depends on the modality and ND brand, the maxima of asymmetric and symmetric bands at 3410 and $3230 \mathrm{~cm}^{-1}$ correspond to strongly hydrogen-bonded species and, in several cases, the band at $3290 \mathrm{~cm}^{-1}$, which is probably the overtone band of liquid adsorbed water, $2 v_{2}$ is present [16].

All four asymmetric and antisymmetric aliphatic vibrations of $\mathrm{sp}^{3} \mathrm{CH}_{\mathrm{x}}$ stretch vibrations in the range $3100-2800 \mathrm{~cm}^{-1}$ are observed, and in most brands, ATR shows low sensitivity (Table 5). The band at $1470 \mathrm{~cm}^{-1}$ corresponds to $\mathrm{CH}_{2}$ wagging and correlates with the intensity of $\mathrm{CH}_{\mathrm{x}}$ stretch at the $2900 \mathrm{~cm}^{-1}$ range. Bands at 1400-1395 and 1375-1370 $\mathrm{cm}^{-1}$ can be attributed as $\mathrm{CH}_{2} / \mathrm{CH}_{3}$ deformation bends as well as $\mathrm{C}-\mathrm{O}-\mathrm{H}$ bends (see below), so their intensities are not correlated with purely $\mathrm{CH}_{\mathrm{x}}$ bands at $3100-2800 \mathrm{~cm}^{-1}$.

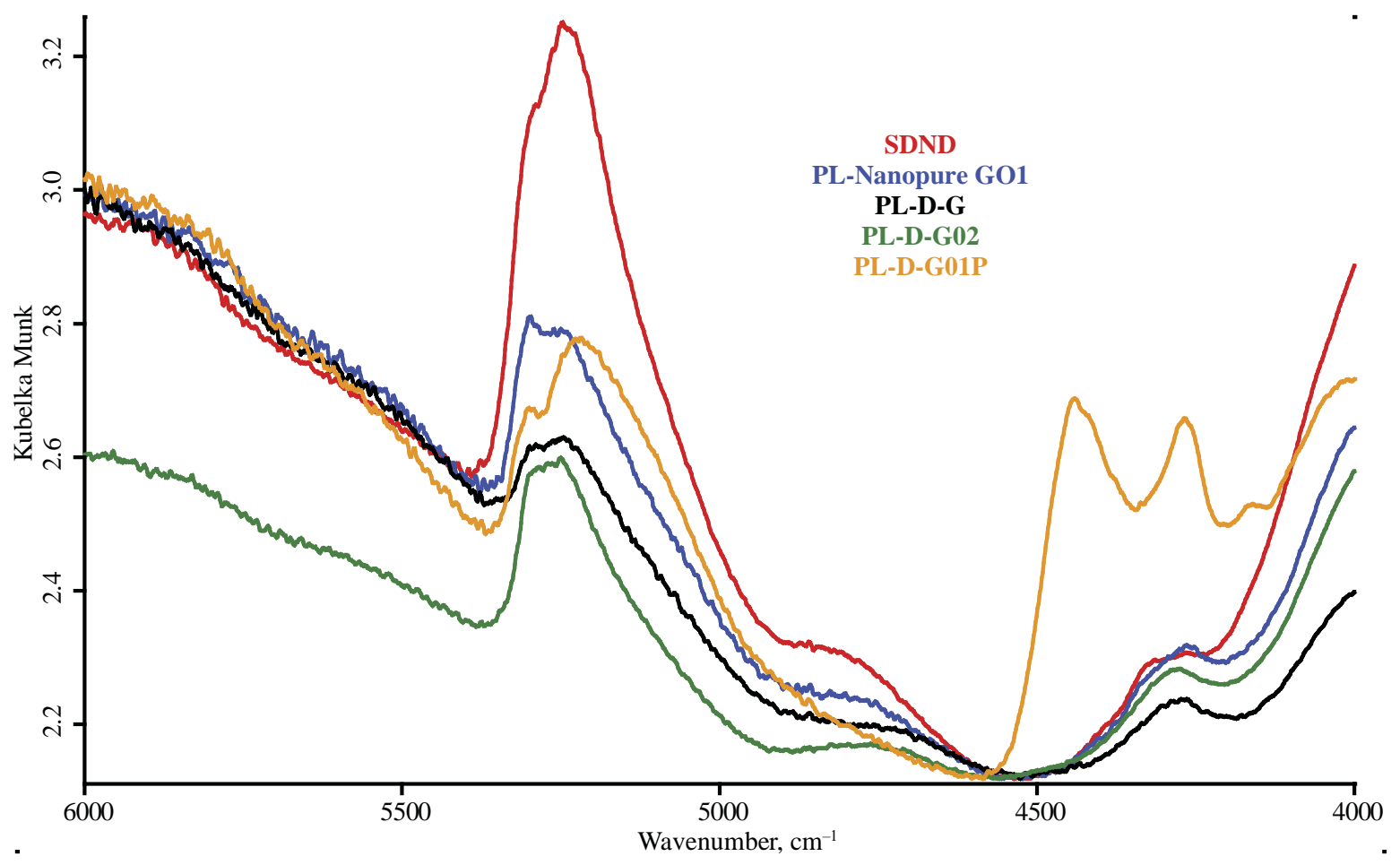

(a)

Figure 1. Cont. 


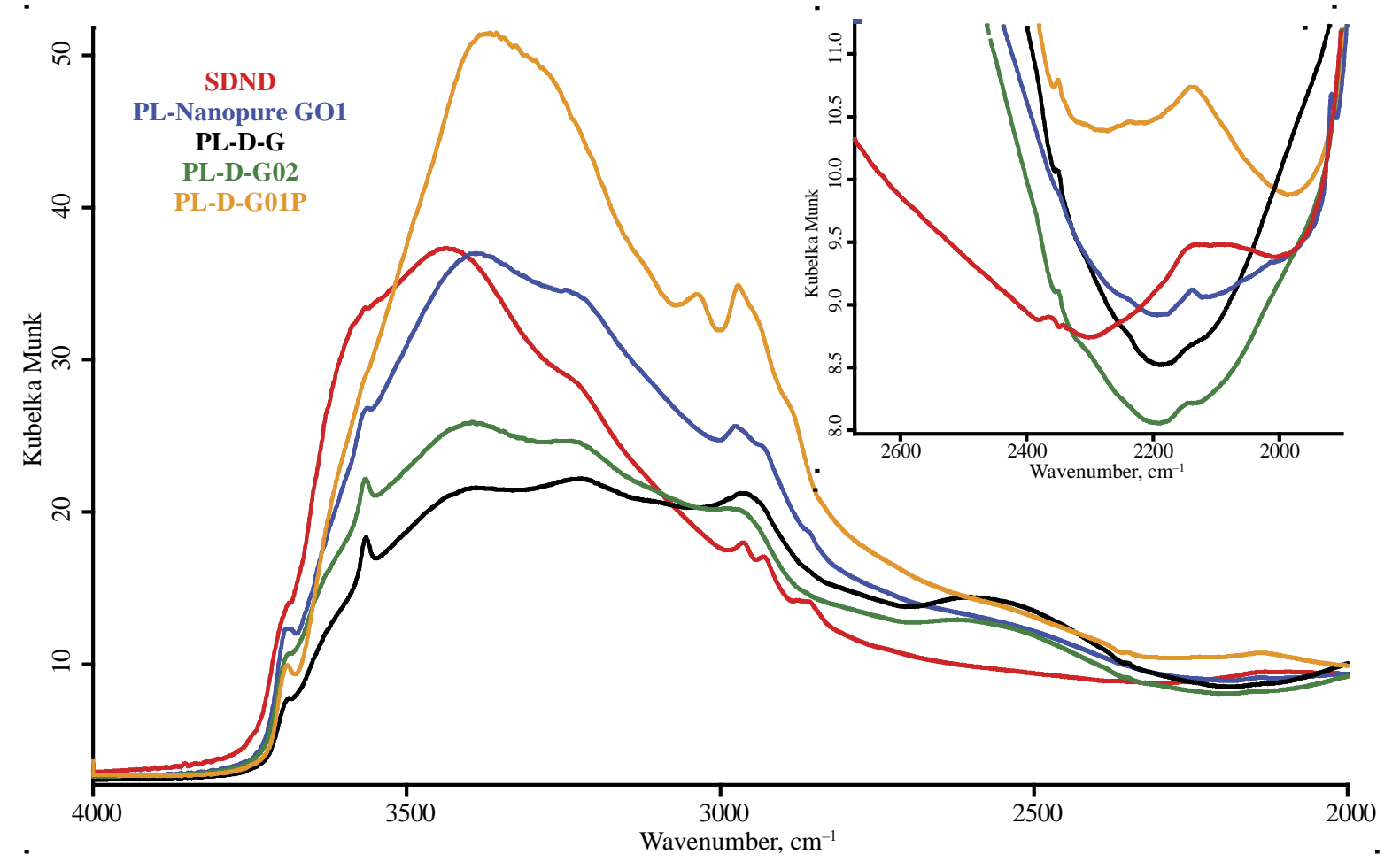

(b)

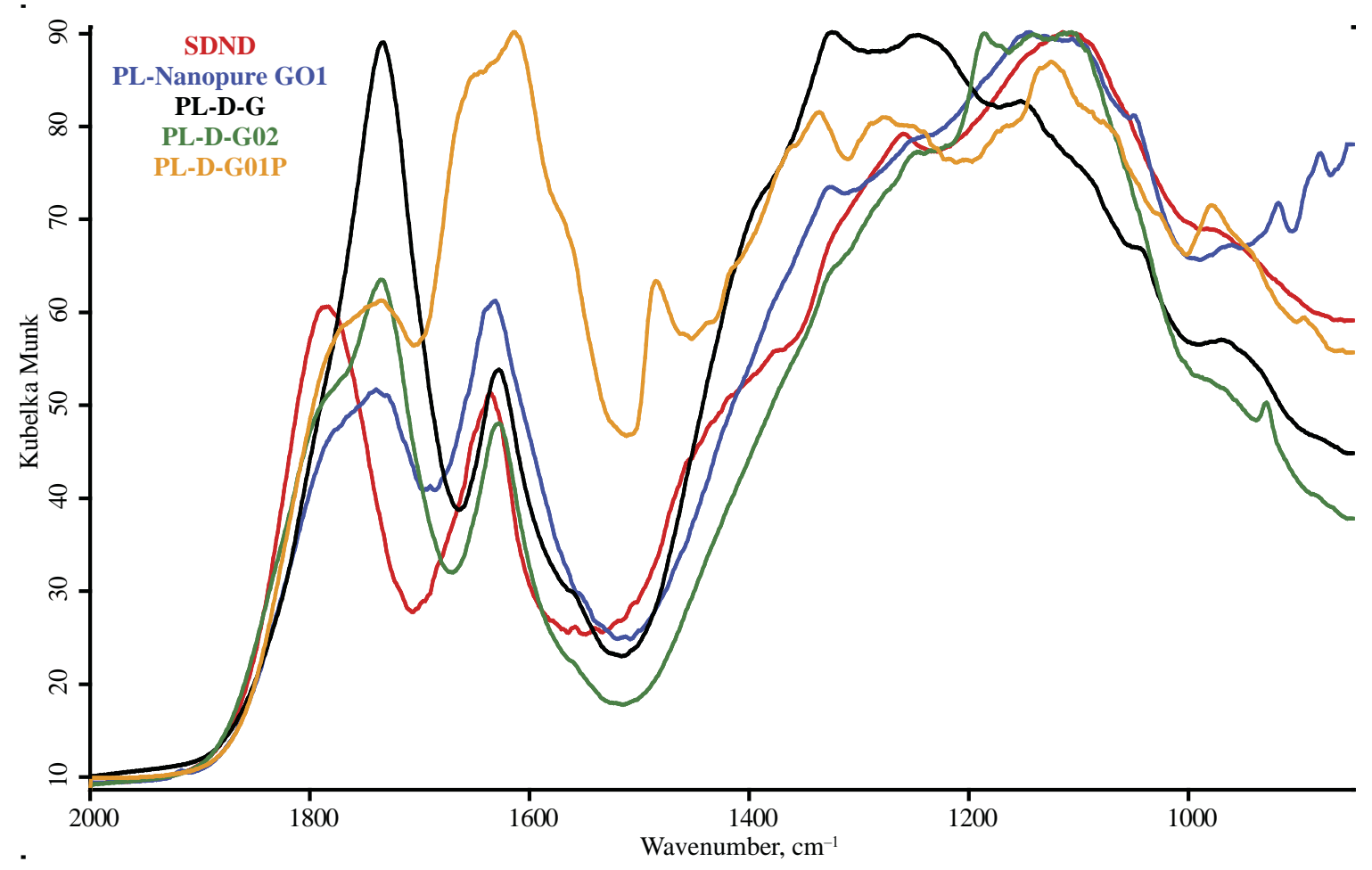

(c)

Figure 1. Diffuse reflectance mode, LN-MCT photovoltaic detector; nanodiamond brands: red, SDND; blue, PL-Nanopure GO1; black, PL-D-G; green, PL-D-G02; orange, PL-D-G01P; (a) $6000-4000 \mathrm{~cm}^{-1}$, (b) $4000-2000 \mathrm{~cm}^{-1}$ (c) $2000-800 \mathrm{~cm}^{-1}$ range. Spectra are smoothed (13 points) and normalized to maximize each spectrum. 


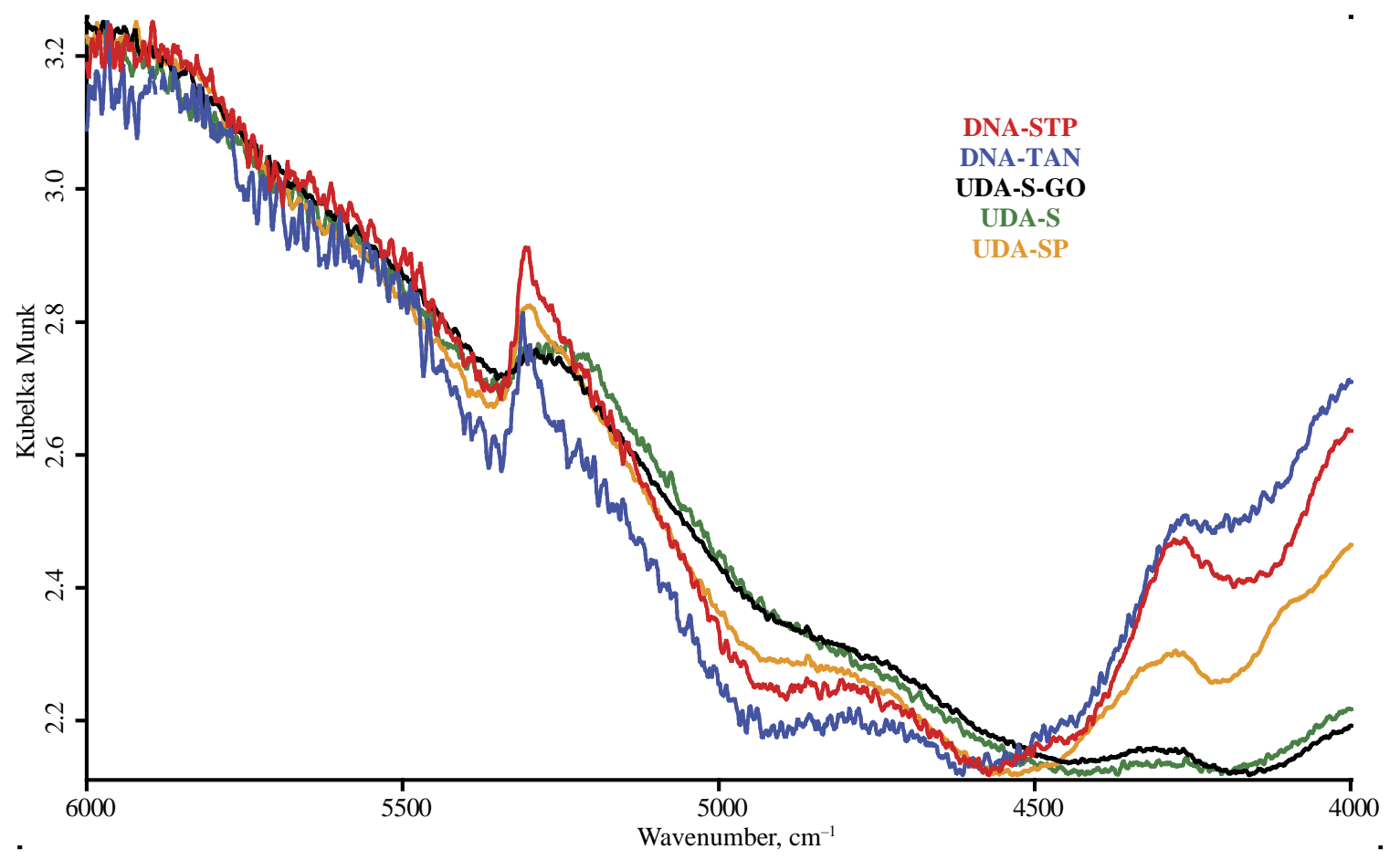

(a)

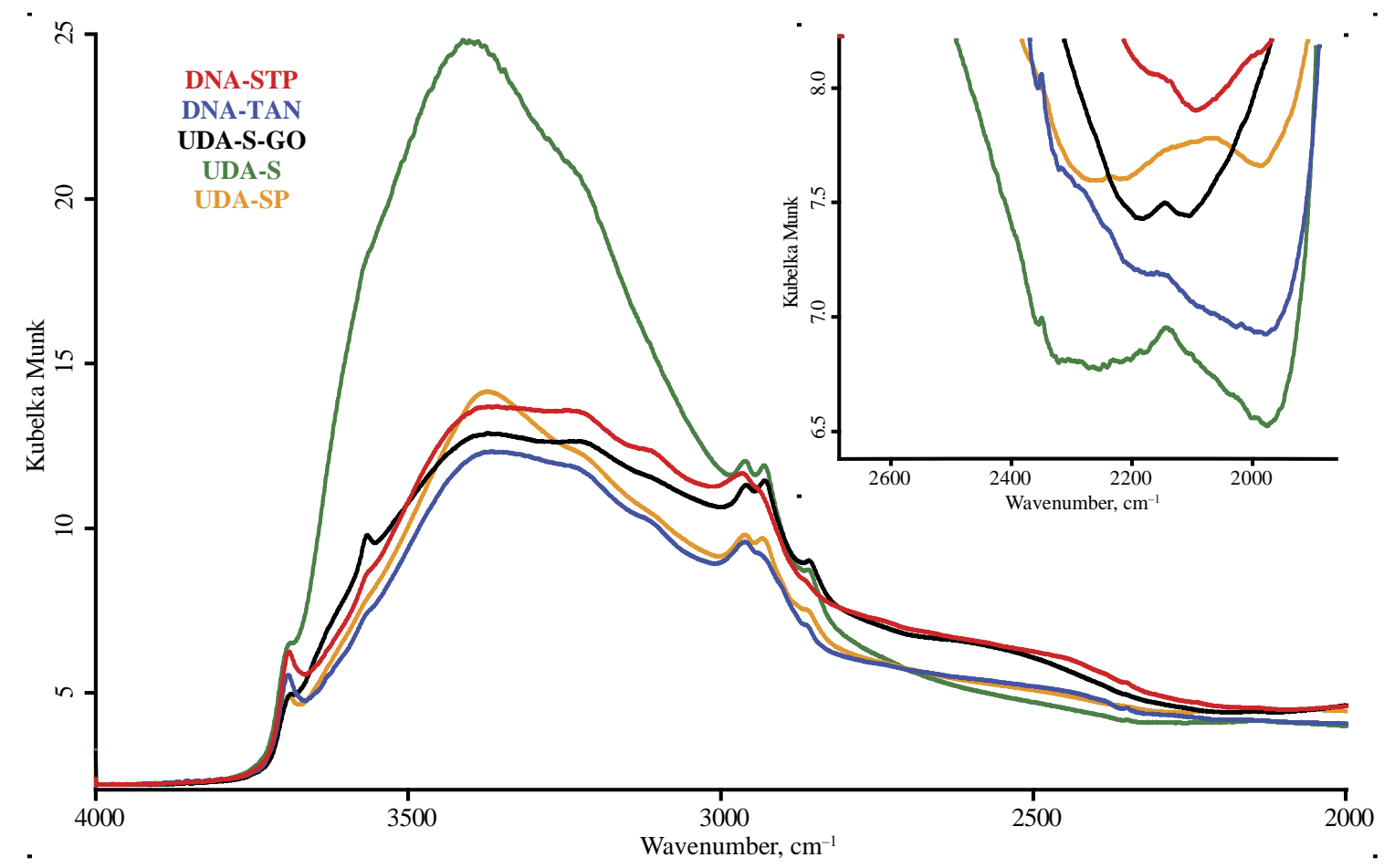

(b)

Figure 2. Cont. 


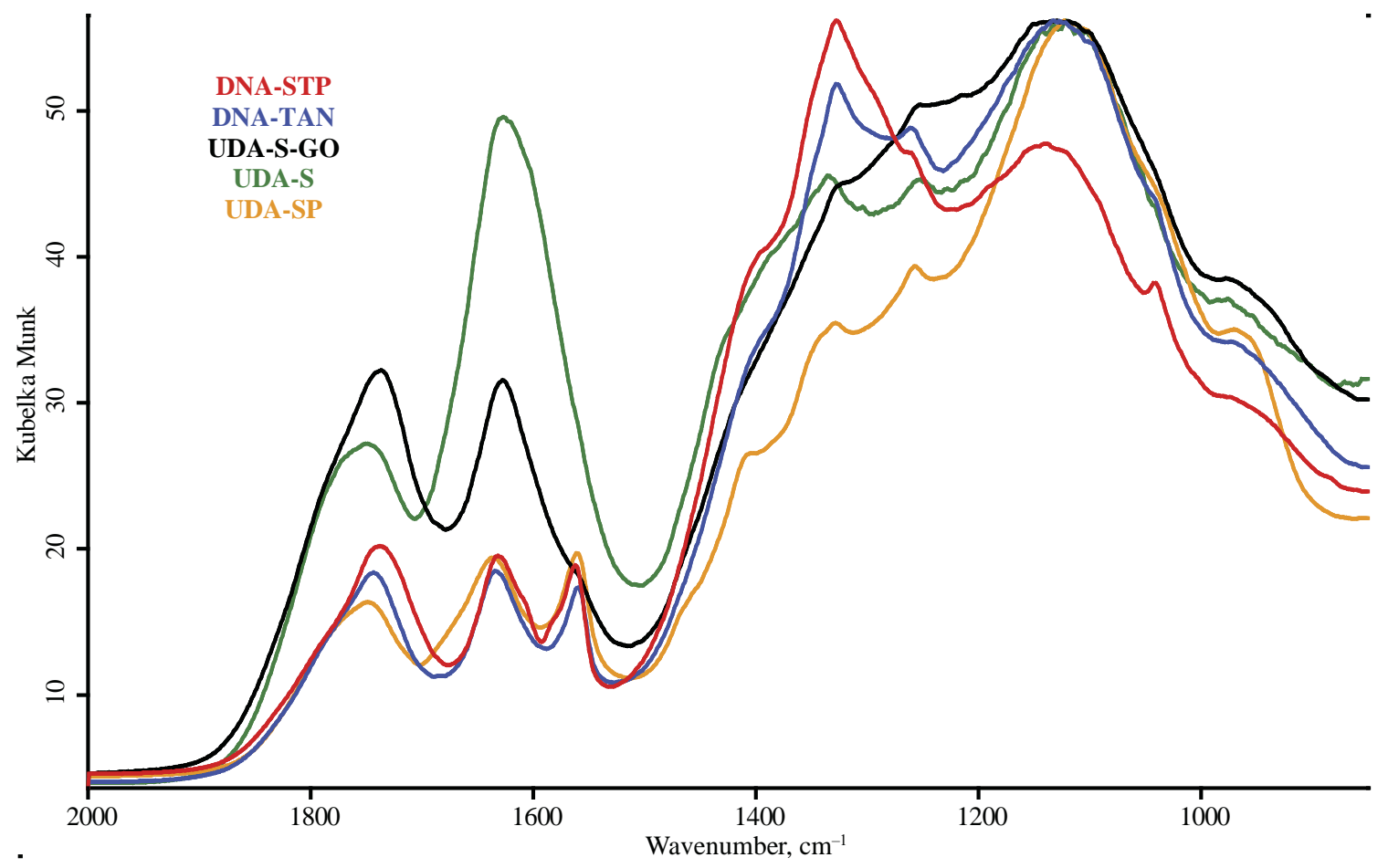

(c)

Figure 2. Diffuse reflectance mode, LN-MCT photovoltaic detector; nanodiamond brands: red, DNA-STP; blue, DNA-TAN; black, UDA-S-GO; green, UDA-S; orange, UDA-SP; (a) $6000-4000 \mathrm{~cm}^{-1}$, (b) $4000-2000 \mathrm{~cm}^{-1}$ (c) $2000-800 \mathrm{~cm}^{-1}$ range. Spectra are smoothed (13 points) and normalized to maximize each spectrum.

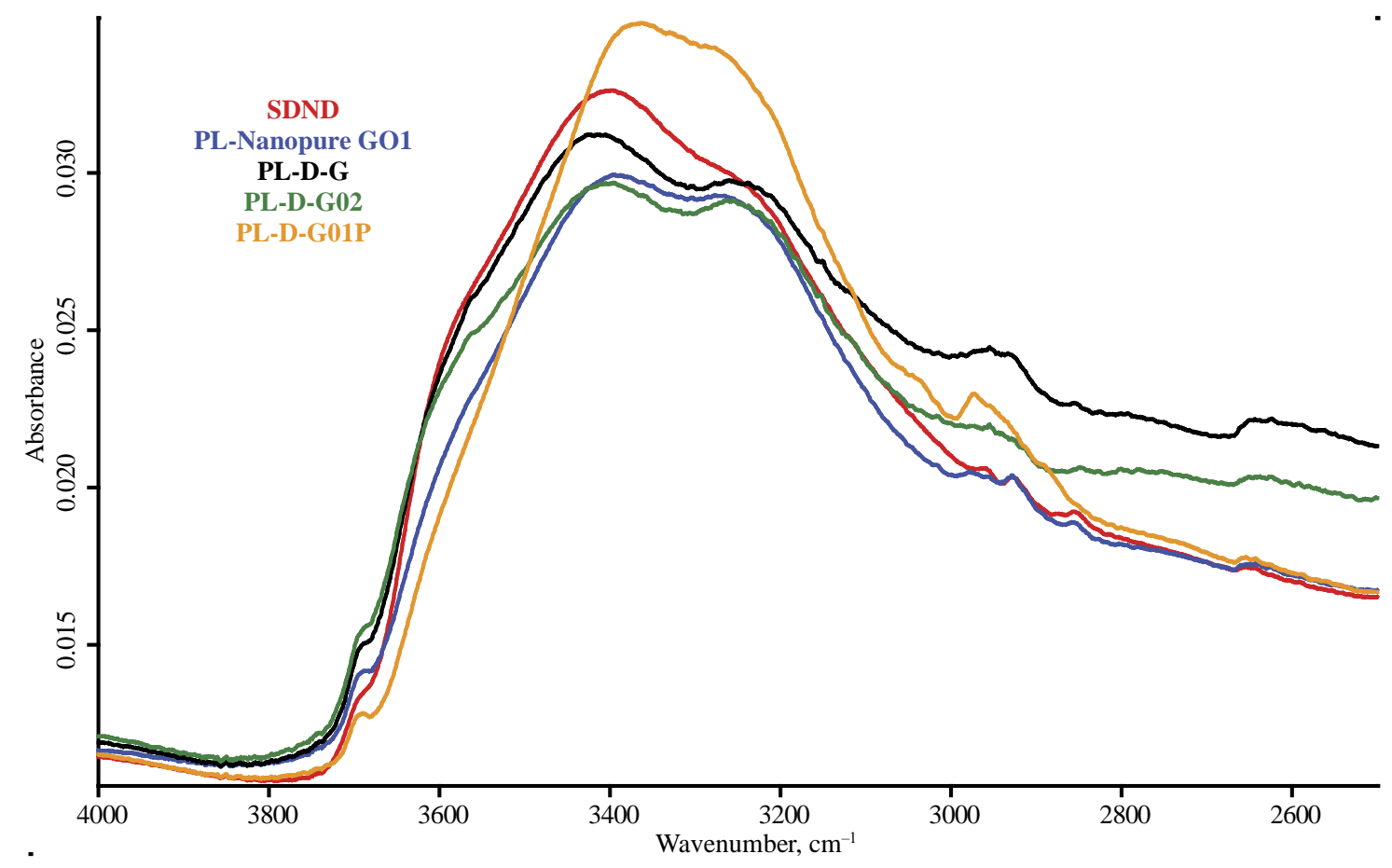

(a)

Figure 3. Cont. 


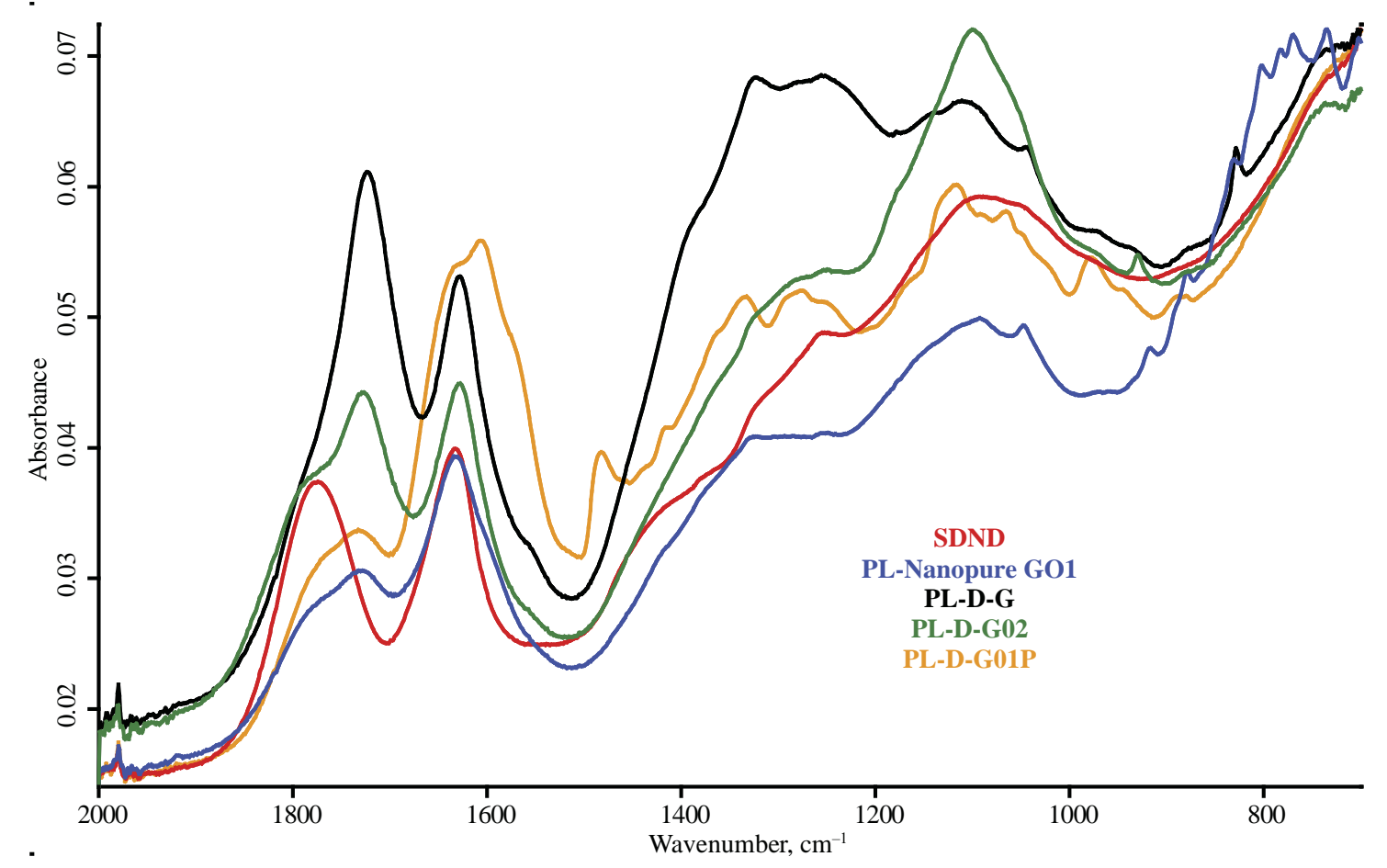

(b)

Figure 3. ATR mode, LN-MCT photovoltaic detector; nanodiamond brands: red, SDND; blue, PL-Nanopure GO1; black, PL-D-G; green, PL-D-G02; orange, PL-D-G01P; (a) 4000-2500 cm-1, (b) $2000-400 \mathrm{~cm}^{-1}$ range. Spectra were smoothed (13 points) and normalized to maximize each spectrum.

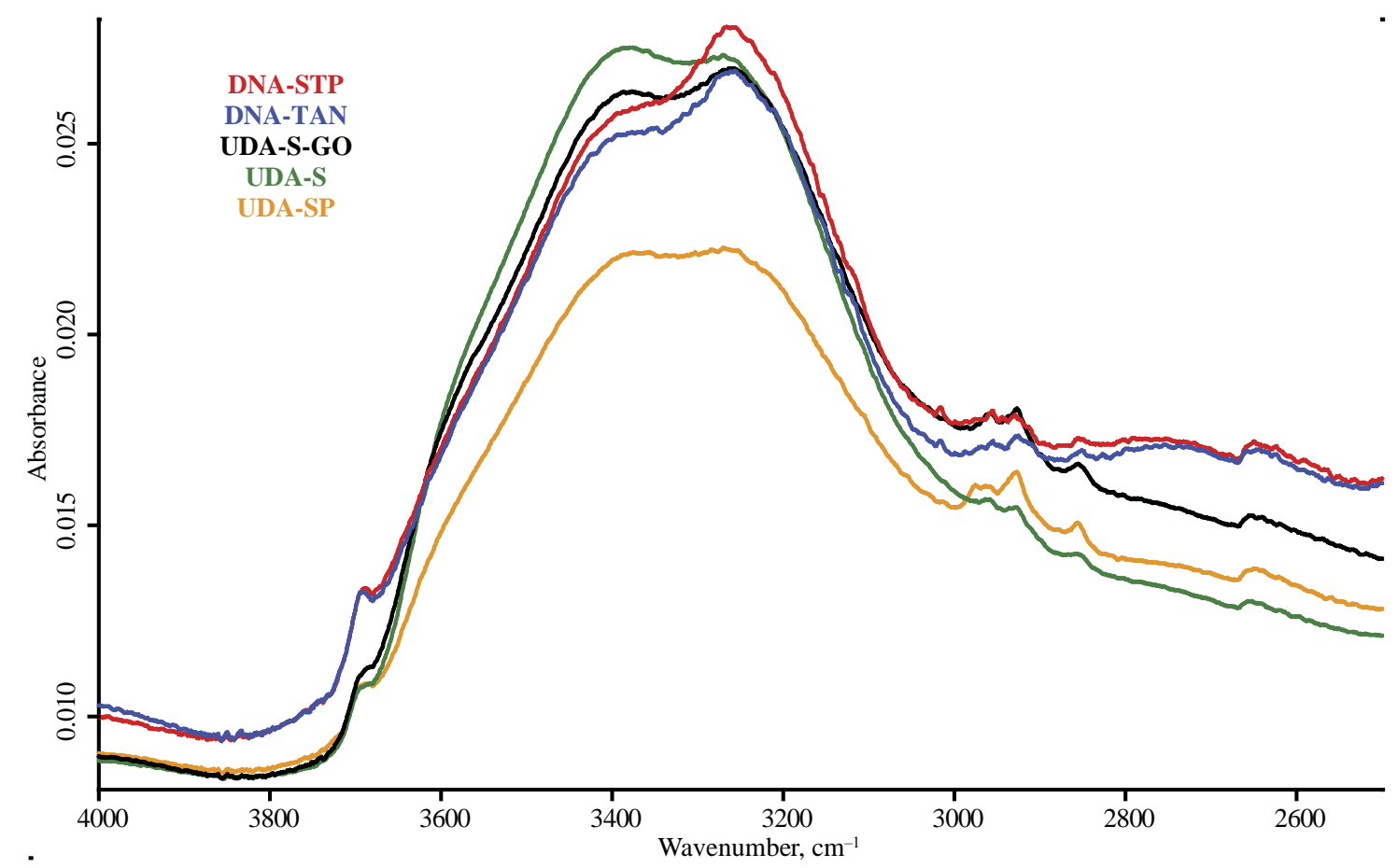

(a)

Figure 4. Cont. 


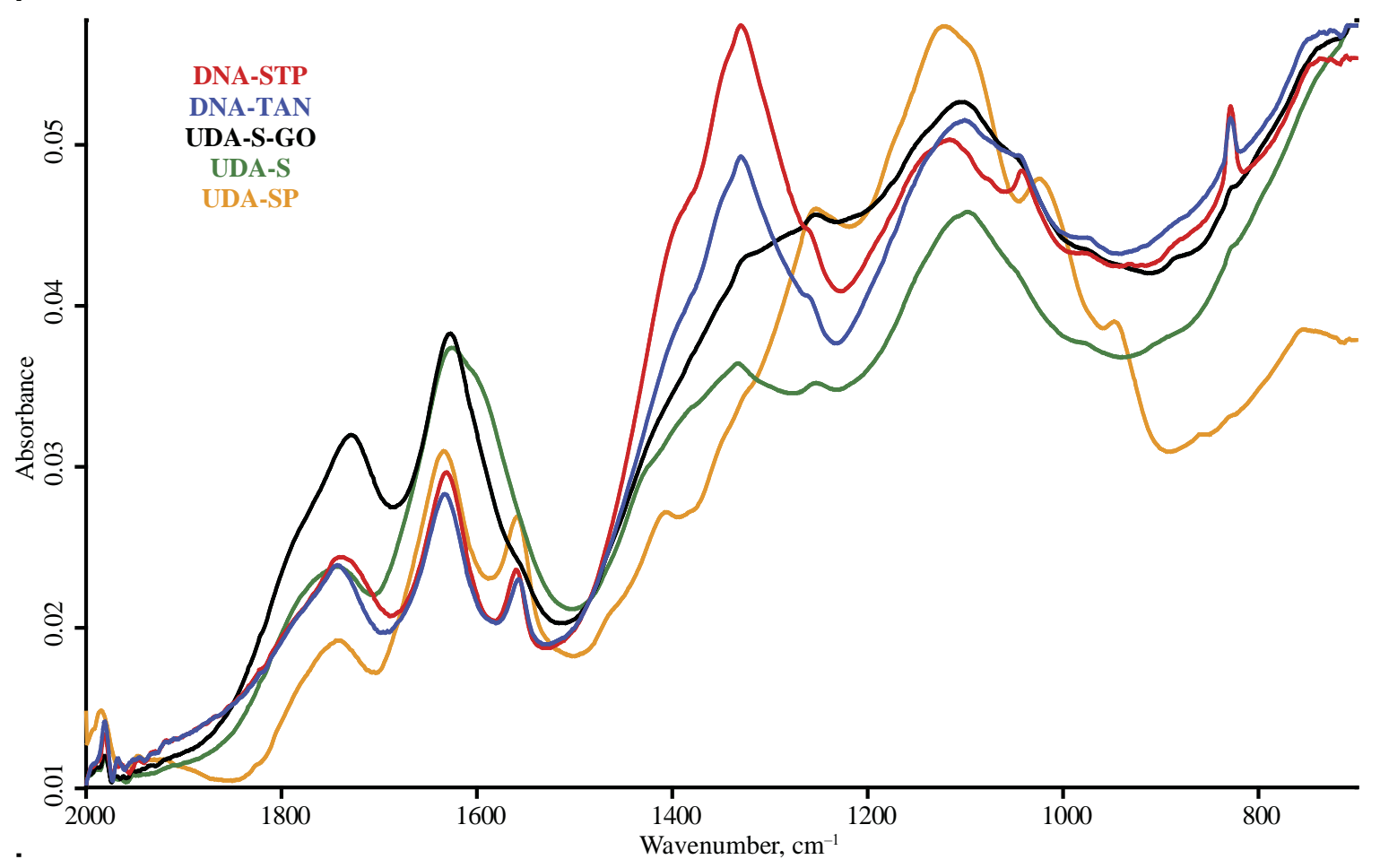

(b)

Figure 4. ATR mode, LN-MCT photovoltaic detector; nanodiamond brands: red, DNA-STP; blue, DNA-TAN; black, UDA-S-GO; green, UDA-S; orange, UDA-SP; (a) $4000-2500 \mathrm{~cm}^{-1}$, (b) $2000-400 \mathrm{~cm}^{-1}$ range. Spectra were smoothed (13 points) and normalized to maximize each spectrum.

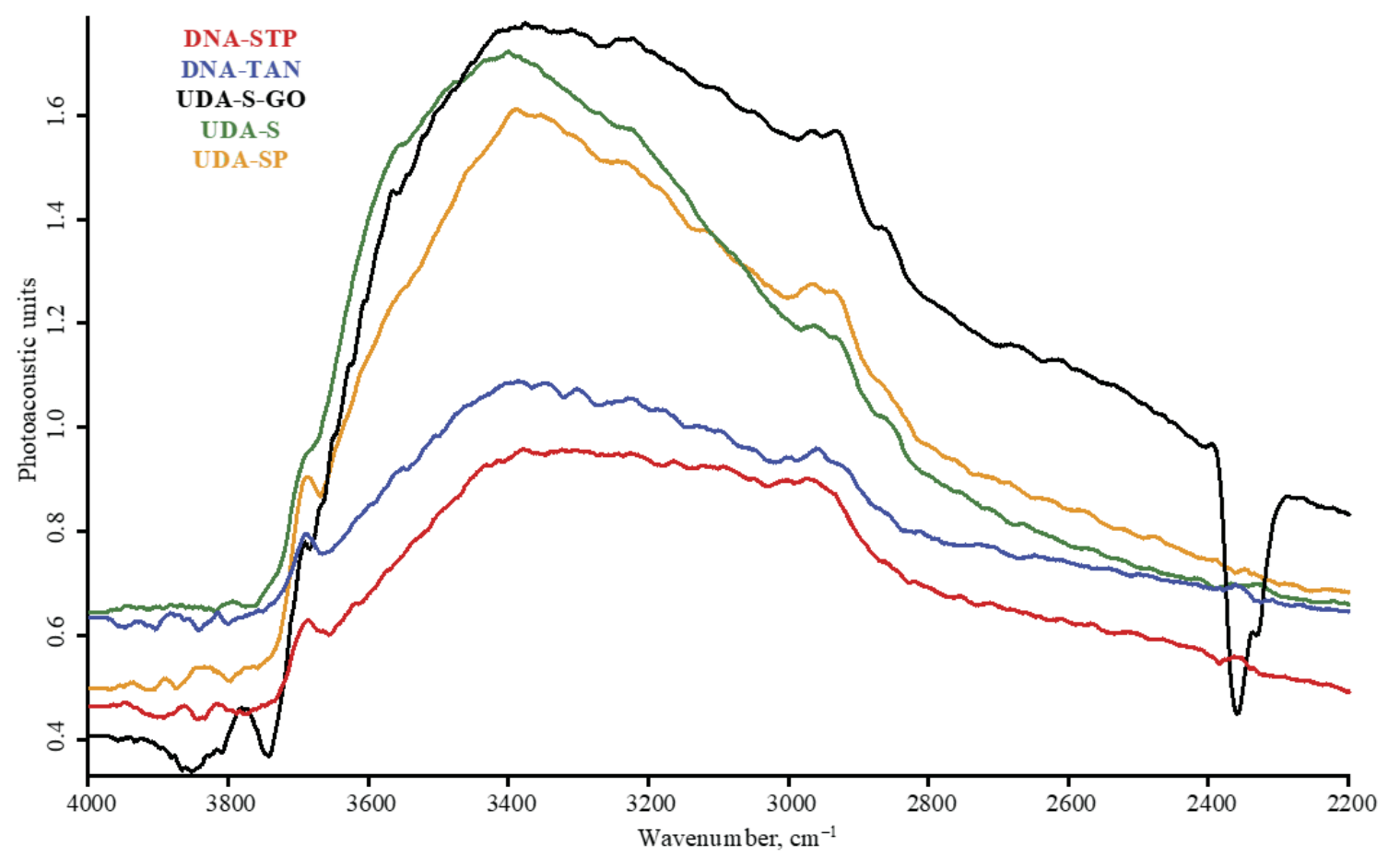

Figure 5. Cont. 


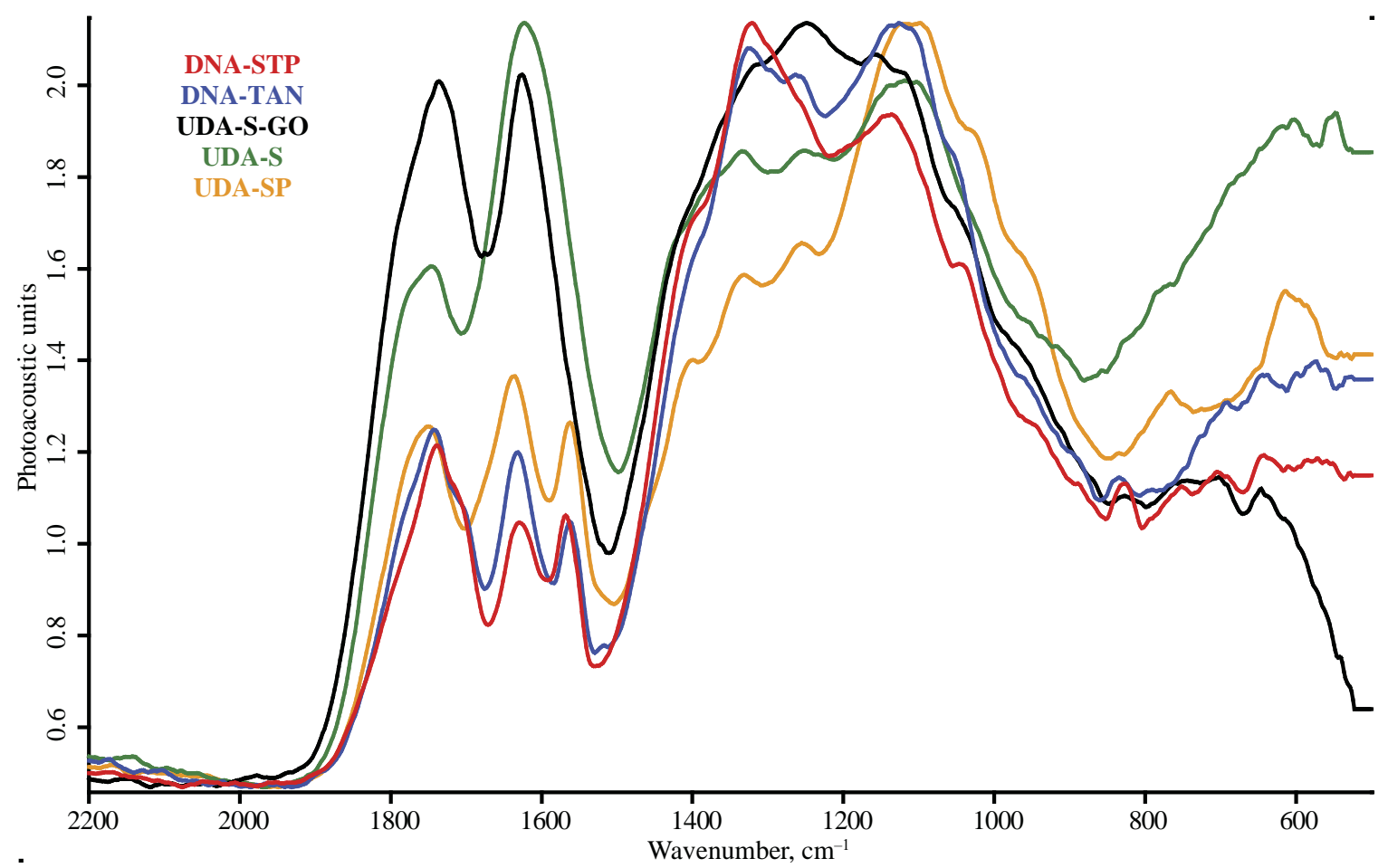

(b)

Figure 5. Photoacoustic mode, $1.6 \mathrm{kHz}$; nanodiamond brands: red, DNA-STP; blue, DNA-TAN; black, UDA-S-GO; green, UDA-S; orange, UDA-SP; (a) $4000-2200 \mathrm{~cm}^{-1}$, (b) $2200-400 \mathrm{~cm}^{-1}$ range. Spectra were smoothed ( 25 points) and normalized to maximize each spectrum.

Apart from aliphatic bands, some brands show aromatic C-H stretching at $3100-3050 \mathrm{~cm}^{-1}$ [42] and the band at $1580-1560 \mathrm{~cm}^{-1}$ (most probably, $\mathrm{C}=\mathrm{C}$ stretch). These bands are accompanied with distinct bands at 1060 and $760 \mathrm{~cm}^{-1}$ that can be attributed to in-plane $\mathrm{C}=\mathrm{C}-\mathrm{H}$ and polyaromatic $\mathrm{C}=\mathrm{C}-\mathrm{H}$ bending, respectively. Additionally, a band of $410 \mathrm{~cm}^{-1}$ is attributed to $\mathrm{C}-\mathrm{C}$ in-phase vibrations [40]. A band at $960 \mathrm{~cm}^{-1}$ can be attributed to $=\mathrm{CH}_{2}$ wag.

The range of $1900-1200 \mathrm{~cm}^{-1}$ reveals the maximum number of bands. Here, the stretch of the carbonyl $\mathrm{C}=\mathrm{O}\left(1770-1650 \mathrm{~cm}^{-1}\right)$ is dominant, usually in the form of a continuum from 2000 to $1600 \mathrm{~cm}^{-1}$; bands at $1760-1740 \mathrm{~cm}^{-1}$ attributed to the carbonyl of carboxylic groups and less strong bands (for not all the brands) at $1670 \mathrm{~cm}^{-1}$ attributed to the $\mathrm{C}=\mathrm{O}$ stretch of non-carboxyl moieties are dominant (Figure 6). There is also a weak broad band of $1550 \mathrm{~cm}^{-1}$, also belonging to asymmetric $\mathrm{C}=\mathrm{O}$ stretching vibrations $[35,43]$ or asymmetric stretching vibrations of deprotonated carboxyl $\mathrm{O}-\mathrm{C}=\mathrm{O}[43,44]$; however, the comparison of the blank in FTIR-PAS, ATR, and DRIFT shows that such low-intensity bands in the range $1600-1400 \mathrm{~cm}^{-1}$ are mostly enveloped narrow bands of gaseous water. In the case of DRIFT and ATR, they are positive, but in the case of FTIR-PAS, these peaks are inverted, and in the case of low-intensity, signals can be wrongly interpreted as the broader bands red-shifted, compared to other modalities. These artefact bands were excluded from further consideration. 


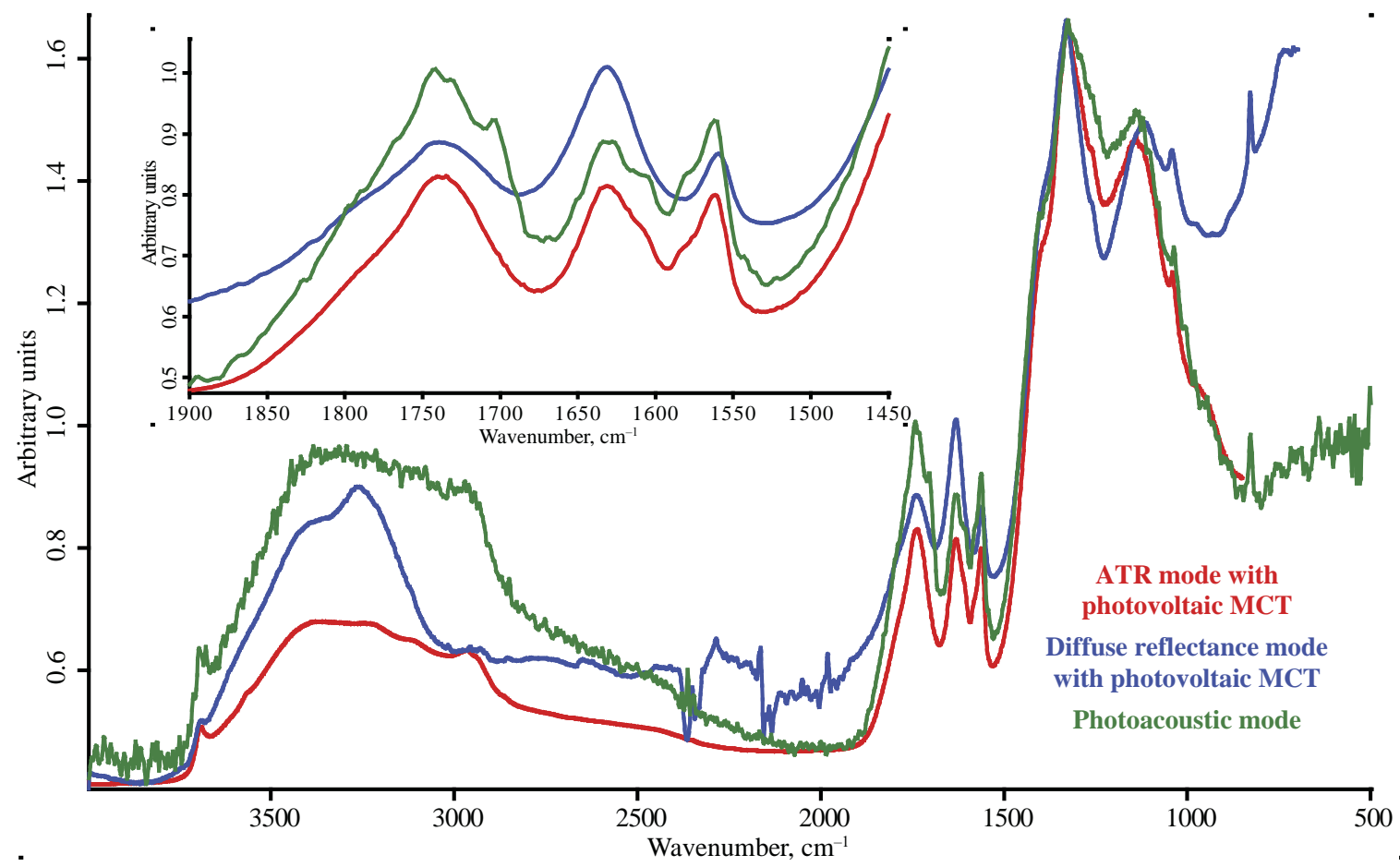

Figure 6. DNA-STP nanodiamonds; red, ATR mode with photovoltaic MCT detector; blue, diffuse reflectance mode with photovoltaic MCT detector; green, photoacoustic mode. Spectra are not smoothed but normalized to maximize each spectrum.

The band intensities at $1700 \mathrm{~cm}^{-1}$ correlate well with the signal from a weak broad band $2700-2600 \mathrm{~cm}^{-1}$, which is attributed to $\mathrm{O}-\mathrm{H}$ stretch in carboxyl, which is red-shifted O-H compared to the main continuum of $3500-3200 \mathrm{~cm}^{-1}$. The presence of this band can be considered as a proof of carboxylic groups at the surface.

A band of $\mathrm{H}-\mathrm{O}-\mathrm{H}$ bending vibrations of liquid unbound or loosely bound water $1643 \mathrm{~cm}^{-1}$ is present in all the spectra; all the studied air-dried samples contain $5-7 \%$ of water $[45,46]$. Another band of water $\left(1620-1635 \mathrm{~cm}^{-1}\right)$ is present in all the spectra. Its wavenumber is red-shifted compared to liquid water $\left(1643 \mathrm{~cm}^{-1}\right)$, evidencing a high contribution of hydrogen-bonding to the vibrations [47]. Its intensity decreases after drying, but this band does not disappear even after five hours of drying, using ultra dry air at room temperature inside the DRIFT accessory (Figure A3, Appendix A). These bands almost disappeared at temperatures above $100{ }^{\circ} \mathrm{C}$ (Figure 7). The presence of this band is evidence of the water layer at the surface of the nanodiamonds that determines the colloidal solubility of nanodiamonds and its division into "soluble" and "insoluble" brands [5]. In this work, we used drying to confirm the correct assignment of water bands, especially at the $1700-1600 \mathrm{~cm}^{-1}$ region.

Symmetrical bands at 1440 and $1390-1320 \mathrm{~cm}^{-1}$, at least partly, can be assigned to C-O-H in-plane bend for carboxyl $[37,43,44]$ and non-carboxyl groups [38]. The bands at $1270 \mathrm{~cm}^{-1}$ correspond to carboxyl C-O stretch or bending vibrations of epoxy C-O $[35,43,44]$. Weakly pronounced asymmetric bending vibrations that can be assigned to $\mathrm{C}-\mathrm{O}-\mathrm{C}$ are observed in the range of $1150-1110 \mathrm{~cm}^{-1}[35,43,44]$. The band at $1100-1040 \mathrm{~cm}^{-1}$ can be attributed to non-carboxyl $\mathrm{C}-\mathrm{O}$ stretch or asymmetric bending vibrations of C-O-C $[35,42-44,48]$ and carboxyl and non-carboxyl out-of-plane $\mathrm{C}-\mathrm{O}-\mathrm{H}$ bend at 940 and $610 \mathrm{~cm}^{-1}$, respectively. The range of $1000-500 \mathrm{~cm}^{-1}$ has an increased overall intensity caused by the extra broad band of water librations. This mostly affects ATR and FTIR-PAS measurements. 


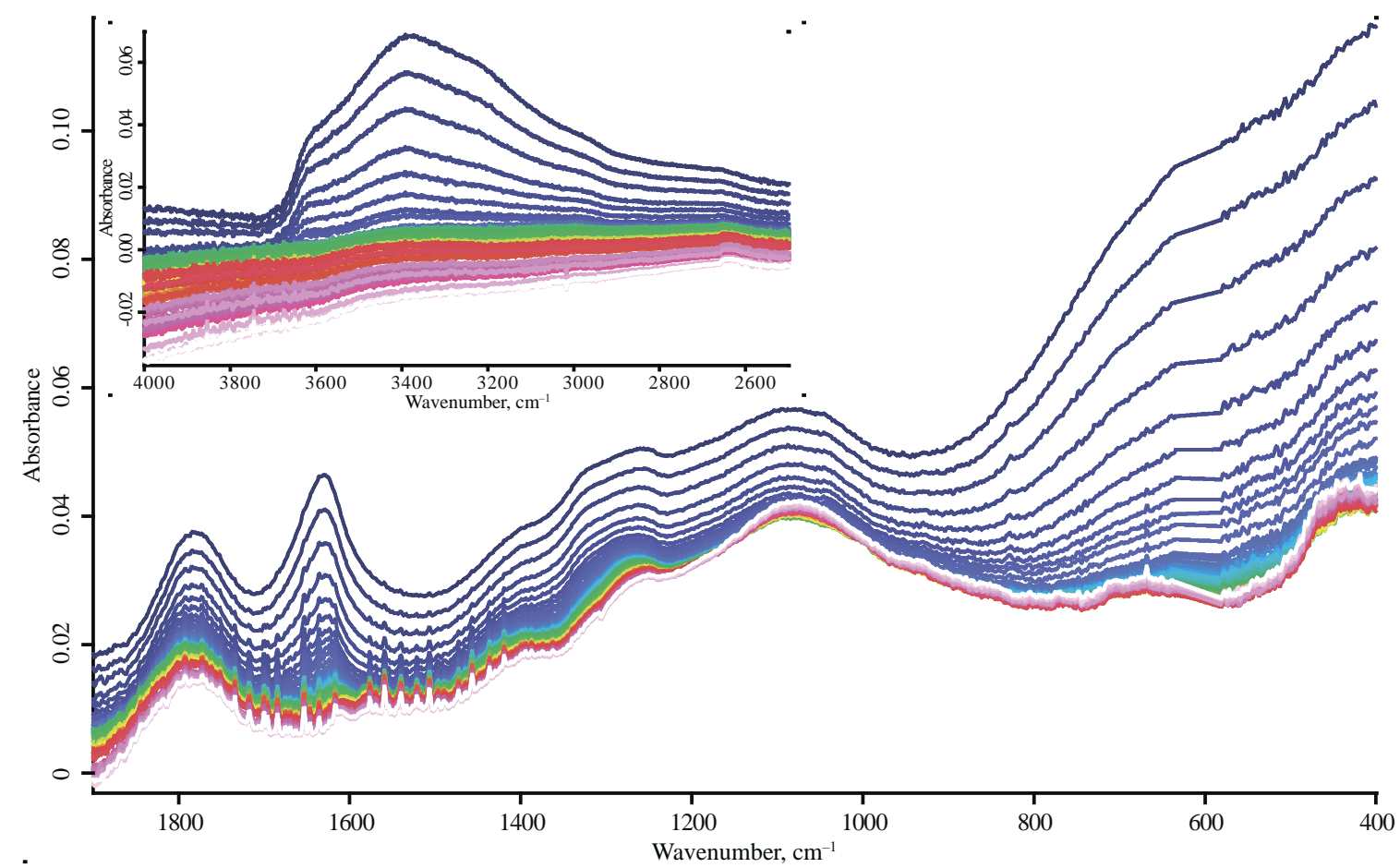

Figure 7. ATR mode, SDND nanodiamonds, heating from $25^{\circ} \mathrm{C}$ (blue) to $215^{\circ} \mathrm{C}$ (pink). Spectra are not smoothed.

\subsection{Signal-Gathering Depth and FTIR-PAS Modulation Frequency Comparison}

The refractive index of nanodiamonds is not equal to the refractive index of diamond due to the developed surface and the presence of many surface groups [16], but it is likely that the refractive index of nanodiamonds of any grade is within the value $2.4 \pm 0.1$ [49]. Thus, the estimation of the penetration (signal-gathering) depth by ATR with Equation (1) at $4000 \mathrm{~cm}^{-1}$ gives the value $240 \mathrm{~nm}$, which is comparable to the characteristic size of ND clusters $[43,50,51]$. The maximum penetration depth of radiation in ATR measurements for a wavenumber of $400 \mathrm{~cm}^{-1}$ is ca. $2.4 \mu \mathrm{m}$, which is more than two orders of magnitude larger than the particle size of the studied nanodiamonds. This agrees with the sensitivity of ATR, which is lower than that of DRIFT and FTIR-PAS in the range $4000-2000 \mathrm{~cm}^{-1}$; additionally, the reproducibility of ATR in this range is also degraded compared to a low wavenumber range-see the next section.

To estimate the penetration depth of radiation by FTIR-PAS, we performed a model calculation of $\mu_{\mathrm{s}}$ for interferometer modulation frequencies (IMF) of 1.6, 2.5, and $10 \mathrm{kHz}$ using Equation (3), Figure A4 (Appendix A). The penetration depth of the radiation in all the mid-IR ranges is $300-1000 \mu \mathrm{m}$, which is much greater than the size of the investigated particles $(0.1-0.2 \mu \mathrm{m})$. Therefore, the radiation in FTIR-PAS must completely pass through all particles and each individual particle must emit thermal waves in all directions of space and give a high signal to the detector [52].

The FTIR-PAS spectrum of nanodiamonds at $2.5 \mathrm{kHz}$ has a large baseline profile in the range of 4000-1900 cm $\mathrm{cm}^{-1}$. The absorption bands of asymmetric $2920 \mathrm{~cm}^{-1}$ and symmetric $2860 \mathrm{~cm}^{-1}$ [42] stretching $-\mathrm{CH}_{\mathrm{x}}$ vibrations remain in the spectra. The reason for the differences in spectra is the selection of the amplification mode for the sample signal. A twofold change in the signal amplification mode and a slight decrease in the radiation penetration depth causes significant changes in the spectrum. In both spectra, the band of stretching vibrations $-\mathrm{C}=\mathrm{O}$ at $1750 \mathrm{~cm}^{-1}$ [44], and the band of stretching vibrations of the deprotonated carboxyl group at $1680 \mathrm{~cm}^{-1}$ [44] are manifested. There is also a band of asymmetric stretching vibrations of deprotonated carboxyl $-\mathrm{C}=\mathrm{O} 1550 \mathrm{~cm}^{-1}[43,44]$. Additionally, at $1.6 \mathrm{kHz}$, the band of asymmetric stretching vibrations of the carboxyl C-O stretch at 
$1270-1250 \mathrm{~cm}^{-1}$ and symmetric C-C-C vibrations with a wavenumber of $1190-1100 \mathrm{~cm}^{-1}[35,43,48]$ are weaker. The $970 \mathrm{~cm}^{-1}$ band of $\mathrm{C}-\mathrm{O}-\mathrm{C}$ bending vibrations [42] has a high intensity. FTIR-PAS spectra at an IMF of $5 \mathrm{kHz}$ shows the same bands as lower IMF with the signal-noise ratio, thus with degraded information. A serious difference between low and high IMFs may result from thermal scattering that increases the overall background in FTIR-PAS. Thus, high IMFs for FTIR-PAS of nanodiamond powders are not recommended.

\subsection{Band Reproducibility}

For ATR-FTIR and DRIFT, the shape of the all the test bands and the positions of the maxima are reproduced, except for the $1750 \mathrm{~cm}^{-1}$ band (carboxyl $\mathrm{C}=\mathrm{O}$ ), where a small scatter is observed after vector normalization. The range of $3000-2000 \mathrm{~cm}^{-1}$, as well as the absorption bands of $\mathrm{CH}_{\mathrm{x}}$ stretching vibrations, contain $\mathrm{CO}_{2}$ absorption bands and, in ATR, the absorption band of the ATR attachment crystal (2350-1900 $\left.\mathrm{cm}^{-1}\right)$, which seriously degrade the reproducibility of ATR measurements in this range. In the range of $2000-1000 \mathrm{~cm}^{-1}$, the band at $1400 \mathrm{~cm}^{-1}(\mathrm{C}-\mathrm{O} / \mathrm{C}-\mathrm{H})$ has the highest RSD value among all the analyzed bands due to its lowest intensity in this range. In the range of $1000-400 \mathrm{~cm}^{-1}$, a significant increase in the baseline is observed due to water librations, which entails the need for a baseline-correction procedure.

For FTIR-PAS (IMF, $1.6 \mathrm{kHz}$ ), the shapes and positions of band maxima are also reproduced. In the range of 4000-3000 $\mathrm{cm}^{-1}$, many narrow bands in the range $3920-3550 \mathrm{~cm}^{-1}$ are observed, which belong to stretching vibrations of adsorbed water either on the walls of the IR spectrometer and attachment on the surface of nanodiamonds. After the vector normalization procedure, main absorption bands at 1760 and $1630 \mathrm{~cm}^{-1}$, as well as $1267 \mathrm{~cm}^{-1}$ are most clearly traced. High-intensity artifacts are observed in the range $500-400 \mathrm{~cm}^{-1}$, which is why this range is not considered further in FTIR-PAS. For two spectra out of ten, artifacts are observed in the entire range over the entire considered range of wavenumbers. The bands at 1400 and $1750 \mathrm{~cm}^{-1}$ have the best RSD values. As shown in the previous section, the particle size of nanodiamonds is significantly lower than $\mu_{\text {ATR }}$ in the whole spectral range. However, decreasing the radiation penetration depth upon shifting from the IMF from 1.6 to $2.5 \mathrm{kHz}$ lowers the intensities of all the characteristic bands and increases RSD values, thus negatively affecting the signal-to-noise ratio. Thus, to record a FTIR-PAS spectrum of nanodiamonds in the range $4000-2000 \mathrm{~cm}^{-1}$, it is preferable to use an IMF of $1.6 \mathrm{kHz}$ with a 200 -fold amplification of the background signal and a 1000-fold gain in the sample signal.

The measurement errors for mid-IR spectra can be summed up as follows (spectra reproducibility errors were found by Equation (3); spectra at this stage were not subjected to automatic baseline correction and smoothing). The RSD values of the integrals of the main bands (Table 5) are presented in Tables 6-8 for ATR, FTIR-PAS, and DRIFT, respectively. In the range $4000-3800 \mathrm{~cm}^{-1}$, the RSD can be up to $100 \%$ in FTIR-PAS; in ATR-IR and DRIFT, it does not exceed $35 \%$. In $3800-3000 \mathrm{~cm}^{-1}$, the RSD is $15-30 \%$ for all the techniques. In $3000-2500 \mathrm{~cm}^{-1}$, the RSD for FTIR-PAS is also $15-40 \%$; for ATR this is lower, at $18-20 \%$ (in the absorption range of the diamond crystal, $2350-1900 \mathrm{~cm}^{-1}$, this is $35-45 \%$ ); for DRIFT this is $20-30 \%$. In 1900-1000 $\mathrm{cm}^{-1}$, the minimum RSD in FTIR-PAS is 25\%, and no more than 15-25\% for ATR, and $12-20 \%$ for DRIFT. In $1000-400 \mathrm{~cm}^{-1}$, the RSD for FTIR-PAS and DRIFT does not exceed $40 \%$; in ATR, this does not exceed $20 \%$. Therefore, for NDs, DRIFT shows the best results; the second best is ATR, despite the possibility of mechanical damage to the diamond crystal of the ATR attachment. The spectra are well reproduced, the baseline is less distorted and stable, apart from in the $1000-400 \mathrm{~cm}^{-1}$ range, and no spectral artifacts appear in the whole interval. The same cannot be said for the FTIR-PAS spectra, showing some spectral artefacts. However, in general, the RSD profiles are similar; most differences are observed in the absorption range of the diamond crystal of the ATR attachment (2350-1900 $\left.\mathrm{cm}^{-1}\right)$. 
Table 6. Relative standard deviation of band integral intensities in the wavenumber range $3000-2000 \mathrm{~cm}^{-1}$ by ATR-FTIR (RDDM ND brand).

\begin{tabular}{cccc}
\hline Band Center, $\mathbf{c m}^{\mathbf{- 1}}$ & High-Wave Boundary, $\mathbf{c m}^{\mathbf{- 1}}$ & Low-Wave Boundary, $\mathbf{c m}^{\mathbf{- 1}}$ & RSD \\
\hline 2935 & 2952 & 2918 & 0.27 \\
2837 & 2857 & 2817 & 0.25 \\
2650 & 2673 & 2626 & 0.43 \\
1750 & 1815 & 1684 & 0.21 \\
1630 & 1668 & 1535 & 0.18 \\
1400 & 1417 & 1393 & 0.20 \\
1270 & 1341 & 1249 & 0.21 \\
\hline
\end{tabular}

Table 7. Relative standard deviation of band integral intensities in the wavenumber range $3000-2000 \mathrm{~cm}^{-1}$ by FTIR-PAS (RDDM ND brand).

\begin{tabular}{cccc}
\hline Band Center, $\mathbf{c m}^{\mathbf{- 1}}$ & High-Wave Boundary, $\mathbf{~ m}^{\mathbf{- 1}}$ & Low-Wave Boundary, $\mathbf{c m}^{\mathbf{- 1}}$ & RSD \\
\hline 2935 & 2952 & 2918 & 0.40 \\
2837 & 2857 & 2817 & 0.40 \\
2650 & 2677 & 2622 & 0.27 \\
1750 & 1852 & 1691 & 0.33 \\
1630 & 1690 & 1594 & 0.32 \\
1400 & 1417 & 1393 & 0.33 \\
1270 & 1341 & 1244 & 0.39 \\
\hline
\end{tabular}

Table 8. Relative standard deviation of band integral intensities in the wavenumber range $3000-2000 \mathrm{~cm}^{-1}$ by DRIFT (RDDM ND brand).

\begin{tabular}{cccc}
\hline Band Center, $\mathbf{c m}^{\mathbf{- 1}}$ & High-Wave Boundary, $\mathbf{c m}^{\mathbf{- 1}}$ & Low-Wave Boundary, $\mathbf{c m}^{\mathbf{- 1}}$ & RSD \\
\hline 2935 & 2952 & 2918 & 0.34 \\
2837 & 2857 & 2817 & 0.37 \\
2650 & 2676 & 2619 & 0.23 \\
1750 & 1852 & 1691 & 0.10 \\
1630 & 1690 & 1594 & 0.08 \\
1400 & 1417 & 1393 & 0.11 \\
1270 & 1341 & 1253 & 0.11 \\
\hline
\end{tabular}

\section{Discussion}

\subsection{DRIFT}

This modality provides the maximum number of bands and shows the highest sensitivity in the whole range, from NIR to FIR. The bands discussed above in the NIR range above $4000 \mathrm{~cm}^{-1} \mathrm{are}$ obtained only with this modality, due to a lower noise in DRIFT.

In this study, we used DRIFT with a bare mirror as the background reference sample, the technique that is used for detector or spectrometer calibration [53] but more seldom used in practical DRIFT analysis. The used DRIFT attachment also allows diffuse-reflectance measurements without sample dilution with $\mathrm{KBr}$, without a change in the reproducibility and sensitivity (Figure 8).

This modality is capable of hydrogen-bond continua at 3900-3000 and $2700-2500 \mathrm{~cm}^{-1}$. The latter range can be seen only with DRIFT, as ATR has not enough sensitivity, while FTIR-PAS shows a high-level noise. As shown in Section 3.3, this range suffers an increase in the noise level due to diamond crystal absorption. The range 2400-2300 always shows the artefact peaks of gaseous $\mathrm{CO}_{2}$. 


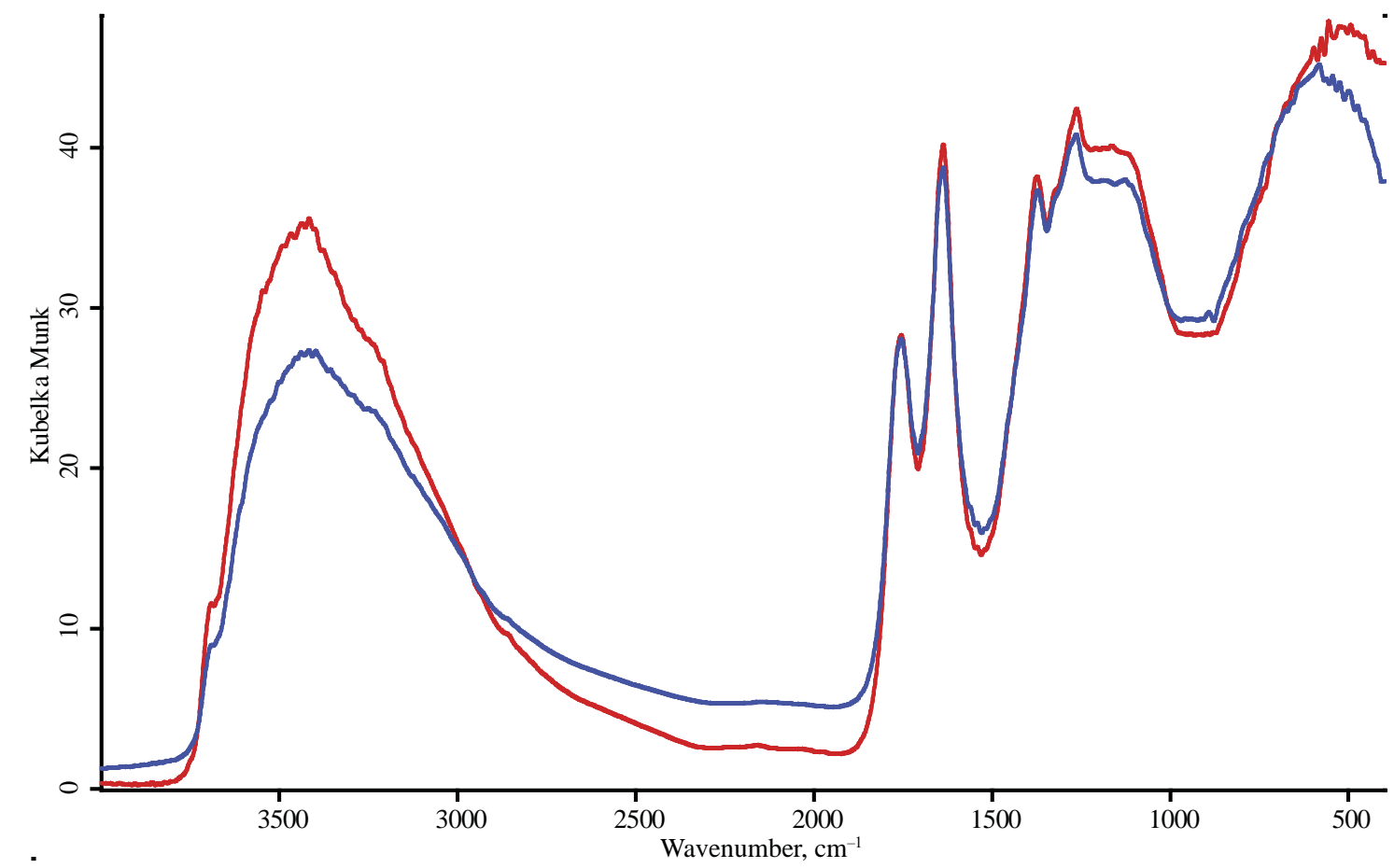

Figure 8. Diffuse reflectance mode, DLaTGS detector, RUDDM nanodiamonds; red, PrayingMantis mirror was used for background collection; blue, $\mathrm{KBr}$ in the sample cup was used for background collection. Spectra are smoothed (13 points) and normalized to maximize each spectrum.

DRIFT also provides the best resolution and sensitivity towards hydrocarbon constituents of the ND shell: $\mathrm{CH}_{x}$ groups at $3000-2700 \mathrm{~cm}^{-1}$. These are accompanied with $\mathrm{CH}_{2} / \mathrm{CH}_{3}$ deformation bends at 1400 and $1370 \mathrm{~cm}^{-1}$, respectively (usually as shoulder bands); however, these bands could also have oxygen-containing components. Additionally, this modality provides well resolved and intense bands at, $1450 \mathrm{~cm}^{-1}$ (C-O-H bend and $-\mathrm{CH}_{2}$ wag vibrations); thus, these ranges would require either a sample preparation or another modality.

Depending on the brand, the $\mathrm{CH}_{\mathrm{x}}$ range in DRIFT shows stretch aromatic vibrations at $3100 \mathrm{~cm}^{-1}$ with rather high sensitivity and correlated bands $940\left(=\mathrm{CH}_{2}\right.$ wag) and $830 \mathrm{~cm}^{-1}$ (aromatic $-\mathrm{C}-\mathrm{H}$ bend), as shown in Figures 1c, $3 b$ and $5 b$. Some brands show a weak band at $760 \mathrm{~cm}^{-1}$ (Figures $1 \mathrm{c}$ and $3 b$ ) that can be attributed to polyaromatic bend vibrations, and the latter band is not seen neither in FTIR-PAS, nor in ATR modalities. Carbon-carbon bonds are represented by $1560 \mathrm{~cm}^{-1}$ (alkene/aromatic stretch) and $410 \mathrm{~cm}^{-1}$ (in-phase vibrations).

The carbonyl band at $1760 \mathrm{~cm}^{-1}$ is most intense in the range $1900-1300 \mathrm{~cm}^{-1}$ (Figures $1 \mathrm{~b}$ and $2 \mathrm{~b}$ ). The right shoulder band at $1790 \mathrm{~cm}^{-1}$ (conjugated carbonyl groups) is less pronounced compared to ATR and FTIR-PAS (DNA-TAN and DNA-STP brands).

The $\mathrm{H}-\mathrm{O}-\mathrm{H}$ band at $1610 \mathrm{~cm}^{-1}$, to which we assign more tightly bound water is weaker than in FTIR-PAS and especially ATR. This allows for revealing actual bands belonging to asymmetric $\mathrm{C}=\mathrm{O}$ and $\mathrm{C}=\mathrm{C}$ stretches in this area (PL-D-G01P, UDA-S, UDA-SP, and DNA-STP).

Despite most intense bands in the range of $1400-1200 \mathrm{~cm}^{-1}$, this is not well-resolved (Figures $1 \mathrm{c}$ and 2c), most probably due to saturation effects [54], and this range is not expedient for band comparison.

Of special interest in DRIFT modality is the range $2300-2000 \mathrm{~cm}^{-1}$, which is not informative in ATR with a diamond crystal due to diamond adsorption and FTIR-PAS due to a high noise level. This range shows a series of rather broad and rather weak bands located at 2230, 2140, and $2050 \mathrm{~cm}^{-1}$ (Figures $1 b$ and $2 b$, insets). The appearance and relative intensity of these bands depends on the ND brand. These bands could be surface groups bound to metal species or nitrile [55] or other $\mathrm{C}-\mathrm{N}-\mathrm{C}$, $\mathrm{C}-\mathrm{N}-\mathrm{N}$ and similar nitrogen-based vibrations [56], which may be the manifestation of $\mathrm{N}$ or $\mathrm{N}$ vacancy 
centers in the ND cores [57]. These bands were found in graphene [12] but require more studies in the case of nanodiamonds. The complete elucidation of these groups is more difficult compared to other groups as only DRIFT modality can be used. The comparison of detectors shows that the selection does not significantly affect the band quality in this range, although photovoltaic detection tends to produce unresolved bands.

From the viewpoint of different aggregates in ND samples or different characteristic sized in ND brands, DRIFT measurements should be corrected to radiation reflections from particles of different sizes [54], and a direct comparison with DRIFT may not be very correct, and may require special attention.

\subsection{ATR-FTIR}

Due to low sensitivity in the far and Mid-IR range of 4000-2000 $\mathrm{cm}^{-1}$, the ATR spectrum shows little-to-no information in this range, $\mathrm{CH}_{x}$ bands are only seen for several brands (UDA-GO-SP family). Additionally, in this range, the band of stretching vibrations of $-\mathrm{O}-\mathrm{H}$ linked by hydrogen bonds, $3690 \mathrm{~cm}^{-1}$, is observed only in some brands, and a weaker band at $3715 \mathrm{~cm}^{-1}$ is not seen with a DLaTGs detector and is very weak with a photovoltaic detector (Figure 9). Some spectra show a low-intensity sharp artefact band at $2660-2650 \mathrm{~cm}^{-1}$ over-imposed with the weak and broad carboxylic O-H stretch visible in some brands only.

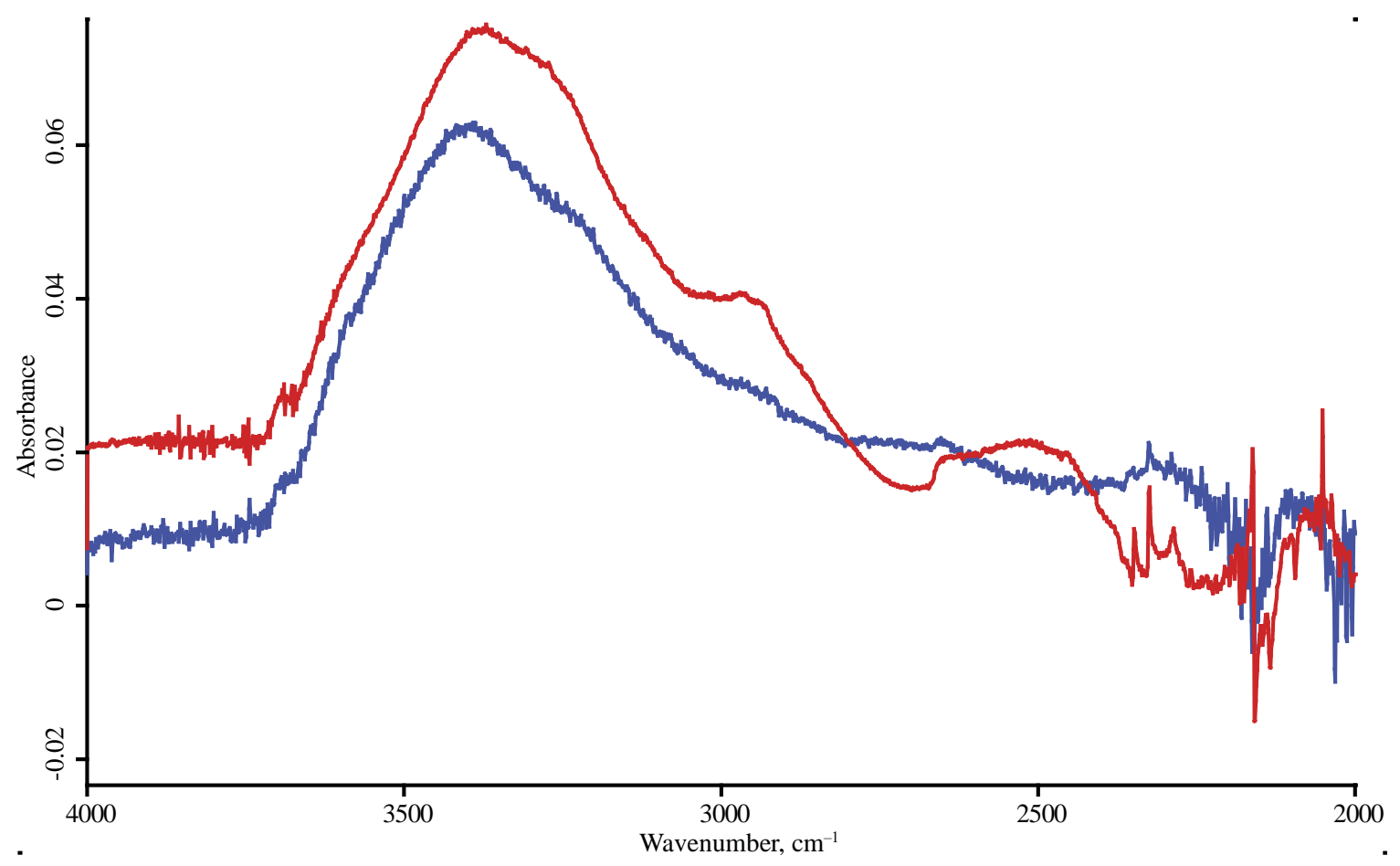

(a)

Figure 9. Cont. 


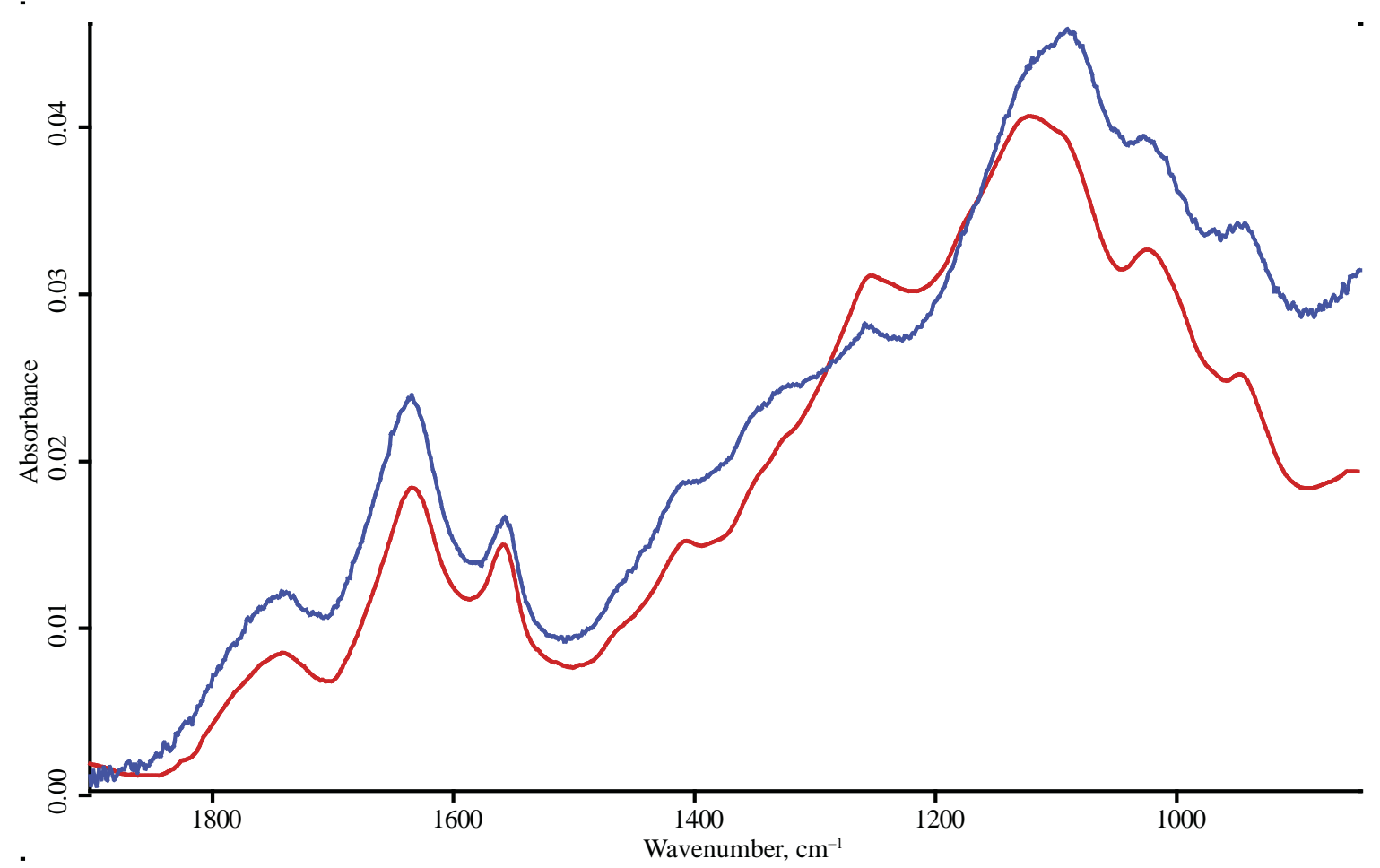

(b)

Figure 9. ATR mode, UDA-SP nanodiamonds; red, LN-MCT photovoltaic detector; blue, DLaTGS detector (a) $4000-2500 \mathrm{~cm}^{-1}$, (b) $2000-800 \mathrm{~cm}^{-1}$ range. Spectra are not smoothed but normalized to maximize each spectrum.

Among oxygen-containing groups, the carbonyl $\mathrm{C}=\mathrm{O}$ stretch $\left(1770-1760 \mathrm{~cm}^{-1}\right)$ bands in ATR spectra is the strongest. Compared to DRIFT, the ATR band at $1760 \mathrm{~cm}^{-1}$ shows a shoulder band at $1790-1800 \mathrm{~cm}^{-1}$, which can be attributed to anhydride or similarly strongly bound carbonyls. This band is weaker than the neighboring band of the water bands at $1630 \mathrm{~cm}^{-1}$ and at $1270 \mathrm{~cm}^{-1}$, which correspond to carboxyl C-O stretch, and at $1100 \mathrm{~cm}^{-1}$ to non-carboxyl C-O stretch. In general, the band at $1770-1760 \mathrm{~cm}^{-1}$ is visible, but its intensity is lower than in DRIFT and FTIR-PAS modalities.

Other characteristic bands in ATR spectra are $\mathrm{H}-\mathrm{O}-\mathrm{H}$ bending vibrations (loosely bound, $1643 \mathrm{~cm}^{-1}$ and strongly bound, $1620-1635 \mathrm{~cm}^{-1}$ ). All other bands attributed to water in the low-wave Mid-IR range are well pronounced as well. The problem of water-vapor artefact bands at $1580-1500 \mathrm{~cm}^{-1}$ is least pronounced in ATR due to the minimum effect of water vapors due to low signal-generating depth; however, the intensity is lower compared to other modalities, and if ATR modality is selected, a high-sensitive detector is required.

Additionally, bands of $1485 \mathrm{~cm}^{-1}\left(-\mathrm{CH}_{2}\right.$ wag), at $1390-1370 \mathrm{~cm}^{-1}\left(-\mathrm{CH}_{2}\right.$ deformation and C-O-H in-plane bend) are also visible, while the weak band at $1440 \mathrm{~cm}^{-1}$, which is attributed to aromatic ring stretch/C-O-H, does not appear. It is noteworthy that many of these bands can be attributed to the different types of functional groups (hydrocarbon and oxygen-containing) and their intensities are much lower than in the case of DRIFT. Along with a lower intensity of carbonyl bands, compared to DRIFT, this may evidence that ATR is more sensitive to the hydrocarbon layers than functional groups. This range is, thus, quite important to be probed with two IR modalities as the ratios.

ATR becomes the dominant modality for $1100 \mathrm{~cm}^{-1}$ and below, when DRIFT shows more enveloping bands and FTIR-PAS shows the saturation effects and high noise levels. The ATR-FTIR spectrum has a weakly pronounced band at $940 \mathrm{~cm}^{-1}$ (Figures $3 \mathrm{~b}$ and $4 \mathrm{~b}$ ), which is not revealed in DRIFT and FTIR-PAS. On the contrary, these two modalities show a band at $960 \mathrm{~cm}^{-1}$, but the intensity of $940 \mathrm{~cm}^{-1}$ is quite low. In our opinion, this band at $960 \mathrm{~cm}^{-1}$ is non-carboxyl out-of-plane C-O-H 
bend, while the peak at $940 \mathrm{~cm}^{-1}$ is $=\mathrm{CH}_{2}$ wag, which is revealed in brands with large contents of nonsaturated and aromatic hydrocarbons (UDA-SP, D-G01P brands). The same situation is for the band at $830 \mathrm{~cm}^{-1}$ (aromatic $\mathrm{CH}_{2}$ ). A characteristic band at $410 \mathrm{~cm}^{-1}$ is clearly visible only in ATR and can be attributed to $C-C$ in-phase vibrations [40]. However, the bands at 760 and $610 \mathrm{~cm}^{-1}$ have lower intensities compared to other modalities.

\subsection{FTIR-PAS}

In general, FTIR-PAS spectra at IMF of 1.6 and $2.5 \mathrm{kHz}$ are similar to DRIFT and show the same intensity ratios. For most brands spectra at IMF of 1.6 and $2.5 \mathrm{kHz}$ are the same relative to intensity ratios. In the range $4000-3600 \mathrm{~cm}^{-1}$, FTIR-PAS exhibit weak stretching vibration bands of isolated hydrogen bonded species at $3780 \mathrm{~cm}^{-1}$ [35], which is not visible with other modalities, and the sensitivity towards other hydrogen-bonded species is similar to DRIFT. Bands at 1750, 1640, 1250, and $1100 \mathrm{~cm}^{-1}$ are present in all FTIR-PAS spectra for the whole IMF range 1.6-10 kHz.

Weak bands of asymmetric $\mathrm{CH}_{\mathrm{X}}$ vibrations in the range $2955-2920 \mathrm{~cm}^{-1}$ are pronounced, and the sensitivity is the same as in the case of DRIFT, while the sensitivity towards symmetric vibrations seems lower than in DRIFT. The range $2700-1900 \mathrm{~cm}^{-1}$ is noisy, contains the $\mathrm{CO}_{2}$ peaks, and are not informative.

As in ATR, the carbonyl band at $1760 \mathrm{~cm}^{-1}$ shows a shoulder at $1790 \mathrm{~cm}^{-1}$ of conjugated carboxyls. The bands at 1610 and $1560 \mathrm{~cm}^{-1}$, characteristic of some ND brands, are quite intense, as in DRIFT; in this range, FTIR-PAS provides the same resolution (Figure 5). However, in this range, FTIR-PAS experiences the maximum effect from water vapor peaks, so this can lead to a wrong interpretation of the results (because of negative water vapor sharp bands). Thus, DRIFT seems the most expedient in this range. However, the $\mathrm{CH}_{2}$ band at $1450 \mathrm{~cm}^{-1}$ is almost hidden being in the shoulder of the more intense $\mathrm{C}-\mathrm{O}-\mathrm{H}$ broad band at $1330 \mathrm{~cm}^{-1}$.

In an FTIR-PAS spectrum recorded with an interferometer frequency of $2.5 \mathrm{kHz}$ or higher, FTIR-PAS provides a different picture in the $1900-1500 \mathrm{~cm}^{-1}$ range compared to DRIFT and ATR. FTIR-PAS shows a different ratio of intensities of major bands of $\mathrm{C}=\mathrm{O}$ stretch of isolated carboxyl groups at 1760 and a band of $\mathrm{HOH}$ vibrations $\left(1635-1620 \mathrm{~cm}^{-1}\right)$. While in almost all the brands, the $\mathrm{C}=\mathrm{O}$ band has the maximum intensity compared to other bands, in FTIR-PAS, this band is higher in intensity only for an IMF $1.6 \mathrm{kHz}$, while for IMFs of $2.5-10 \mathrm{kHz}$, the most intense is the water band.

For the range $1500-1000 \mathrm{~cm}^{-1}$, the band at $1100 \mathrm{~cm}^{-1}$ (non-carboxyl C-O stretch) is equally as strong as in DRIFT and ATR-FTIR, but FTIR-PAS shows higher sensitivity to bands at 1330 and $1260 \mathrm{~cm}^{-1}$ compared to DRIFT, and the shape of the IR spectra in this range is coincident with ATR spectra. The range $1400-1200 \mathrm{~cm}^{-1}$ is less resolved compared to ATR but still has a higher sensitivity compared to ATR. The region of $1200-900 \mathrm{~cm}^{-1}$ is not well-defined intensity-wise, as the intensities are distorted due to saturation effects [32,58], which was previously shown to have effect on FTIR-PAS identification for soil nanoparticles [30].

Comparison with DRIFT shows almost the same situation as FTIR-PAS to ATR comparison: matrix vibrations mode intensities in DRIFT are degraded, although seen clearly; in concordance with the literature, and much lower sensitivity in the $2500-2000 \mathrm{~cm}^{-1}$ region is shown, compared to FTIR-PAS [59].

Contrary to DRIFT, especially under the conditions of rapid-scan modes used in this study, FTIR-PAS spectra are mainly affected with thermal penetration depth, which is governed by thermal parameters of the ND diamond matrix and independent from the particle size. Thus, FTIR-PAS spectra have become directly comparable from the viewpoint of composition being more ready, while retaining most features of DRIFT unrevealed in ATR spectra. In the frames of this study, no significant differences between FTIR-PAS and DRIFT spectra were observed (Figure 5). 


\subsection{ND Brand Features}

The aim of this study was not the complete characterization of specific brands, but differences in the composition are obvious can be used as examples of capabilities of different IR modalities in ND analysis.

All the brands differ in the position of the main maximum and the width of the band of carbonyl at $1750 \mathrm{~cm}^{-1}$. For most brands, it is located at $1740 \mathrm{~cm}^{-1}$, for DNA-TAN and DNA-STP it is located at $1786 \mathrm{~cm}^{-1}$, for RUDDM, $1760 \mathrm{~cm}^{-1}$, and for PL-D-G-01 and PL-D-G02 it is pure bimodal with maxima at 1780 and $1750 \mathrm{~cm}^{-1}$ (Figures $1 \mathrm{a}$ and $3 \mathrm{c}$ ). The reproducibility of this band is highest among the other bands in the spectrum and it is usually the same for different brands of the same manufacturer (DNA-TAN and DNA-STP). For most ND brands, this band is a rather wide continuum with a width of $300 \mathrm{~cm}^{-1}$ overlapped with the water peak at $1640 \mathrm{~cm}^{-1}$, but its left shoulder is well resolved (Figure $1 \mathrm{~b}$, Figure 2b, Figure 3c, and Figure 4c). The shape of this band is not affected by drying (Figures 7 and A3, Appendix A).

From the viewpoint of ND brand characterization, these groups of nanodiamonds can be distinguished by the amount of bound water $\left(1630 \mathrm{~cm}^{-1}\right)$ and the intensity of the $\mathrm{OH}$ continuum $3600-3000 \mathrm{~cm}^{-1}$ and carboxyl C=O and C-O-H bands at 1760-1740 and 1440-1340 $\mathrm{cm}^{-1}$. Upon drying, the spectra of such brands show a decrease in the bands associated with loosely bound water, while the intensities of the carboxyl bands remain the same. For the RUDDM brand, Figure A1 (Appendix A) shows that a decrease in the peak at $3695 \mathrm{~cm}^{-1}$ (water hydrogen bonds, there is an increase in the band $3715 \mathrm{~cm}^{-1}$ (hydrogen bonds for non-water species). Additionally, these brands do not show a separate band of loosely bound water at $1643 \mathrm{~cm}^{-1}$, and this is revealed as a blue-shifter asymmetry of the $1630 \mathrm{~cm}^{-1}$ band.

It is noteworthy that the intensities and intensity ratio $1760 / 1630 \mathrm{~cm}^{-1}$ and other peaks in the range 1900-1500 $\mathrm{cm}^{-1}$ can probably be used for ND brand selection. The nanodiamonds with high colloidal solubility have higher intensities of both major bands, and usually sharper shapes, which may evidence a domination of single moieties at the surface (carboxyl groups) and larger amounts of bound water. Additionally, the peak at $1760 \mathrm{~cm}^{-1}$ is located at $1760-1750 \mathrm{~cm}^{-1}$, which corresponds to the existing data on carboxyl carbonyl and is accompanied with bands at $1460-1440 \mathrm{~cm}^{-1}$ (carboxyl C-O-H) and larger intensities of $-\mathrm{O}-\mathrm{H}$ continuum at $2650 \mathrm{~cm}^{-1}$. The intensity of the carboxyl band is higher than in the water band. "Insoluble" NDs have a water peak which is more intense than the carboxyl band and is accompanied with weak bands of surface bound water at $1610-1600 \mathrm{~cm}^{-1}$; other carboxyl-related bands have lower intensities and other $\mathrm{C}-\mathrm{O}$ bands are more intense.

Thus, these two bands can be used for the preliminary estimation of their properties in aqueous solutions, and for monitoring the properties upon thermal or directed chemical treatments. Our studies show that any FTIR modality can be used for this, with ATR having the advantage of working with small amounts and dried dispersions, while DRIFT provides better sensitivity, better distinguishing of the signal from gaseous water artefact peaks. In this task, FTIR-PAS does not have real advantages from the viewpoint of sensitivity and resolution, if other bands in the spectra are not considered.

From the viewpoints of classification, $\mathrm{C}-\mathrm{H}$ bands provide relevant information with rather different compositions of brands. Most brands, aliphatic $\mathrm{CH}_{2}\left(2940-2930\right.$ and $\left.2850 \mathrm{~cm}^{-1}\right)$ have the maximum intensity of corresponding bands, evidencing the contribution from long aliphatic chains. In several cases, such as RDDM, this correlates with the graphite as the ND production source. However, UDA-GO-SP-M1 and UDA-GO-SP-M2 show predominant peaks at 2950 and $2880 \mathrm{~cm}^{-1}$, corresponding to $\mathrm{CH}_{3}$ groups, and PL-D-G01P reveals similar intensities of $\mathrm{CH}_{2}$ and $\mathrm{CH}_{3}$ bands. UDA-GO-SP-M1 and -M2 also show a medium-intensity band at $2970 \mathrm{~cm}^{-1}$ of alkene groups. Several brands, PL-D G01P and RUDDM also show high intensity bands over $3000 \mathrm{~cm}^{-1}$, assigned to aromatic compounds which, in the latter case, correlate with the manufacturers' information of the ND source material, trinitrotoluene. This correlates with the bands at $1000-700 \mathrm{~cm}^{-1}$ (Table 5), attributed to aromatic C-H vibrations. Brands with high contribution from $\mathrm{C}-\mathrm{H}$ have distinct bands in near IR DRIFT of $4800-4100 \mathrm{~cm}^{-1}$ (Figures $1 \mathrm{a}$ and $2 \mathrm{a}$ ). To sum up, a detailed study of $\mathrm{C}-\mathrm{H}$ composition of NDs may require both DRIFT 
and ATR modalities to have the maximum sensitivity in high-frequency and low-frequency parts of the spectra to provide cross checking in different spectral ranges and modalities. However, some caution with this is in order: such bulk spectra relate to nanodiamonds as materials, which can in fact contain ND clusters as well some accompanying components that may seriously affect IR spectra. For instance, ND analysis of visible spectra of some ND brands with visible transmission/optoacoustic spectroscopy with multistage centrifugation reveal the smallest non-diamond $\mathrm{sp}^{2}$ fraction [51], which can affect the overall unfractionated sample spectra.

Apart from major bands than can be used for general estimations of ND brands, spectra in different modalities and detectors reveal a more detailed difference in NDs. For instance, PL-D G01P, UDA-S and UDA-SP, and DNA-STP form a specific subset of ND brands of different manufacturers, which have several common features, already discussed above upon modality comparison. They have distinct bands at 1610 and $1560 \mathrm{~cm}^{-1}$ that are absent in most other brands (Figure 6). The band at $1560 \mathrm{~cm}^{-1}$ is considered the most uncertain for complex samples [29] and can be attributed to carbon bonds [60-62] and absorbed water. It is noteworthy that the brands with the distinct band at $1560 \mathrm{~cm}^{-1}$ have the main water band red-shifted, compared to the most common position of $1635 \mathrm{~cm}^{-1}$. For UDA-GO-SP and PL-D G01P, the ATR spectrum contains only one band of stretching vibrations of the carbonyl group $-\mathrm{C}=\mathrm{O}$ at $1750 \mathrm{~cm}^{-1}$, as with other brands, while in DRIFT and FTIR-PAS, a low-intensity band of deprotonated carboxyl at $1680 \mathrm{~cm}^{-1}$ appears [44], which distinguishes this brand from other counterparts, even from the same manufacturer. It is noteworthy that PL-D G01P shows a structure of the band of $1630 \mathrm{~cm}^{-1}$ with maxima at 1646,1636, and $1626 \mathrm{~cm}^{-1}$ and a band at $980 \mathrm{~cm}^{-1}$ (Figure 6). The brands with the high intensity of $\mathrm{CH}_{\mathrm{x}}$ bands (UDA-GO-SP-M1 and UDA-GO-SP-M2 and PL-D G02) show an intensity band at $1190 \mathrm{~cm}^{-1}$ that can be assigned to $\mathrm{C}-\mathrm{C}(\mathrm{O})-\mathrm{C}$ vibrations.

From the viewpoint of $\mathrm{C}-\mathrm{H}$ features, many brands also reveal some specific features. UDA-GO-SP-M1 and UDA-GO-SP-M2 are similar and, apart from the highest intensity of $\mathrm{CH}_{3}$ bands among all the studied NDs (Figures A1 and A2, Appendix A), a shoulder band at $1670 \mathrm{~cm}^{-1}$ appears (DRIFT), which can be attributed to $C=C$ stretch (Table 5). As well, UDA-GO-SP-M1 and UDA-GO-SP-M2, brands show a distinct band at $830 \mathrm{~cm}^{-1}$ (Figure A2c, Appendix A). PL-D-G01 is distinguishable from all other brands by a series of sharp and rather intense bands at 920, 880, 830, 800, 785,770 , and $740 \mathrm{~cm}^{-1}$ (Figure A5, Appendix A), which can also be attributable to aromatic chains, as well as the high intensity of the band at $630 \mathrm{~cm}^{-1}$. PL-D-G01P shows intense bands at $1480 \mathrm{~cm}^{-1}$ (C-C aromatic stretch, Figure 1c) and $3035 \mathrm{~cm}^{-1}$ (C-H aromatic stretch, Figure 1b).

As we mentioned in the previous sections, the range $2300-2000 \mathrm{~cm}^{-1}$ is characterized with a series of weak and rather sharp bands, which are very characteristic for certain brands. The band at $2230 \mathrm{~cm}^{-1}$ is characteristic to UDA-GO-SP, PL-D-G01 P, UDA-TAN, PL-D G01, and the band at 2050 $\mathrm{cm}^{-1}$ is present in DRIFT spectra of different brands (Figures $1 \mathrm{~b}$ and $2 \mathrm{~b}$, insets), UDA-GO-SP-M1, UDA-GO-SP-M2, UDA-SP, SDND, and RUDDM. In several cases, this band falls within the left shoulder of the continuum band of the carbonyl, so it is completely undetectable. The band at $2140 \mathrm{~cm}^{-1}$ is characteristic for most brands and is the only band in this range for UDA-S, UDA-S-GO, and PL-D-G02.

\subsection{Modality Comparison}

Contrary to some similar studies on IR modality comparison for complex objects [29,30,36,63,64], we cannot conclude that all the modalities are equal in ND characterization and can be used alone. Though it is rather obvious that all the modalities can provide the relevant information on ND surface composition, not a single modality provides the whole information, and the combination of modalities seems quite important. In our opinion, this could result from the DRIFT conditions used in this study: contrary to other studies $[29,30,36,63,64]$, we used a bare mirror as a reference sample, which decreased the noise and provided the good sensitivity and reproducibility. Additionally, using an attachment that provided diffuse-reflection measurements with sample dilution and change provided much more valuable information from DRIFT spectra and made this technique most informative and reliable for ND characterization. 
Although, in several cases, ATR has the advantage of a small sample amount, DRIFT still seems to be the best choice, as it provides good sensitivity (especially with a photovoltaic detector, Figure A6, Appendix A) and the widest spectral range of near-IR and mid-IR that contains the most important information on NDs. The best sensitivity of DRIFT in hydrogen-bond, $\mathrm{CH}_{\mathrm{x}}$, and $\mathrm{C}=\mathrm{O} /$ water ranges makes it possible to distinguish various trademarks, monitor the changes during surface modification and thermal treatment and other studies. The range of $1200-400 \mathrm{~cm}^{-1}$ has the secondary value in DRIFT due to saturation and lower sensitivity. High sensitivity of DRIFT provides a rather detailed study in the $\mathrm{CH}_{\mathrm{x}}$ range and the low-intensity peaks in the $2700-2000 \mathrm{~cm}^{-1}$ range that cannot be revealed by other modalities. Still, the cross-examination of ND brands with DRIFT may be taken with caution due to the particle-size effect. From the viewpoint of $\mathrm{C}-\mathrm{H}$ characterization of ND surface, DRIFT modality has the obvious advantage of sensitivity in the whole mid-IR range, while ATR provides a more unified picture, distinguishing high $\mathrm{CH}_{x}$ /low $\mathrm{CH}_{x}$ brands only; however, it provides additional information due to high sensitivity in the far IR region-e.g., the $C-C$ peaks at $410 \mathrm{~cm}^{-1}$.

ATR provides good sensitivity for liquid-water and $\mathrm{C}-\mathrm{H}$ bands in nanodiamond spectra in the range $2000-400 \mathrm{~cm}^{-1}$, but shows mediocre sensitivity towards the medium and minor bands that are attributed to carbon-oxygen bands. This makes this modality most expedient for monitoring the drying and surface oxidation of nanodiamonds, as these processes change the major functional groups and water [5], while retaining the reference points of $\mathrm{C}-\mathrm{H}$ bands. ND brand comparison, which is based on $\mathrm{CH}_{\mathrm{x}}$ bands at $3000 \mathrm{~cm}^{-1}$ and minor oxygen-containing groups using ATR is probably less expedient, and DRIFT or FTIR-PAS should be used instead. ATR can be used as a secondary checking technique with DRIFT due to its higher sensitivity in the $2000-400 \mathrm{~cm}^{-1}$ range, lower effects from gaseous water, and better resolution in the ranges (Figure 10), when DRIFT and FTIR-PAS techniques experience optical or thermal saturation. In ATR spectra, the spectral information in the range of $2700-1900 \mathrm{~cm}^{-1}$ is lost due to the absorption of the diamond crystal itself and the closeness of the nanodiamond/diamond refractive index. Additionally, in the range $1100-400 \mathrm{~cm}^{-1}$, water librations should be taken into account. Additionally, our experiments show that detector sensitivity is quite important in ATR, and a room-temperature DLaTGs detector can be recommended for major band monitoring, while a photovoltaic detector seriously increases the spectral information (Figure 11), making ATR closer to FTIR-PAS, while retaining all the advantages of ATR.

Compared to ATR-FTIR, FTIR-PAS in general provides more informative spectra and shows the maximum sensitivity or resolution or both for absorption bands that do not have enough sensitivity in ATR-IR spectra-the whole continuum of $\mathrm{C}=\mathrm{O}$ stretch of carboxyl groups $\left(1760 \mathrm{~cm}^{-1}\right)$ and a better resolution in a complex band $1500-800 \mathrm{~cm}^{-1}$ with $\mathrm{C}-\mathrm{H}, \mathrm{C}-\mathrm{C}$, and $\mathrm{C}-\mathrm{O}$. Still, the comparison of FTIR-PAS and DRIFT shows not many differences from the latter with a room-temperature DLaTGs detector, although a lower sensitivity compared to DRIFT was detected with a photovoltaic detector. Along with a higher noise, FTIR-PAS, especially at a single interferometer modulation frequency, cannot be recommended as a primary IR technique for nanodiamonds. Its main feature is a lower dependence on the particle size, due to large signal-penetration depth, resulting from high thermal-conductivity of nanodiamond. Thus, it can be used as a support/check technique for either DRIFT or ATR. Another feature of FTIR-PAS, depth profiling with an IMF change obviously does not affect the spectra in a positive way and can be instead used for investigating thermal properties of nanodiamonds. Additionally, the disadvantage of this modality is a high penetration depth (up to $1 \mathrm{~mm}$ ), which requires rather large sample volumes lest to have the effect of sample support on the spectra. 


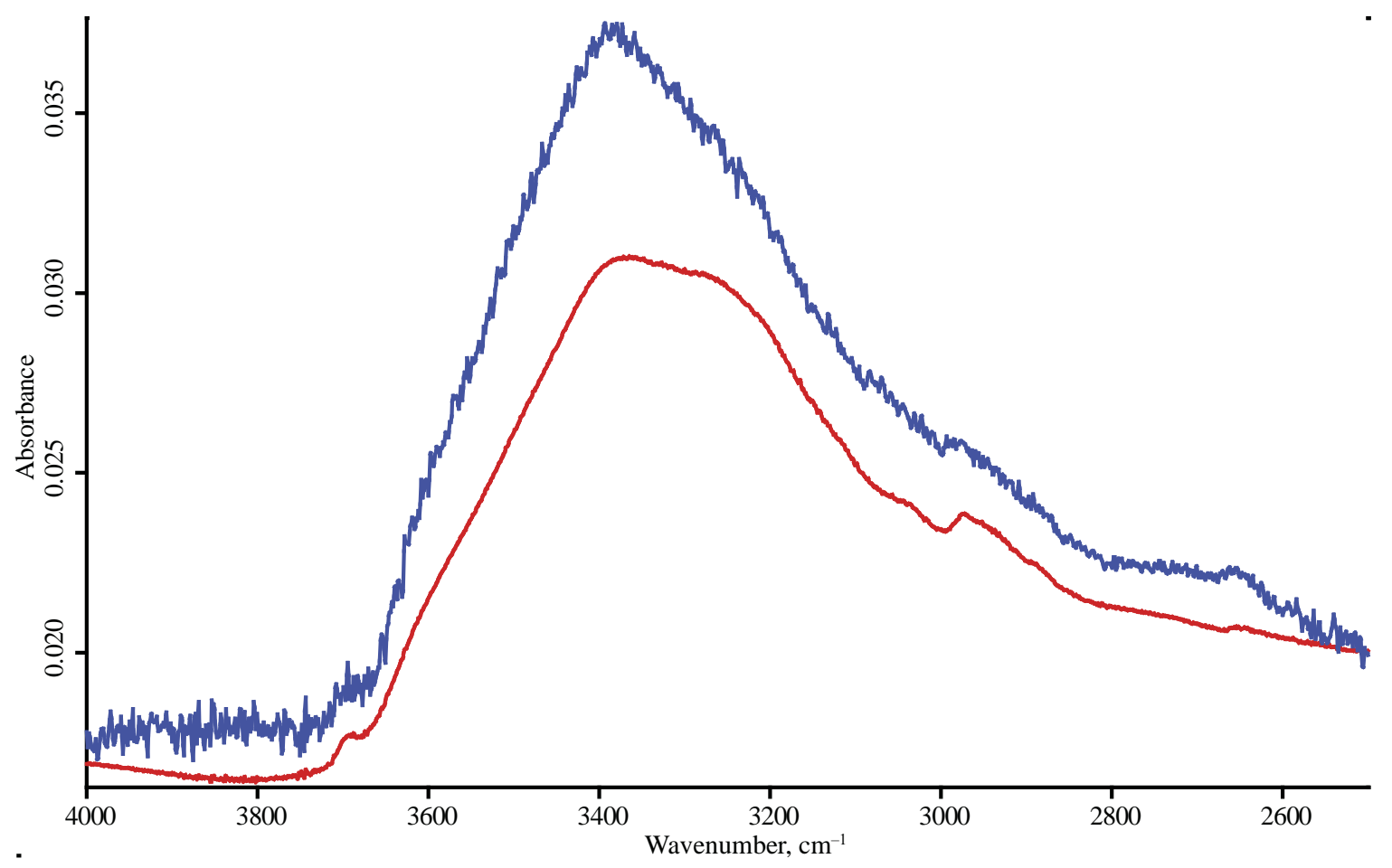

(a)

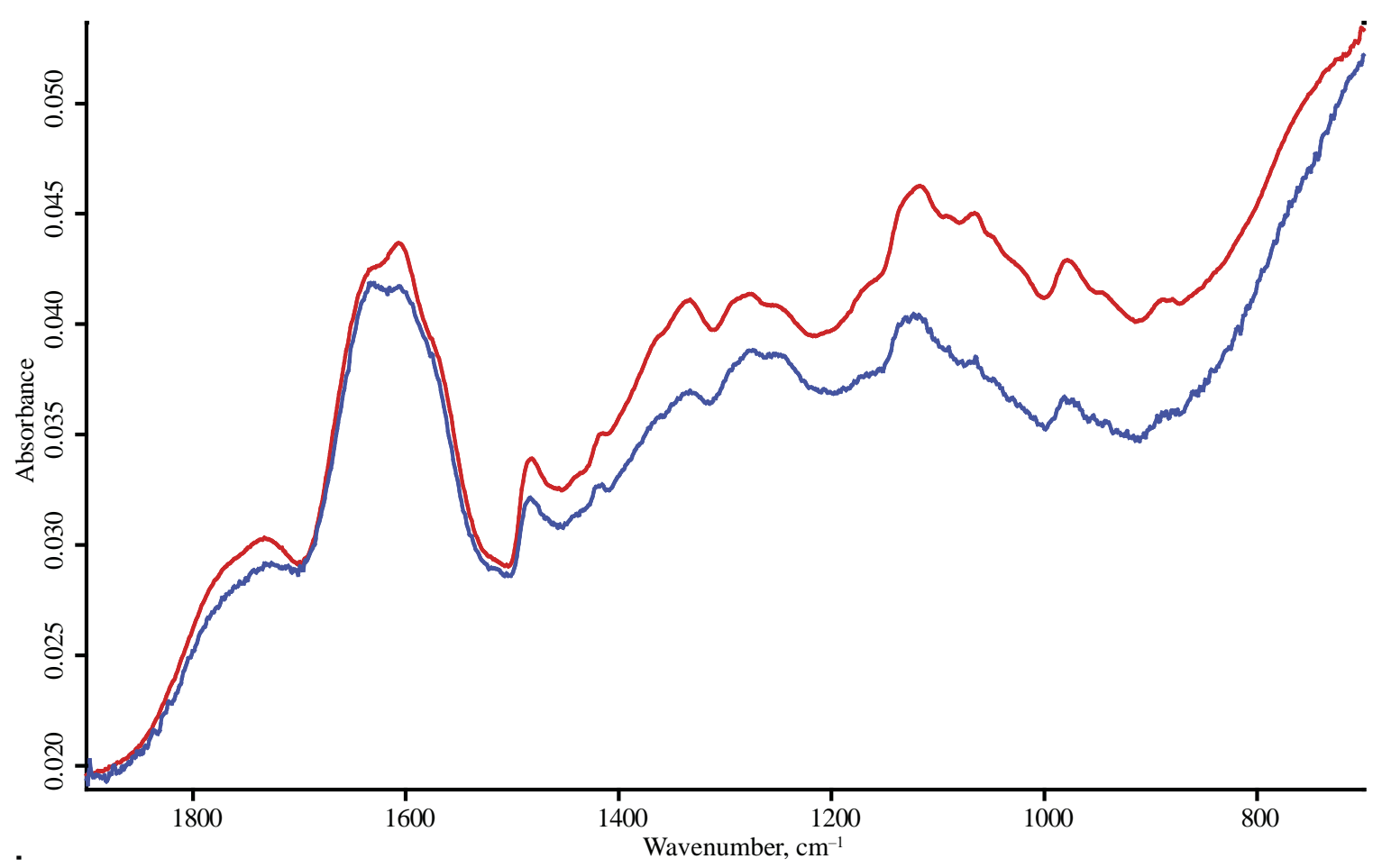

(b)

Figure 10. ATR mode, PL-D-G-01P nanodiamonds; red, LN-MCT photovoltaic detector; blue, DLaTGS detector; (a) $4000-2500 \mathrm{~cm}^{-1}$, (b) 2000-800 $\mathrm{cm}^{-1}$ range. Spectra were not smoothed but normalized to maximize each spectrum. 


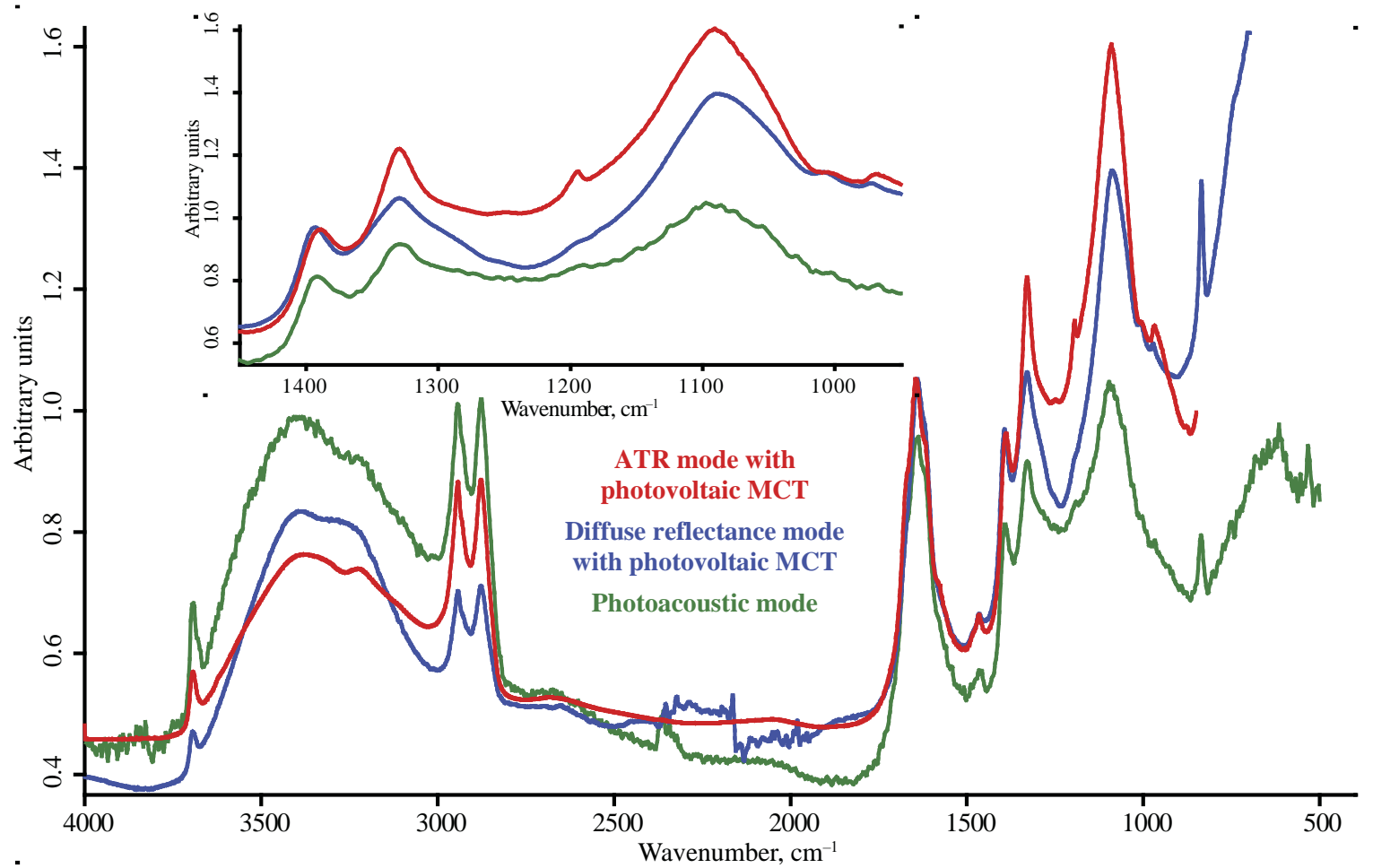

Figure 11. UDA-GO-SP-M1 nanodiamonds; red, ATR mode with a photovoltaic MCT detector; blue, diffuse reflectance mode with a photovoltaic MCT detector; green, photoacoustic mode. Spectra were not smoothed but normalized to maximize each spectrum.

Thus, three scenarios can be considered. (1) An overall survey of nanodiamonds using the major bands of $\mathrm{CH}_{\mathrm{x}}$, water, and carboxyl groups; this may be implemented with any single modality. ATR is preferable from the simplicity and rapidity aspects and does not require a sensitive detector; DRIFT can be used in all the conditions; FTIR-PAS at a low IMF with a careful check for artefacts from gaseous water at $1600-1500 \mathrm{~cm}^{-1}$ can be used. (2) Brand comparison by major and secondary bands (main surface moieties) to show the changes upon some surface modification, centrifugation, etc. Such a scenario requires two IR modalities; DRIFT as a primary modality to have the maximum sensitivity of all the bands. ATR can also be used but requires a sensitive detector. The pairs DRIFT/ATR, DRIFT/PAS or ATR/PAS can be used; FTIR-PAS as a primary technique is not recommended due to a high noise level. (3) The case of a complete analysis of the surface required for applications of nanodiamonds, especially in biomedicine. In such a scenario, all the modalities should be used. DRIFT should be used with a high-sensitive detector in the NIR region to cross-check the major $\mathrm{C}-\mathrm{H}$ and $\mathrm{HOH}$ bands and in the range $2700-1900 \mathrm{~cm}^{-1}$; while ATR is used at 2000-300 $\mathrm{cm}^{-1}$. The range $1500-900 \mathrm{~cm}^{-1}$ is measured with DRIFT, ATR, and FTIR-PAS (probably at two IMFs) to reveal possible artefact peaks, optical/thermal saturation, and revealing the nature of complex peaks can be comprised by hydrocarbon and functional groups).

Thus, the region of 1500-900 $\mathrm{cm}^{-1}$ should be further taken into account as the selected unmodified ND brands did not allow for the final reliable information on the bands at 1470, 1440, 1400, 1370, 1330, $1270,1210,1190,1140,1100,1050,950 \mathrm{~cm}^{-1}$; this would require a more detailed study with samples with known functional groups and a cross-comparison with other nanoparticle materials different from nanodiamonds.

Apart from the band maxima positions and relative intensities, another parameter of bands is its width is peak widths, which can be related to the crystal structures or grain sizes of nanodiamond materials. From the first estimations, the band width for most ND samples within a single modality and measurement conditions differed insignificantly, though some changes in the same samples for 
different modalities can be elucidated. However, the detailed analysis of the peak width, considering the ND characteristic size and modality-based factor, requires modeling that was out of the scope of this study.

Although it is not a direct comparison of IR modalities for NDs, it is noteworthy that $\mathrm{CH}_{x}$ bands at 3000-2800 and $1300 \mathrm{~cm}^{-1}$ (shoulder) of stretching and bending $\mathrm{CH}_{\mathrm{x}}$ vibrations, respectively, do not disappear or change significantly upon drying, oxidizing by rather harsh conditions of acidic treatments [5] so they can be used as a kind of internal standard for quantification and brand comparison.

From the viewpoint of quantification, which was not considered in this study, some conclusions can be given: in general, most obvious application is the estimation of water and carbonyl contents aby the area $1900-1200 \mathrm{~cm}^{-1}$. In this case, all the techniques showed enough sensitivity for the estimation and discrimination of various samples. Both ATR and DRIFT seem most expedient due to a low noise level and sensitivity. In the case of hydrocarbon contents, DRIFT shows the maximum possibility, especially with a photovoltaic detector due to high sensitivity and a satisfactory noise level. The identification shows that DRIFT can potentially be used for the discrimination of $\mathrm{CH} 3$ and alkane/alkene/aromatic $\mathrm{CH}_{\mathrm{x}}$ groups. This would require a reference method, such as NMR, the elucidation of absorption coefficients for the ND materials of these bands, and working out the data handling for the quantification (most probably, integrated peak intensities should be used as was shown for soil particles [30]). Among other possible quantification techniques are correlation studies between several counterparts of the functional groups like carboxyls at 2700, 1800, and $1400 \mathrm{~cm}^{-1}$ ), studies of possible contributions of core groups at $2400-2200 \mathrm{~cm}^{-1}$ and quantification of "non-standard" groups at $1600-1300 \mathrm{~cm}^{-1}$. In all these studies, DRIFT with a high-sensitive detector is most expedient. The range $1100-400 \mathrm{~cm}^{-1}$, though it contains some important information on NDs, seems most troublesome from the viewpoint of quantification, due to possible optical and thermal-saturation effect, possible contributions of several functional groups and rather high noise levels in spectra. This requires some further studies before discussing the real possibilities. From the viewpoint of this study, the use of FTIR-PAS for ND surface quantification seems less expedient compared to ATR and especially to DRIFT.

\section{Conclusions}

Thus, from the viewpoint of qualitative analysis of the nanodiamond surface by FTIR spectrometry, we cannot conclude that all the modalities are equal in ND characterization and can be used alone. In fact, the analysis of the ND surface requires all three modalities-diffuse-reflectance, attenuated total reflection, and photoacoustic modalities. Although ATR is advantageous from the viewpoint of small sample amounts, DRIFT seems to be the best choice as it provides good sensitivity, especially with a high-sensitivity photovoltaic detector and, thus, results in the maximum number of bands among all three modalities. Additionally, the configuration of DRIFT measurements used in this study provided low noise and good reproducibility of measurements, which is relevant for quantification, which should be the subject of a separate study. As discussed, three scenarios can be considered for the use of FTIR modalities for nanodiamonds: (1) An overall survey of nanodiamonds using the major bands of $\mathrm{CH}_{\mathrm{x}}$, water, and carboxyl groups; it may be implemented with any single modality. Here, ATR is preferable as a simple rapid mode without a need for a sensitive detector; DRIFT can be used as well. (2) The second scenario is nanodiamond brand comparison by changes in surface moieties and groups upon some surface modification, centrifugation, etc. This requires two IR modalities-DRIFT to attain the maximum sensitivity, and ATR as a secondary technique (FTIR-PAS is not recommended as a primary technique due to a high noise). (3) The complete analysis of the surface. Here, all three modalities should be used-DRIFT with a high-sensitive detector and in the NIR region to cross-check the major bands in the region $2700-1900 \mathrm{~cm}^{-1}$ and ATR at 2000-300 $\mathrm{cm}^{-1}$. The most informative range of $1500-900 \mathrm{~cm}^{-1}$ should be measured with all three modalities to check for possible artefact bands, saturation effects etc. to ensure the reliability of qualitative and quantitative analysis. 
Author Contributions: Conceptualization, D.S.V. methodology, D.S.V.; formal analysis, M.A.P. and D.S.V.; investigation, D.S.V. and P.K.K.; resources, D.S.V.; data curation, D.S.V.; writing-original draft preparation, M.A.P., D.S.V. and P.K.K.; writing-review and editing, M.A.P. and D.S.V.; visualization, D.V and P.K.K.; supervision, M.A.P.; project administration, D.S.V.; funding acquisition, D.S.V. All authors have read and agreed to the published version of the manuscript.

Funding: This work was funded by the Russian Foundation for Basic Research (RFBR) and Moscow City Government according to the research project no. 19-33-70068 mol_a_mos.

Conflicts of Interest: The authors declare no conflict of interest.

\section{Appendix A}

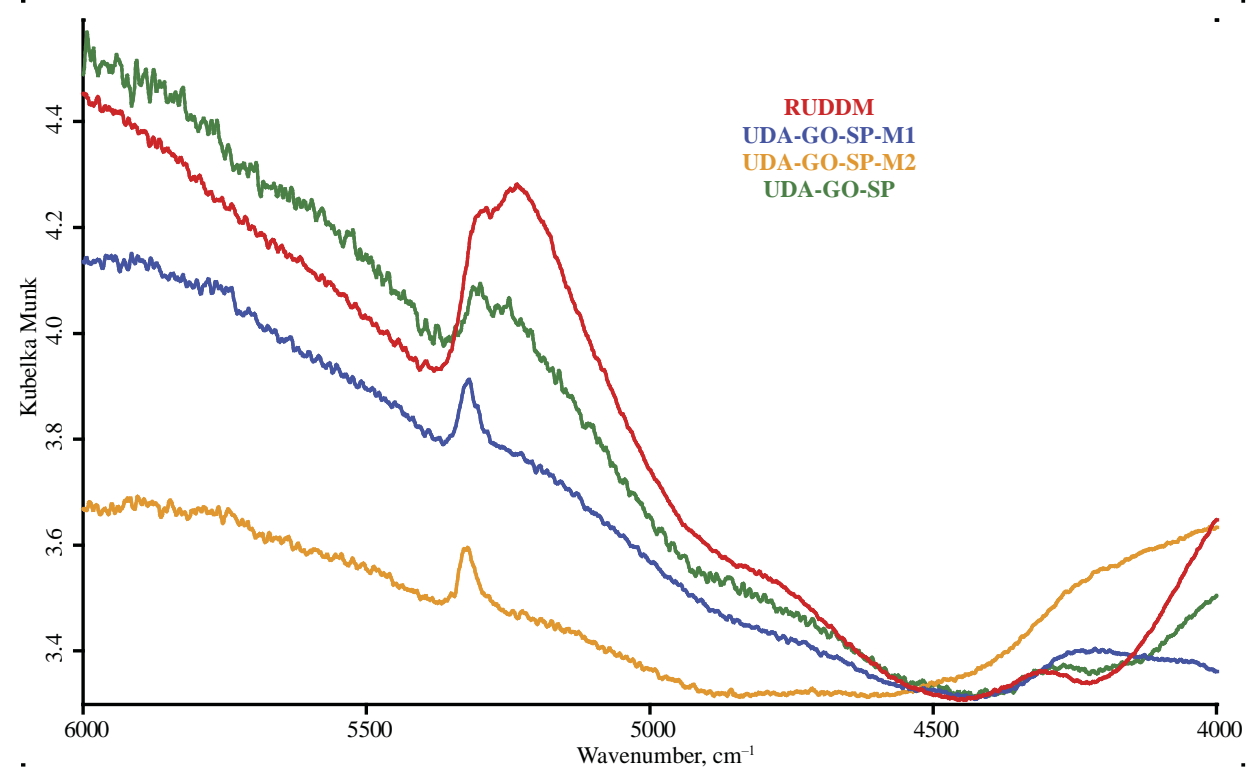

(a)

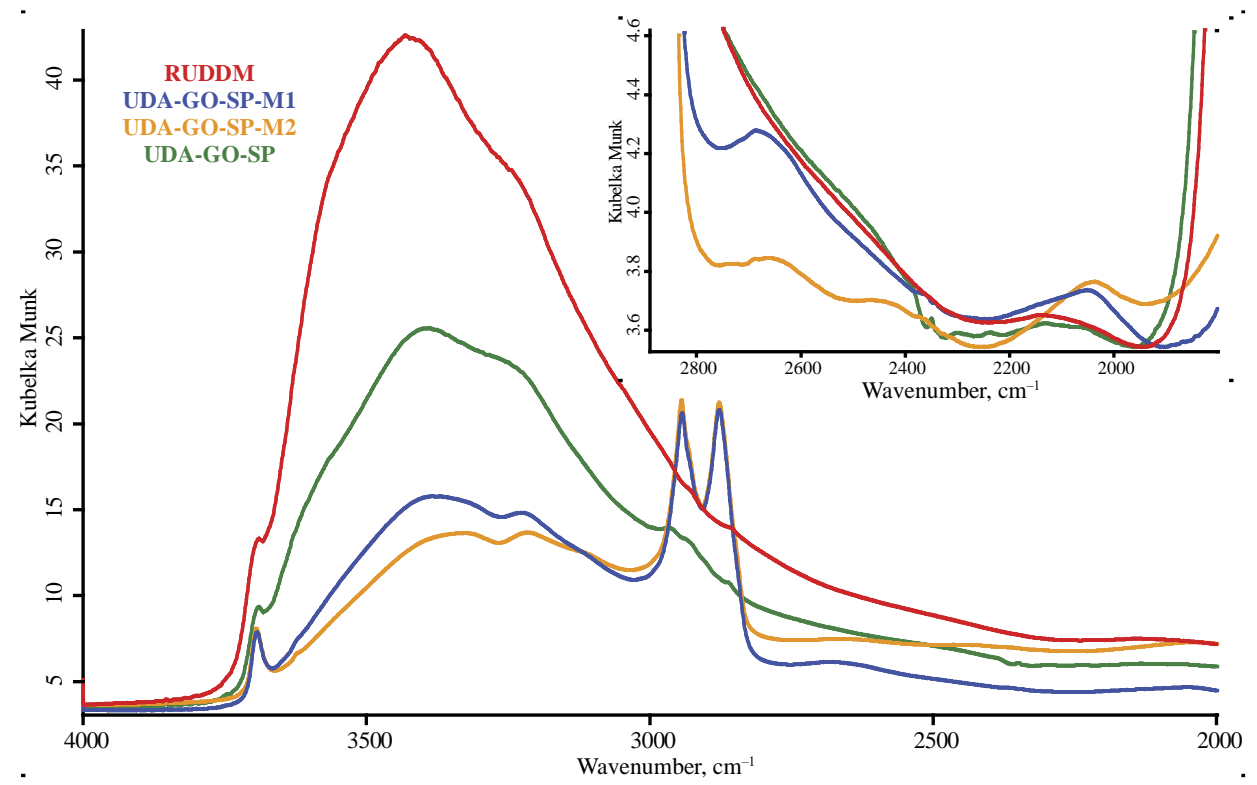

(b)

Figure A1. Cont. 


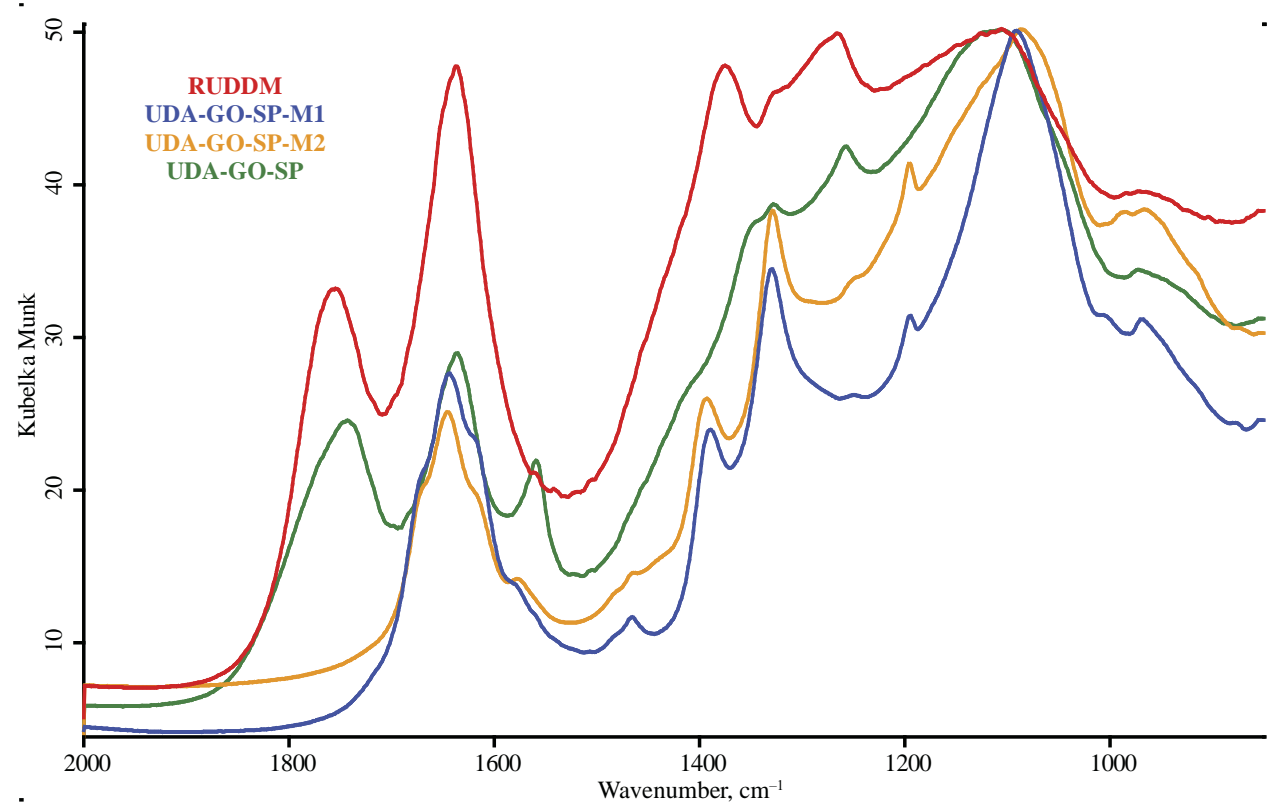

(c)

Figure A1. Diffuse reflectance mode, LN-MCT photovoltaic detector; nanodiamond brands: red, RUDDM; blue, UDA-GO-SP-M1; orange- UDA-GO-SP-M2; green, UDA-GO-SP; (a) 6000-4000 cm ${ }^{-1}$, (b) $4000-2000 \mathrm{~cm}^{-1}$ (c) $2000-800 \mathrm{~cm}^{-1}$ range. Spectra were smoothed (13 points) and normalized to maximize each spectrum.

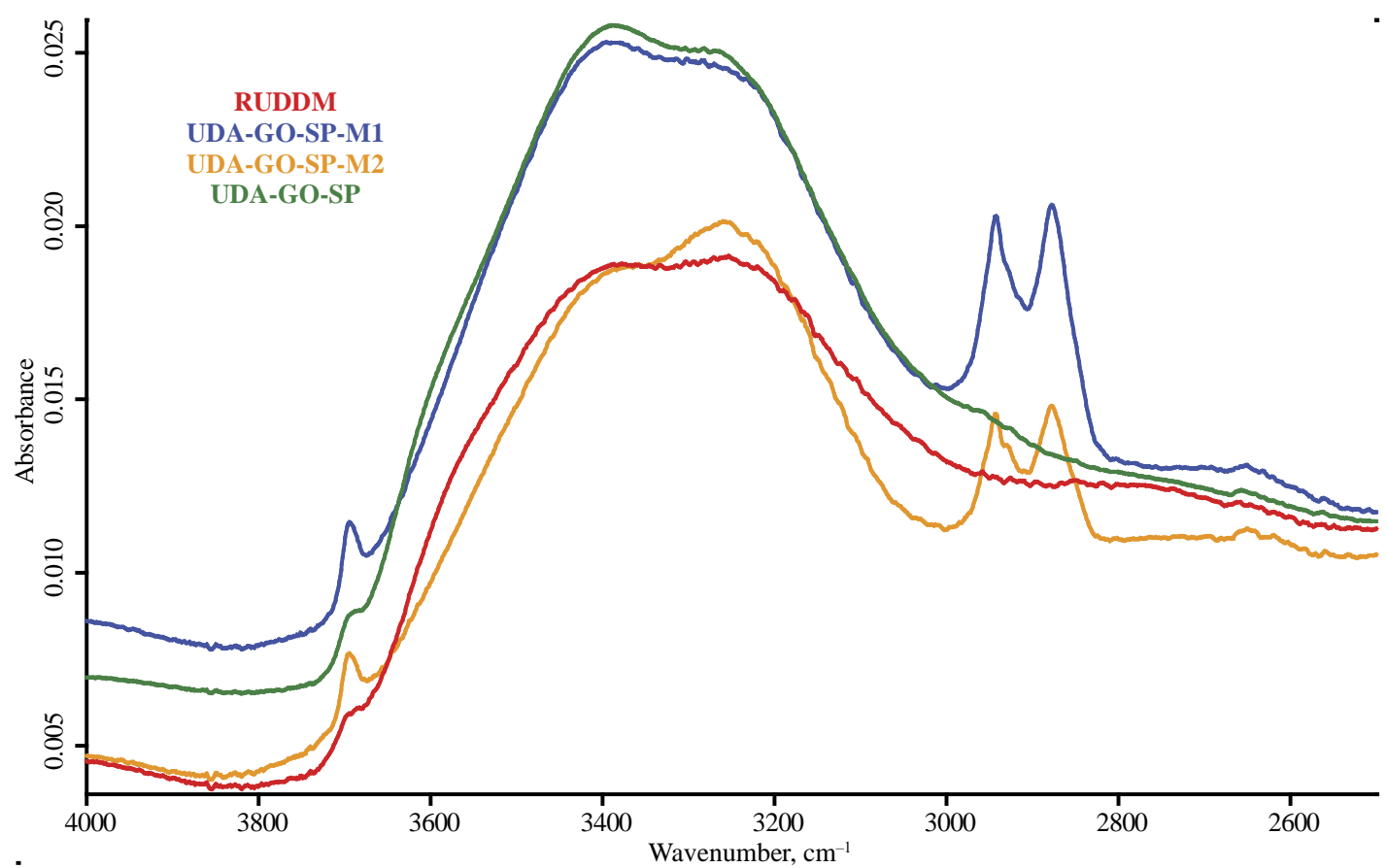

(a)

Figure A2. Cont. 


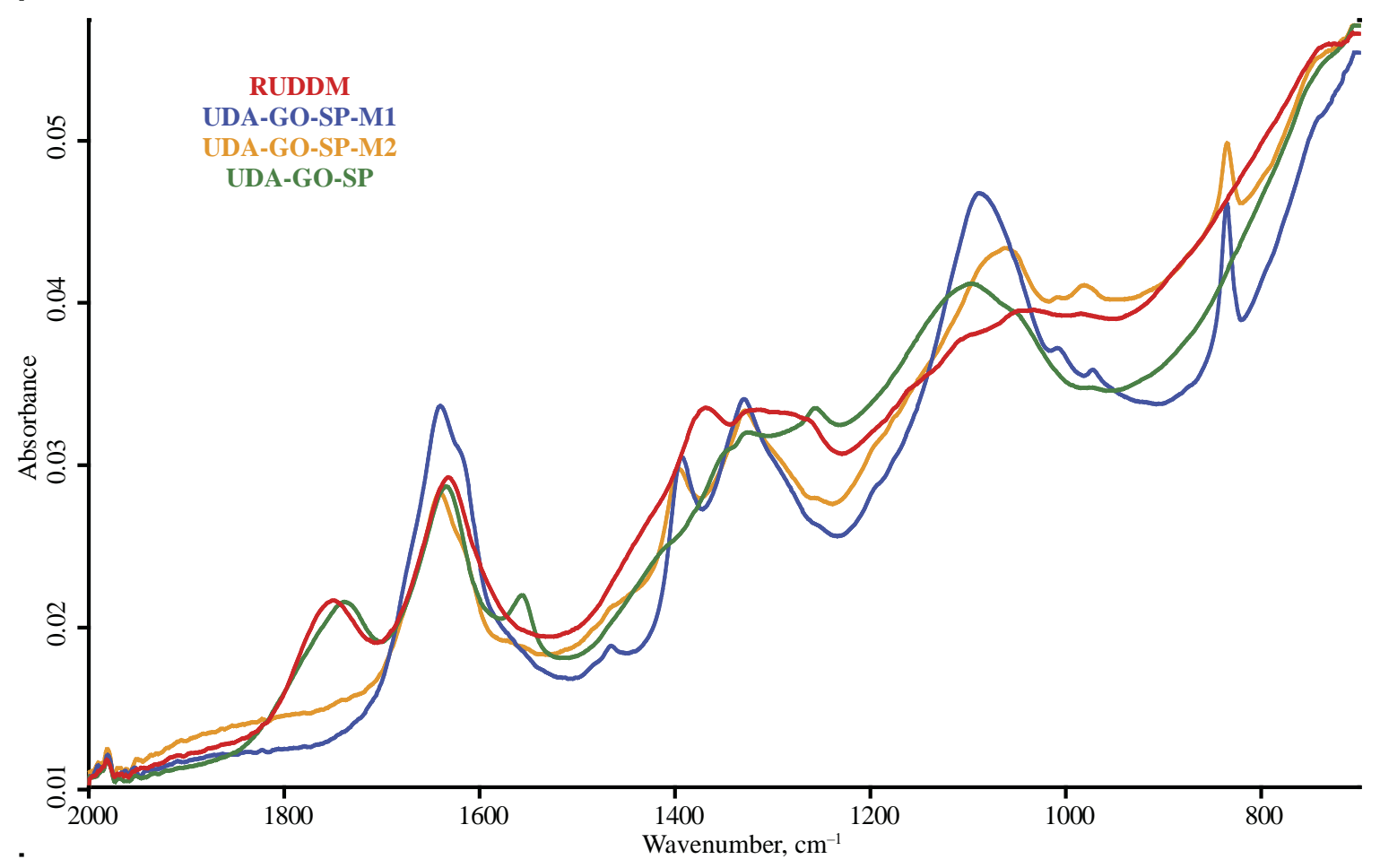

(b)

Figure A2. ATR mode, LN-MCT photovoltaic detector; nanodiamond brands: red, RUDDM; blue, UDA-GO-SP-M1; orange, UDA-GO-SP-M2; green, UDA-GO-SP; (a) $4000-2500 \mathrm{~cm}^{-1}$, (b) $2000-400 \mathrm{~cm}^{-1}$ range. Spectra were smoothed (13 points) and normalized to maximize each spectrum.

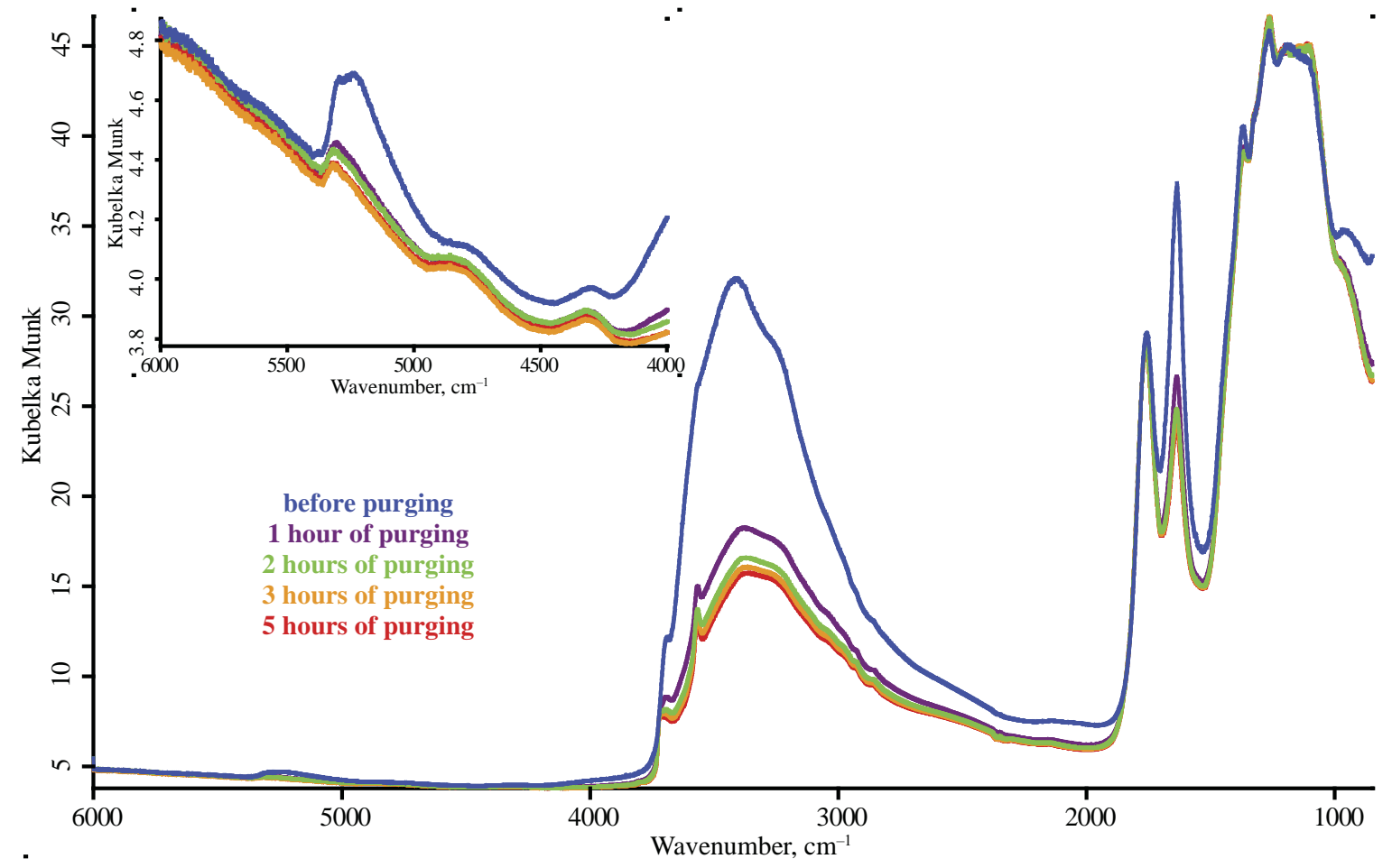

Figure A3. RUDDM nanodiamonds, DRIFT with MCT; blue, immediately when the sample was placed into accessory; purple, after $1 \mathrm{~h}$ of purging sample inside accessory; green, $2 \mathrm{~h}$; orange, $3 \mathrm{~h}$; red, $5 \mathrm{~h}$. Spectra were not smoothed and normalized. 


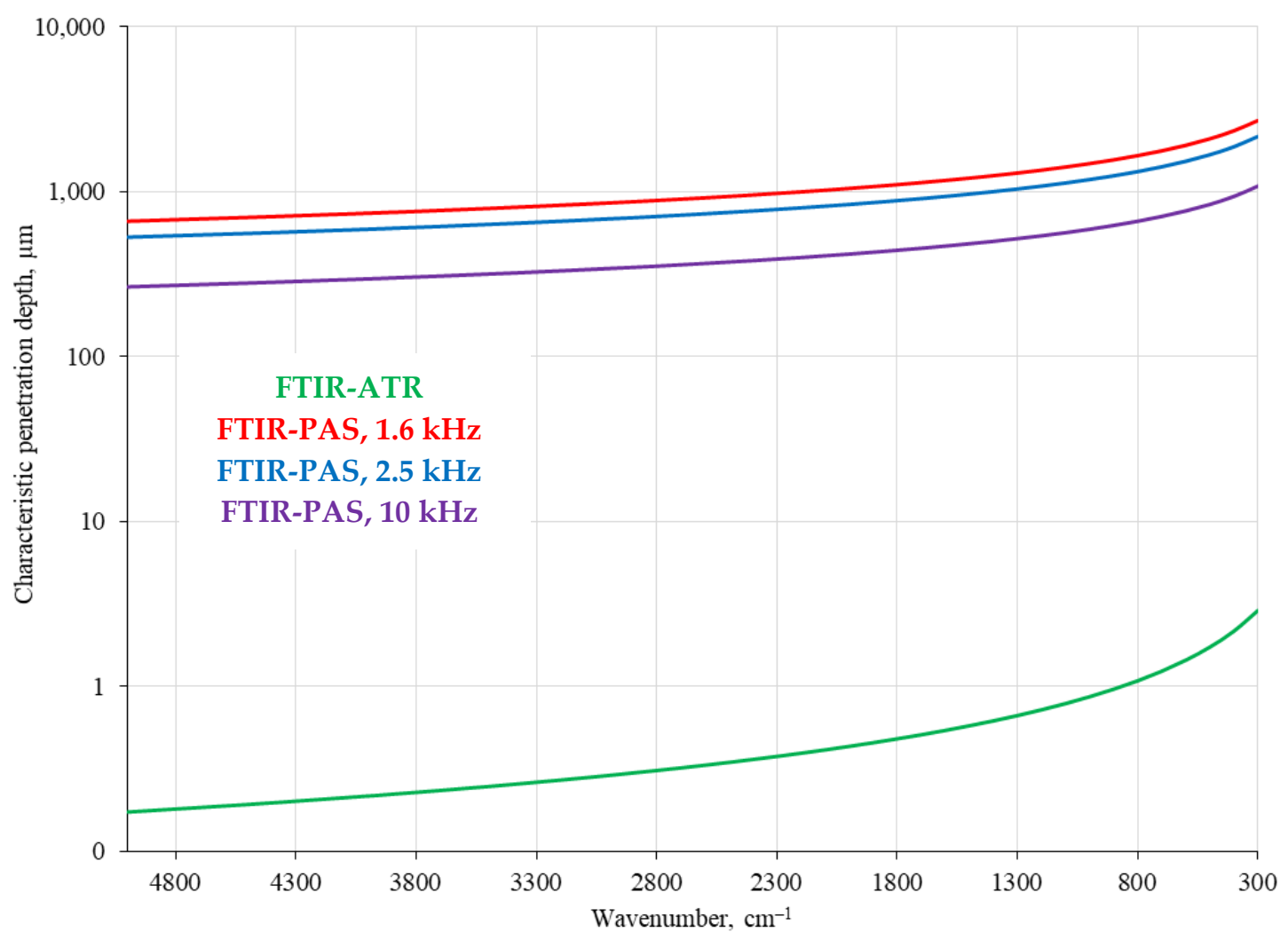

Figure A4. Radiation penetration depth into nanodiamond sample for ATR (green curve) and photoacoustic IR measurements at interferometer modulation frequencies 1.6 (red), 2.5 (blue) and $10 \mathrm{kHz}$ (violet line).

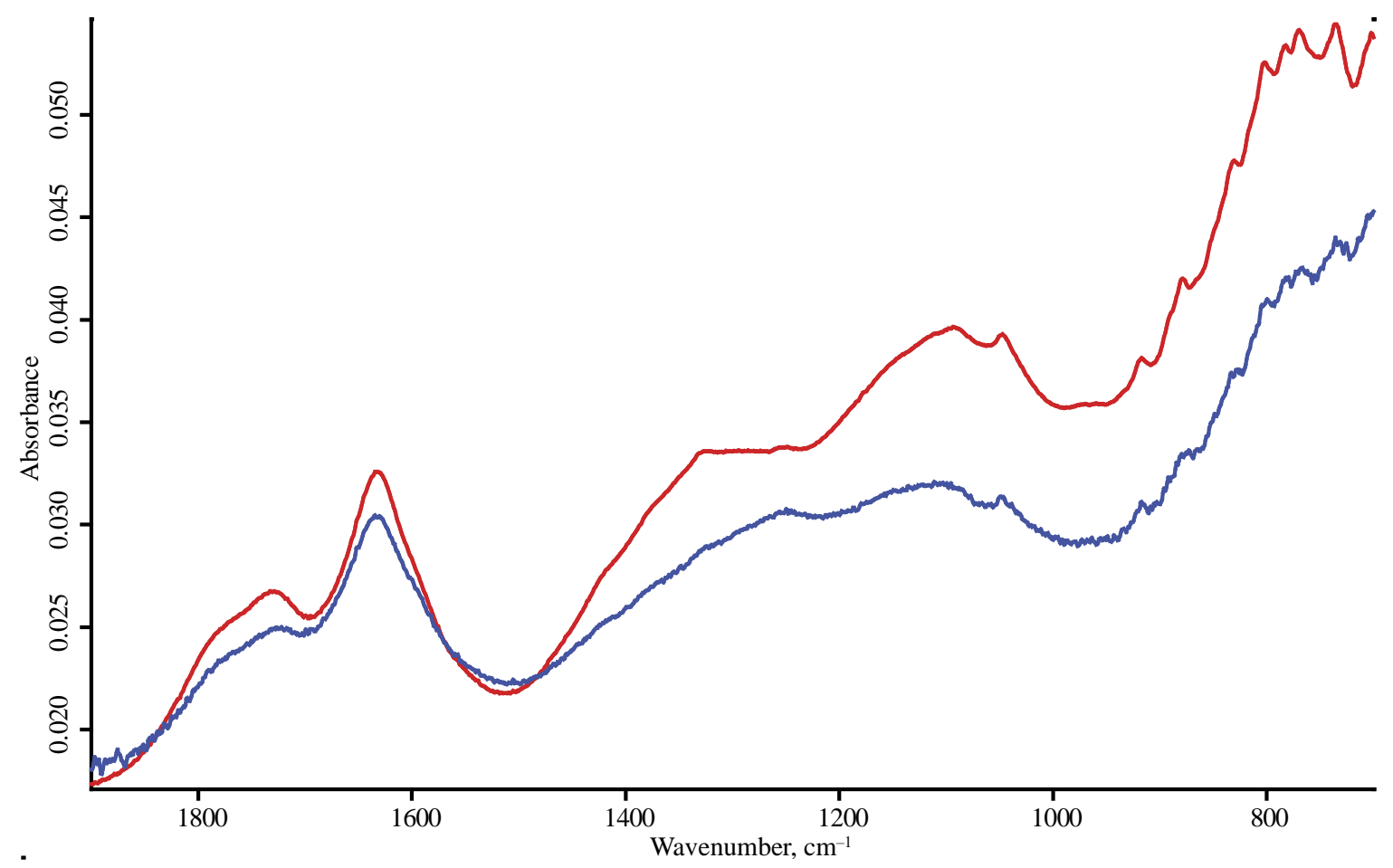

Figure A5. ATR mode, PL-Nanopure-G01P nanodiamonds; red, LN-MCT photovoltaic detector; blue, DLaTGS detector. Spectra are not smoothed but normalized to maximize each spectrum. 


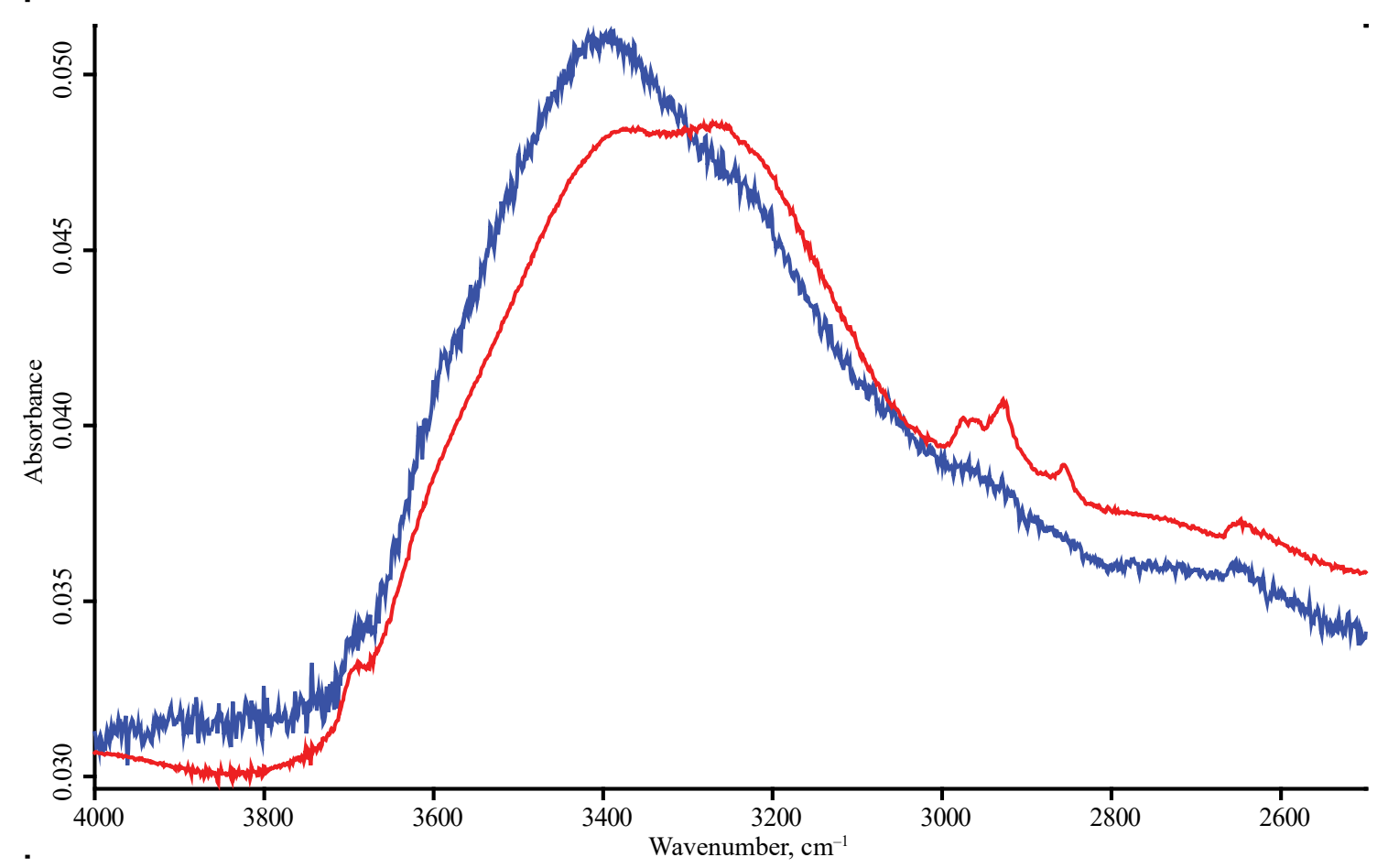

(a)

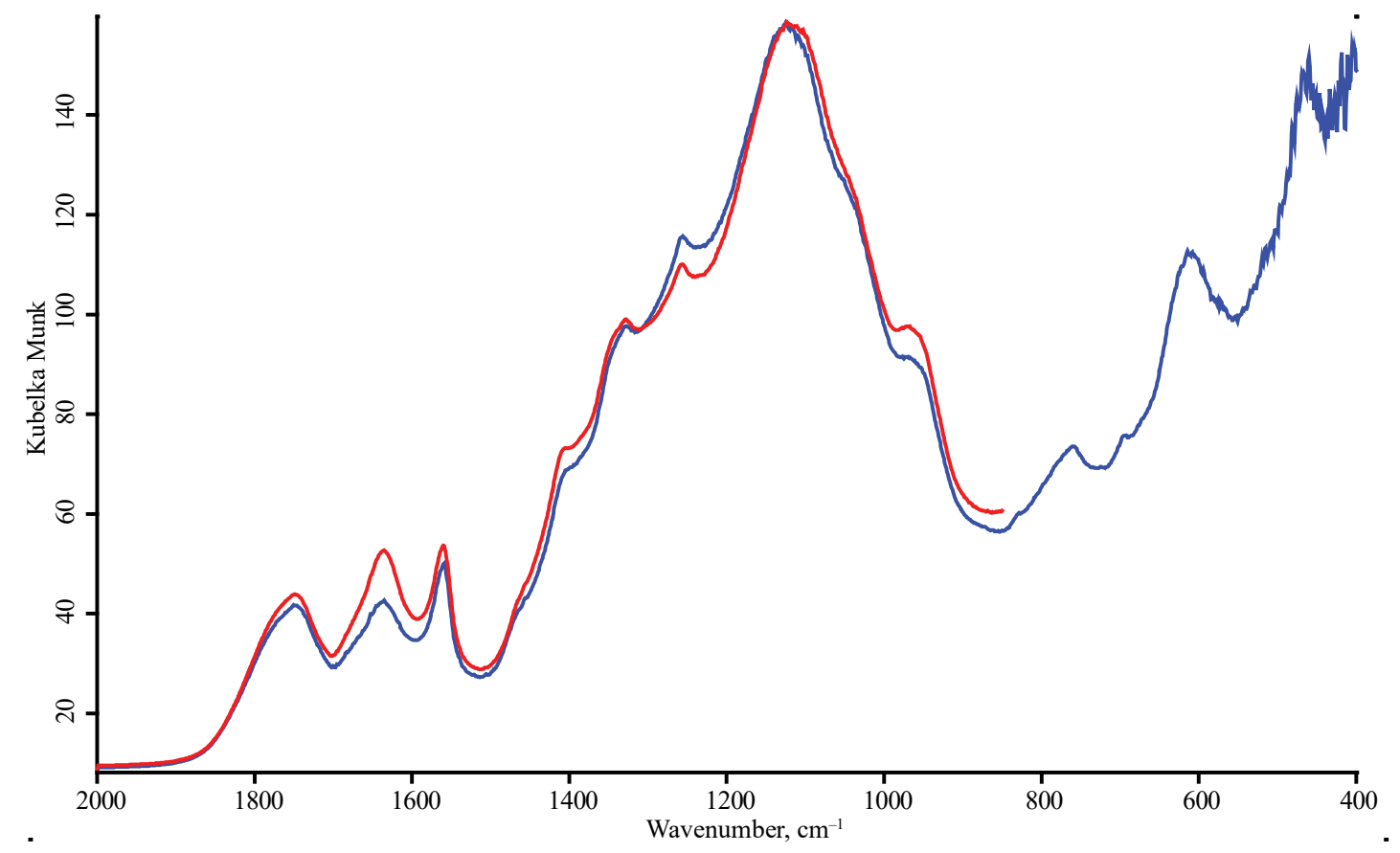

(b)

Figure A6. Diffuse reflectance mode (mirror was used for background collection), UDA-SP nanodiamonds; red, LN-MCT photovoltaic detector; blue, DLaTGS detector (a) $4000-2000 \mathrm{~cm}^{-1}$, (b) 2000-400 $\mathrm{cm}^{-1}$ range. Spectra were not smoothed but normalized to maximize each spectrum. 


\section{References}

1. Buchatskaya, Y.; Romanchuk, A.Y.; Yakovlev, R.; Shiryaev, A.; Kulakova, I.; Kalmykov, S. Sorption of actinides onto nanodiamonds. Radiochim. Acta 2015, 103, 205-211. [CrossRef]

2. Stehlik, S.; Varga, M.; Ledinsky, M.; Jirasek, V.; Artemenko, A.; Kozak, H.; Ondic, L.; Skakalova, V.; Argentero, G.; Pennycook, T.; et al. Size and Purity Control of HPHT Nanodiamonds down to $1 \mathrm{~nm}$. J. Phys. Chem. C 2015, 119, 27708-27720. [CrossRef] [PubMed]

3. Peristyy, A.; Koreshkova, A.; Paull, B.; Nesterenko, P.N. Ion-exchange properties of High Pressure High Temperature synthetic diamond. Diam. Relat. Mater. 2017, 75, 131-139. [CrossRef]

4. Peristyy, A.; Paull, B.; Nesterenko, P.N. Ion-exchange properties of microdispersed sintered detonation nanodiamond. Adsorption 2016, 22, 371-383. [CrossRef]

5. Volkov, D.S.; Krivoshein, P.K.; Mikheev, I.V.; Proskurnin, M.A. Pristine detonation nanodiamonds as regenerable adsorbents for metal cations. Diam. Relat. Mater. 2020, 110, 108121. [CrossRef]

6. Dolmatov, V.Y. Detonation-synthesis nanodiamonds: Synthesis, structure, properties and applications. Russ. Chem. Rev. 2007, 76, 339-360. [CrossRef]

7. Chernysheva, M.G.; Popov, A.G.; Tashlitsky, V.N.; Badun, G.A. Cationic surfactant coating nanodiamonds: Adsorption and peculiarities. Colloids Surfaces A Physicochem. Eng. Asp. 2019, 565, 25-29. [CrossRef]

8. Shenderova, O.A.; Gruen, D.M. Ultrananocrystalline Diamond, 2nd ed.; Elsevier Inc.: Amsterdam, The Netherlands, 2012.

9. Zhang, K.; Zhao, Q.; Qin, S.; Fu, Y.; Liu, R.; Zhi, J.; Shan, C.-X. Nanodiamonds conjugated upconversion nanoparticles for bio-imaging and drug delivery. J. Colloid Interface Sci. 2019, 537, 316-324. [CrossRef]

10. Qin, S.-R.; Zhao, Q.; Cheng, Z.-G.; Zhang, D.-X.; Zhang, K.-K.; Su, L.-X.; Fan, H.-J.; Wang, Y.-H.; Shan, C.-X. Rare earth-functionalized nanodiamonds for dual-modal imaging and drug delivery. Diam. Relat. Mater. 2019, 91, 173-182. [CrossRef]

11. Mochalin, V.N.; Pentecost, A.; Li, X.-M.; Neitzel, I.; Nelson, M.; Wei, C.; He, T.; Guo, F.; Gogotsi, Y. Adsorption of Drugs on Nanodiamond: Toward Development of a Drug Delivery Platform. Mol. Pharm. 2013, 10, 3728-3735. [CrossRef]

12. Ţucureanu, V.; Matei, A.; Avram, A.M. FTIR Spectroscopy for Carbon Family Study. Crit. Rev. Anal. Chem. 2016, 46, 502-520. [CrossRef] [PubMed]

13. Sun, X.; Ding, Y.; Zhang, B.; Huang, R.; Su, D.S. New insights into the oxidative dehydrogenation of propane on borate-modified nanodiamond. Chem. Commun. 2015, 51, 9145-9148. [CrossRef] [PubMed]

14. Remes, Z.; Kozak, H.; Rezek, B.; Ukraintsev, E.; Babchenko, O.; Kromka, A.; Girard, H.A.; Arnault, J.-C.; Bergonzo, P. Diamond-coated ATR prism for infrared absorption spectroscopy of surface-modified diamond nanoparticles. Appl. Surf. Sci. 2013, 270, 411-417. [CrossRef]

15. Stehlik, S.; Glatzel, T.; Pichot, V.; Pawlak, R.; Meyer, E.; Spitzer, D.; Rezek, B. Water interaction with hydrogenated and oxidized detonation nanodiamonds-Microscopic and spectroscopic analyses. Diam. Relat. Mater. 2016, 63, 97-102. [CrossRef]

16. Petit, T.; Puskar, L. FTIR spectroscopy of nanodiamonds: Methods and interpretation. Diam. Relat. Mater. 2018, 89, 52-66. [CrossRef]

17. Mayerhöfer, T.G.; Mutschke, H.; Popp, J. Employing Theories Far beyond Their Limits-The Case of the (Boguer-) Beer-Lambert Law. ChemPhysChem 2016, 17, 1948-1955. [CrossRef]

18. Zhang, J.; Su, D.S.; Blume, R.; Schlogl, R.; Wang, R.; Yang, X.; Gajovic, A. Surface chemistry and catalytic reactivity of a nanodiamond in the steam-free dehydrogenation of ethylbenzene. Angew. Chem. 2010, 122, 8822-8826. [CrossRef]

19. Beyler-Çiğil, A.; Çakmakçı, E.; Vezir Kahraman, M. Thermal properties of phosphorylated nanodiamond reinforced polyimides. Polym. Compos. 2016, 37, 2285-2292. [CrossRef]

20. Girard, H.A.; Perruchas, S.; Gesset, C.; Chaigneau, M.; Vieille, L.; Arnault, J.-C.; Bergonzo, P.; Boilot, J.-P.; Gacoin, T. Electrostatic Grafting of Diamond Nanoparticles: A Versatile Route to Nanocrystalline Diamond Thin Films. ACS Appl. Mater. Interfaces 2009, 1, 2738-2746. [CrossRef]

21. Frosch, T.; Chan, K.L.A.; Wong, H.C.; Cabral, J.T.; Kazarian, S.G. Nondestructive Three-Dimensional Analysis of Layered Polymer Structures with Chemical Imaging. Langmuir 2010, 26, 19027-19032. [CrossRef] 
22. Inel, G.A.; Ungureau, E.-M.; Varley, T.S.; Hirani, M.; Holt, K.B. Solvent-surface interactions between nanodiamond and ethanol studied with in situ infrared spectroscopy. Diam. Relat. Mater. 2016, 61, 7-13. [CrossRef]

23. Xing, Z.; Tian, K.; Du, C.; Li, C.; Zhou, J.; Chen, Z. Agricultural soil characterization by FTIR spectroscopy at micrometer scales: Depth profiling by photoacoustic spectroscopy. Geoderma 2019, 335, 94-103. [CrossRef]

24. Bauer, A.; Hertzberg, O.; Küderle, A.; Strobel, D.; Pleitez, M.A.; Mäntele, W. IR-spectroscopy of skin in vivo: Optimal skin sites and properties for non-invasive glucose measurement by photoacoustic and photothermal spectroscopy. J. Biophotonics 2018, 11, e201600261. [CrossRef] [PubMed]

25. Brangule, A.; Skadinšs, I.; Reinis, A.; Gross, K.A.; Kroča, J. In Vitro Characterization Perspectives Using Fourier Transform Infrared Photoacoustic Spectroscopy (FTIR-PAS) and Diffuse Reflectance Infrared Spectroscopy (DRIFT). Key Eng. Mater. 2017, 758, 273-277. [CrossRef]

26. Kizil, R.; Irudayaraj, J. Fourier Transform Infrared Photoacoustic Spectroscopy (FTIR-PAS). In Encyclopedia of Biophysics; Springer Science and Business Media LLC: Berlin/Heidelberg, Germany, 2013; pp. 840-844.

27. Michaelian, K.H.; Wen, Q. Photoacoustic infrared spectroscopy of solids. J. Phys. Conf. Ser. 2010, 214, 012004. [CrossRef]

28. Ando, T.; Inoue, S.; Ishii, M.; Kamo, M.; Sato, Y.; Yamada, O.; Nakano, T. Fourier-transform infrared photoacoustic studies of hydrogenated diamond surfaces. J. Chem. Soc. Faraday Trans. 1993, 89, 749. [CrossRef]

29. Pasieczna-Patkowska, S.; Madej, J. Comparison of photoacoustic, diffuse reflectance, attenuated total reflectance and transmission infrared spectroscopy for the study of biochars. Pol. J. Chem. Technol. 2018, 20, 75-83. [CrossRef]

30. Krivoshein, P.K.; Volkov, D.S.; Rogova, O.B.; Proskurnin, M.A. FTIR photoacoustic spectroscopy for identification and assessment of soil components: Chernozems and their size fractions. Photoacoustics 2020, 18, 100162. [CrossRef]

31. Du, C.; Zhou, J. Application of Infrared Photoacoustic Spectroscopy in Soil Analysis. Appl. Spectrosc. Rev. 2011, 46, 405-422. [CrossRef]

32. Michaelian, K.H.; Photoacoustic, I.R. Spectroscopy: Instrumentation, Applications and Data Analysis; 2nd Revised and Enlarged Edition; Wiley-VCH: Weinheim, Germany, 2010; p. 402.

33. Tokmakoff, A.; Banholzer, W.F.; Fayer, M.D. Thermal diffusivity measurements of natural and isotopically enriched diamond by picosecond infrared transient grating experiments. Appl. Phys. A 1993, 56, 87-90. [CrossRef]

34. Kronenberg, A.K. Chapter 4. Hydrogen Speciation and Chemical Weakening of Quartz. Silica 1994, $123-176$. [CrossRef]

35. Spitsyn, B.; Davidson, J.; Gradoboev, M.; Galushko, T.; Serebryakova, N.; Karpukhina, T.; Kulakova, I.; Novikova, N.N. Inroad to modification of detonation nanodiamond. Diam. Relat. Mater. 2006, 15, $296-299$. [CrossRef]

36. Calderón, F.J.; Mikha, M.M.; Vigil, M.F.; Nielsen, D.C.; Benjamin, J.G.; Reeves, J.B. Diffuse-Reflectance Mid-infrared Spectral Properties of Soils under Alternative Crop Rotations in a Semi-arid Climate. Commun. Soil Sci. Plant Anal. 2011, 42, 2143-2159. [CrossRef]

37. Hadzi, D.; Pintar, M. The $\mathrm{OH}$ in-plane deformation and the $\mathrm{C}-\mathrm{O}$ stretching frequencies in monomeric carboxylic acids and their association shifts. Spectrochim. Acta 1958, 12, 162-168. [CrossRef]

38. Asselin, M.; Sandorfy, C. Anharmonicity and Hydrogen Bonding. The in-plane OH Bending and its Combination with the OH Stretching Vibration. Can. J. Chem. 1971, 49, 1539-1544. [CrossRef]

39. Hens, S.C.; Cunningham, G.; Tyler, T.; Moseenkov, S.; Kuznetsov, V.; Shenderova, O. Nanodiamond bioconjugate probes and their collection by electrophoresis. Diam. Relat. Mater. 2008, 17, 1858-1866. [CrossRef]

40. Colthup, N.B.; Daly, L.H.; Wiberley, S.E. Introduction to Infrared and Raman Spectroscopy, 3rd ed.; Academic Press: New York, NY, USA, 1990; pp. 27-33.

41. Mitev, D.; Dimitrova, R.; Spassova, M.; Minchev, C.; Stavrev, S. Surface peculiarities of detonation nanodiamonds in dependence of fabrication and purification methods. Diam. Relat. Mater. 2007, 16, 776-780. [CrossRef]

42. Jiang, T.; Xu, K. FTIR study of ultradispersed diamond powder synthesied by explosive detonation. Carbon 1995, 33, 1663-1671. [CrossRef] 
43. Korobov, M.V.; Volkov, D.S.; Avramenko, N.V.; Belyaeva, L.A.; Semenyuk, P.I.; Proskurnin, M.A. Improving the dispersity of detonation nanodiamond: Differential scanning calorimetry as a new method of controlling the aggregation state of nanodiamond powders. Nanoscale 2013, 5, 1529-1536. [CrossRef]

44. Tu, J.-S.; Perevedentseva, E.; Chung, P.-H.; Cheng, C.-L. Size-dependent surface CO stretching frequency investigations on nanodiamond particles. J. Chem. Phys. 2006, 125, 174713. [CrossRef]

45. Volkov, D.S.; Proskurnin, M.A.; Korobov, M.V. Elemental analysis of nanodiamonds by inductively-coupled plasma atomic emission spectroscopy. Carbon 2014, 74, 1-13. [CrossRef]

46. Volkov, D.S.; Proskurnin, M.A.; Korobov, M. Survey study of mercury determination in detonation nanodiamonds by pyrolysis flameless atomic absorption spectroscopy. Diam. Relat. Mater. 2014, 50, 60-65. [CrossRef]

47. Max, J.J.; Chapados, C. Isotope effects in liquid water by infrared spectroscopy. III. $\mathrm{H}_{2} \mathrm{O}$ and $\mathrm{D}_{2} \mathrm{O}$ spectra from 6000 to $0 \mathrm{~cm}^{-1}$. J. Chem. Phys. 2009, 131, 184505. [CrossRef] [PubMed]

48. Gibson, N.; Shenderova, O.A.; Luo, T.; Moseenkov, S.; Bondar, V.; Puzyr, A.; Purtov, K.; Fitzgerald, Z.; Brenner, D. Colloidal stability of modified nanodiamond particles. Diam. Relat. Mater. 2009, 18, 620-626. [CrossRef]

49. Chung, K.; Tomljenovic-Hanic, S. Emission Properties of Fluorescent Nanoparticles Determined by Their Optical Environment. Nanomaterials 2015, 5, 895-905. [CrossRef]

50. Batsanov, S.S.; Dan'Kin, D.A.; Gavrilkin, S.M.; Druzhinina, A.I.; Batsanov, A.S. Structural changes in colloid solutions of nanodiamond. New J. Chem. 2020, 44, 1640-1647. [CrossRef]

51. Usoltseva, L.O.; Volkov, D.; Nedosekin, D.; Korobov, M.; Proskurnin, M.A.; Zharov, V. Absorption spectra of nanodiamond aqueous dispersions by optical absorption and optoacoustic spectroscopies. Photoacoustics 2018, 12, 55-66. [CrossRef]

52. Yang, C.Q.; Fateley, W.G. The effect of particle size on fourier-transform infrared photoacoustic spectra. J. Mol. Struct. 1986, 146, 25-39. [CrossRef]

53. Podobedov, V.B.; Eppeldauer, G.P.; Hanssen, L.M.; Larason, T.C. Calibration of spectral responsivity of IR detectors in the range from $0.6 \mu \mathrm{m}$ to $24 \mu \mathrm{m}$. In Proceedings of the Infrared Technology and Applications XLII, Baltimore, MD, USA, 17-21 April 2016; p. 98190. [CrossRef]

54. Nguyen, T.; Janik, L.; Raupach, M. Diffuse reflectance infrared fourier transform (DRIFT) spectroscopy in soil studies. Soil Res. 1991, 29, 49-67. [CrossRef]

55. Deb, P.; Haldar, T.; Kashid, S.M.; Banerjee, S.; Chakrabarty, S.; Bagchi, S. Correlating Nitrile IR Frequencies to Local Electrostatics Quantifies Noncovalent Interactions of Peptides and Proteins. J. Phys. Chem. B 2016, 120, 4034-4046. [CrossRef]

56. Bégué, D.; Qiao, G.G.; Wentrup, C. Nitrile Imines: Matrix Isolation, IR Spectra, Structures, and Rearrangement to Carbodiimides. J. Am. Chem. Soc. 2012, 134, 5339-5350. [CrossRef] [PubMed]

57. Fang, C.; Zhang, Y.; Zhang, Z.; Shan, C.; Shen, W.; Jia, X. Preparation of "natural" diamonds by HPHT annealing of synthetic diamonds. CrystEngComm 2018, 20, 505-511. [CrossRef]

58. McClelland, J.F.; Jones, R.W.; Bajic, S.J.; Griffiths, P.R. Photoacoustic Spectroscopy. In Handbook of Vibrational Spectroscopy; Chalmers, J.M., Griffiths, P.R., Eds.; John Wiley \& Sons, Ltd.: Hoboken, NJ, USA, 2006.

59. Calderón, F.J.; Reeves, J.B.; Collins, H.P.; Paul, E.A. Chemical Differences in Soil Organic Matter Fractions Determined by Diffuse-Reflectance Mid-Infrared Spectroscopy. Soil Sci. Soc. Am. J. 2011, 75, 568-579. [CrossRef]

60. Morterra, C.; Low, M.J.D. The Nature of the $1600 \mathrm{~cm}^{-1}$ Band of Carbons. Spectrosc. Lett. 1982, 15, $689-697$. [CrossRef]

61. Seredych, M.; Rossin, J.A.; Bandosz, T.J. Changes in graphite oxide texture and chemistry upon oxidation and reduction and their effect on adsorption of ammonia. Carbon 2011, 49, 4392-4402. [CrossRef]

62. Navarro-Pardo, F.; Martínez-Barrera, G.; Martinez-Hernandez, A.L.; Castaño, V.M.; Rivera-Armenta, J.L.; Medellín-Rodríguez, F.J.; Velasco-Santos, C. Effects on the Thermo-Mechanical and Crystallinity Properties of Nylon 6,6 Electrospun Fibres Reinforced with One Dimensional (1D) and Two Dimensional (2D) Carbon. Materials 2013, 6, 3494-3513. [CrossRef]

63. Bertaux, J.; Froehlich, F.; Ildefonse, P. Multicomponent analysis of FTIR spectra; quantification of amorphous and crystallized mineral phases in synthetic and natural sediments. J. Sediment. Res. 1998, 68, 440-447. [CrossRef] 
64. Brown, D.J.; Shepherd, K.D.; Walsh, M.G.; Mays, M.D.; Reinsch, T.G. Global soil characterization with VNIR diffuse reflectance spectroscopy. Geoderma 2006, 132, 273-290. [CrossRef]

Publisher's Note: MDPI stays neutral with regard to jurisdictional claims in published maps and institutional affiliations.

(C) 2020 by the authors. Licensee MDPI, Basel, Switzerland. This article is an open access article distributed under the terms and conditions of the Creative Commons Attribution (CC BY) license (http://creativecommons.org/licenses/by/4.0/). 